\title{
Adapting CRISPR/Cas9 Lentivirus Technology for Functional Studies of GATA6 \& GATA4 during Bovine Preimplantation Embryogenesis
}

\section{BY}

\author{
Shicheng (Shayne) Ni \\ 300379121
}

A thesis submitted in fulfilment of

Master of Biomedical Science (by thesis)

Victoria University of Wellington

2020 


\section{Table of Contents}

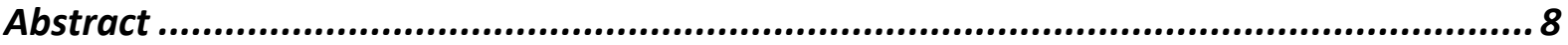

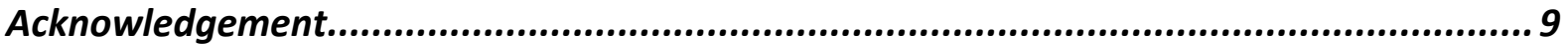

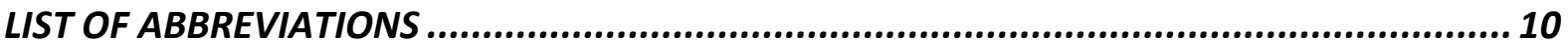

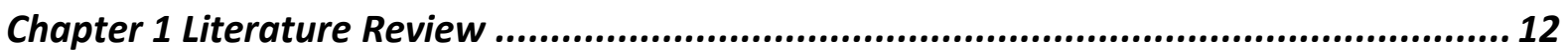

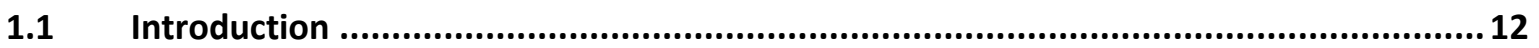

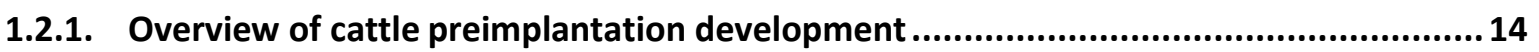

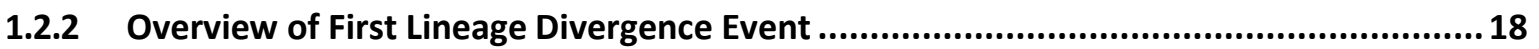

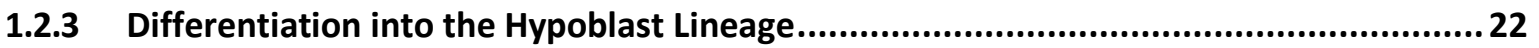

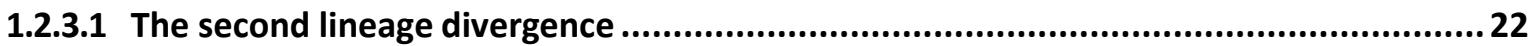

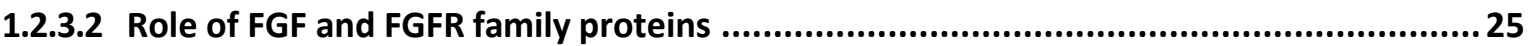

1.3. Developing Methodologies for Embryonic Gene Editing .............................................32

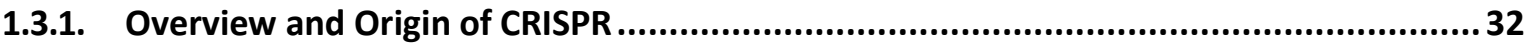

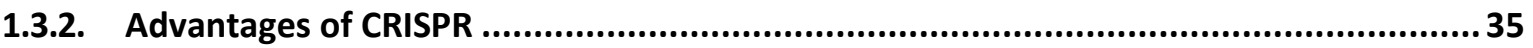

1.3.3. Short-comings and current research goals...................................................................... 36

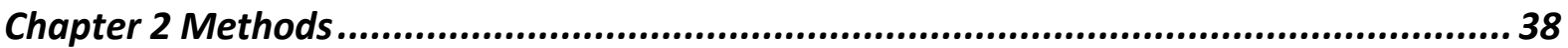

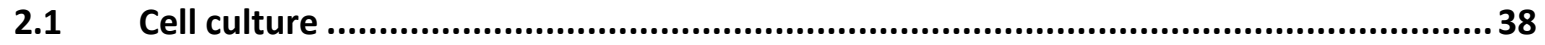

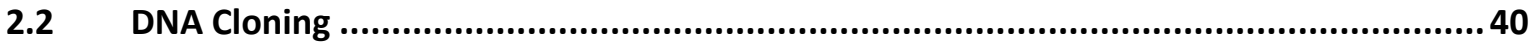

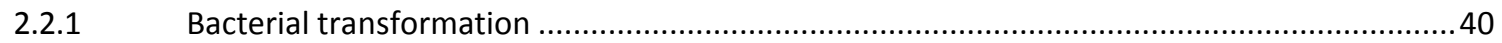

2.2.1.1 Preparation of electrocompetent cells .......................................................................... 40

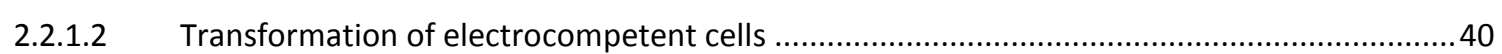

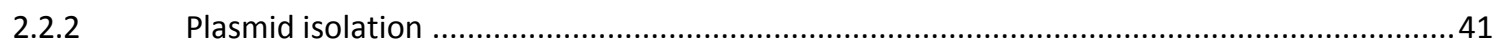

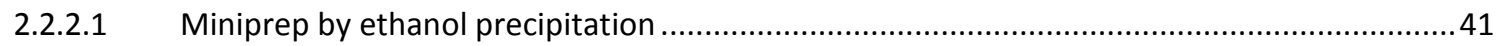

2.2.3 Lentiviral packaging plasmids .......................................................................................... 42

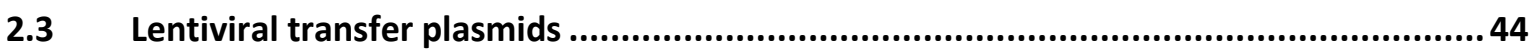

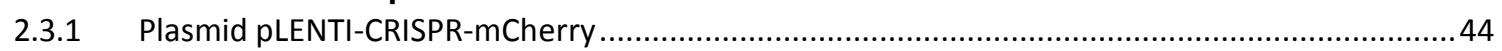

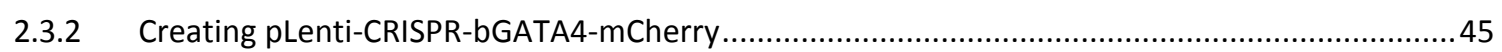

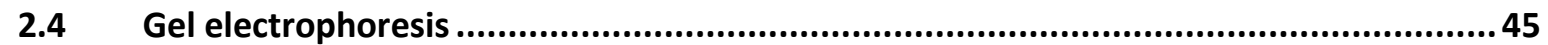

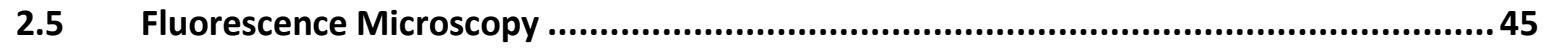

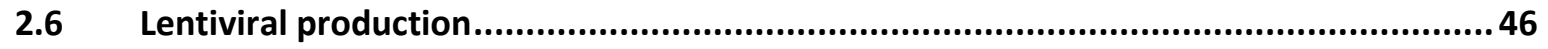

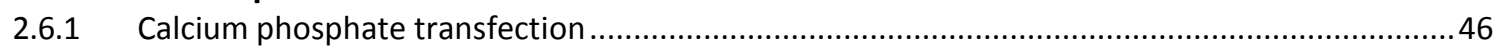

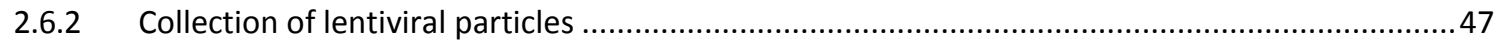

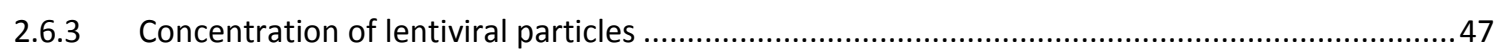

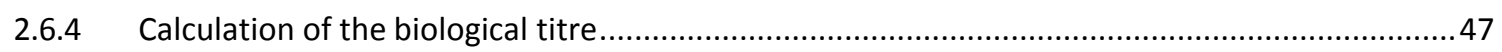

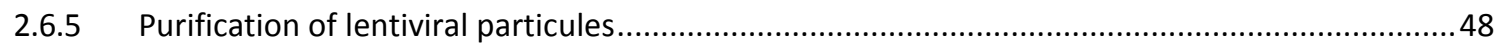

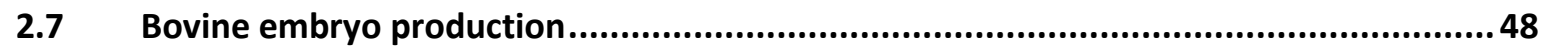




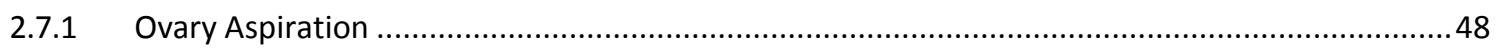

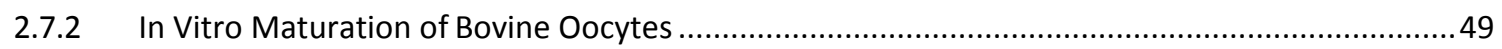

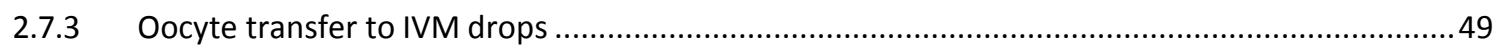

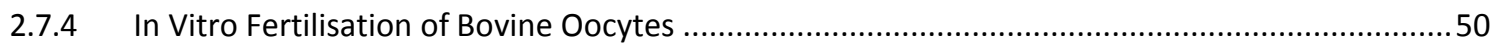

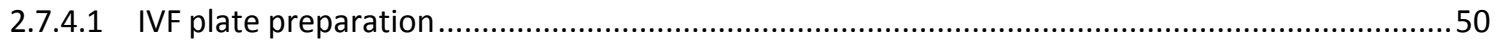

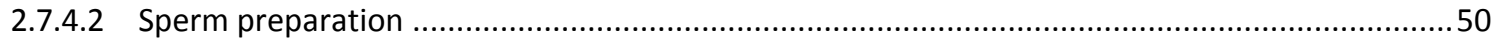

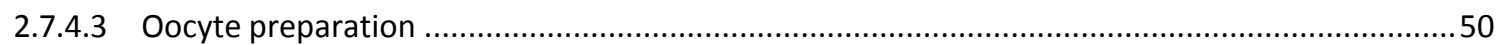

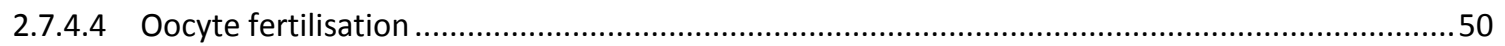

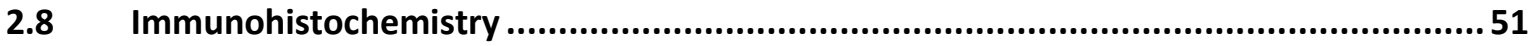

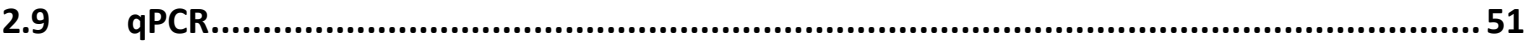

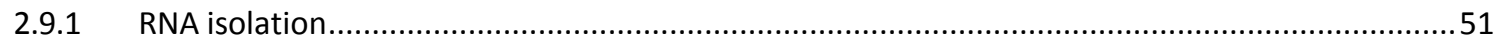

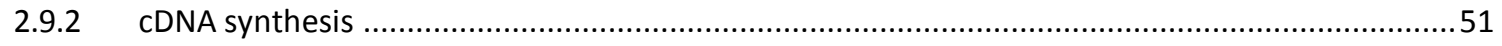

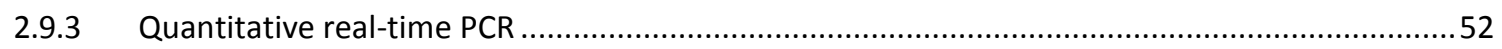

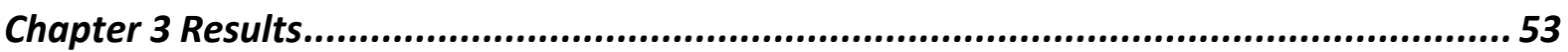

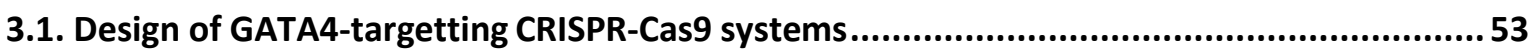

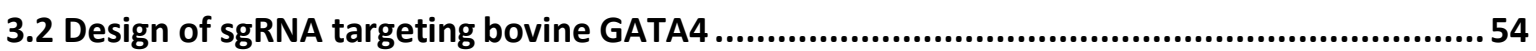

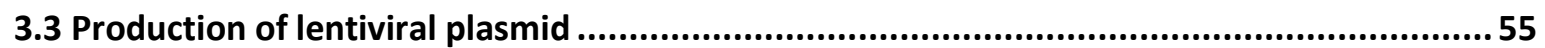

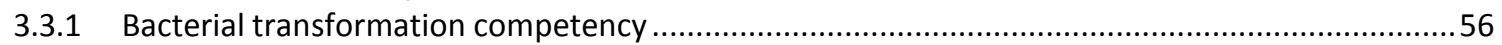

3.4 Verification of Lentiviral Plasmid..................................................................59

3.4.1 Verification by Restriction Digest - Incomplete BsmBI digestion ...........................................60

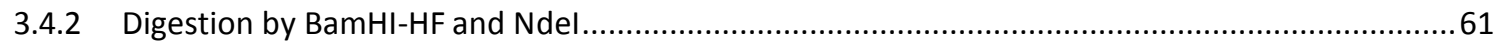

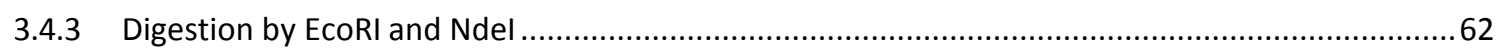

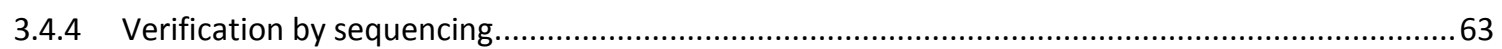

3.5. Transfection and Production of CRISPR-Cas9 Lentivirus..............................................65

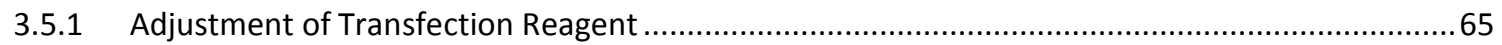

B.6 Biological Titre of CRISPR-Cas9 Lentivirus........................................................68

3.6.1 Transduction by pLenti-GATA6-CRISPR and pLenti-GATA4-CRISPR of HEK293T.........................68

In vitro testing of CRISPR-Cas9-GATA6 lentivirus .................................................. 70

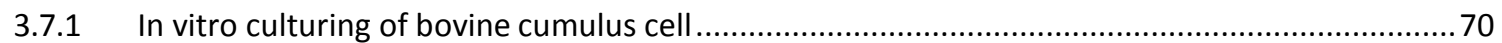

3.7.2 Confirming the expression of Gata4 and Gata6 mRNA in bovine cumulus cells ..........................72

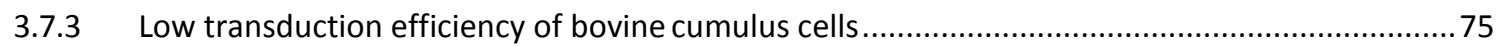

3.7.4 Effect of pLenti-GATA4-CRISPR and Effect of pLenti-GATA6-CRISPR on Gata4 and Gata6 mRNA

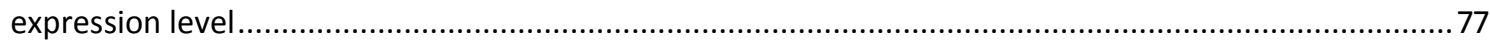

3.7.5 Effect of the two viruses on protein expression level ................................................................ 79

Chapter 4 Discussion ........................................................................................81

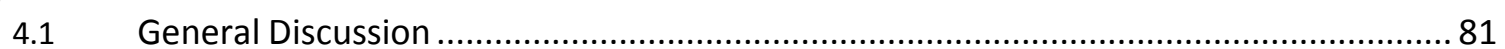

4.2 Design and verification of pLenti-GATA4-CRISPR .............................................. 83 
4.3 Production of pLenti-GATA4-CRISPR and pLenti-GATA6-CRISPR.

4.4 Expression of GATA6 and GATA4 in bovine cumulus cells ....................................86

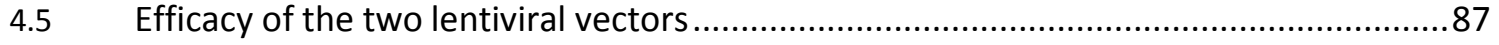

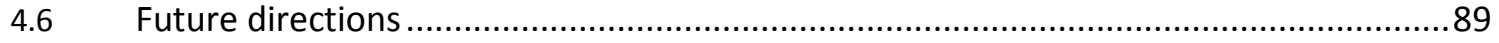

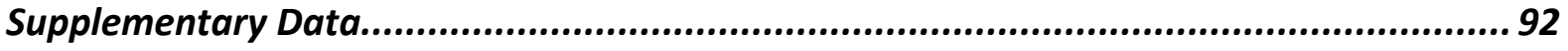

Appendix.............................................................................................. 95

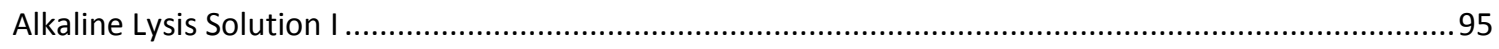

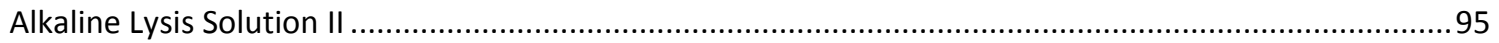

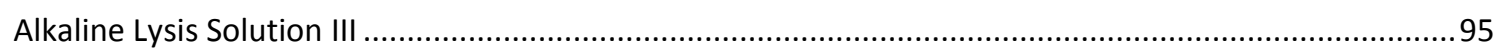

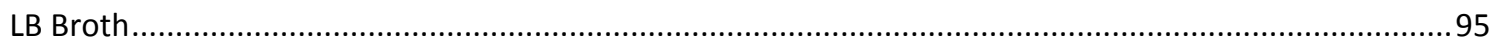

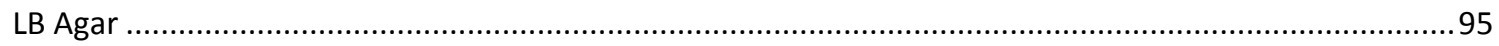

References................................................................................................. 98 
Figure 1 Macroscopic Overview of Bovine Embryo development to the peri-implantation period.

Figure 2 An Illustrated diagramme of development of bovine and murine embryos up to the peri-implantation stage.

Figure 3 Illustrated diagramme summarising the molecular mechanism underpinning the first lineage divergence event .21

Figure 4 Illustrated image of the second lineage divergence event in eutherian embryos.......26 Figure 5 Role of FGF signalling in mouse embryos during the second lineage divergence event in mouse embryos

Figure 6 Illustrated imaged of the hypothesised role of FGF and MAPK signalling on fate decision across mouse, bovine and human embryos.

Figure 7 Illustrated diagramme of GATA6 and NANOG expression in different mouse, human and cattle blastocyst stages.

Figure 8 Illustrated summary of CRISPR-Cas9 system's application in genetic engineering. 34

Figure 9 Restriction map of psPAX2 and pMD2.G.

Figure 10 Restriction map of pLenti-CRISPR-mCherry ....................................................44

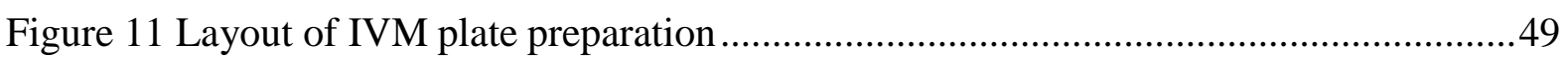

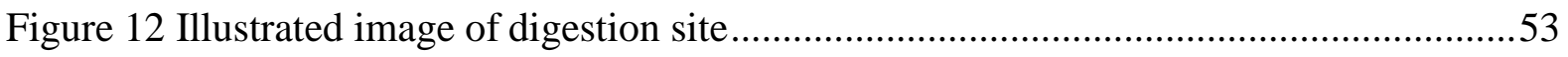

Figure 13 Gel Electrophoresis of pLenti-CRISPR-mCherry digested with BsmBI. ...............55

Figure 14 Self-prepared chemically competent cells tested with trial plasmid pUC.

Figure 15 LB ampicillin plates with (A) OneShot chemically competent bacetrial or (B) selfmade electrocompetent bacteria following transformation of pLenti-GATA4-CRISPR. .......58

Figure 16 Gel electrophoresis of ligated plasmid from overnight bacterial culture.

Figure $17 \mathrm{Gel}$ electrophoresis of ligated plasmids from miniprep plasmid extractions...........61

Figure $18 \mathrm{Gel}$ electrophoresis of digested plasmid with EcoRI and NdeI............................62

Figure 19 Sequencing data aligned using the Geneious software ........................................64

Figure 20 Plasmid transfection efficiency when carried out per the manufactuer's protocols (see 2.6.1)

Figure 21 Fluorescent microscopy showing the effect of plasmid transfection 3 days after initial reaction

Figure 22 Biological titring of the pLenti-GATA4-CRISPR (A; B) and pLenti-GATA6-

CRISPR (C; D).

Figure 23 Light microscopy showing the morphology of bovine cumulus cells. .71

Figure 24 qPCR reaction with GATA4 and HPRT 
Figure 25 qPCR reaction with GATA6 and HPRT

Figure 26 Fluorescent microscope of CRISPR lentivirus treated bovine cumulus cells in (A)

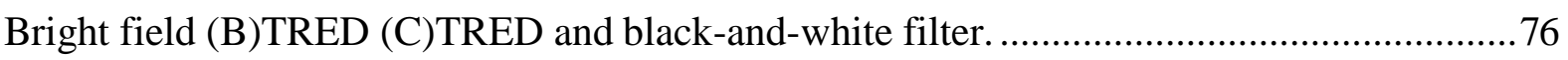

Figure 27 qPCR analysis of bovine cumulus cells with no virus treatment...........................77

Figure 28 qPCR analysis of pLenti-GATA6-CRISPR treated bovine cumulus cells ..............77

Figure 29 qPCR analysis of pLenti-GATA4-CRISPR treated bovine cumulus cells ..............78

Figure 30 Immunohistochemistry of bovine cumulus cells stained with (A) DAPI (B)

GATA6 (C) DAPI following lentiviral treatment (D) GATA6 following lentiviral treatment.

Figure 31 Melt curve graph of qPCR reaction addressing the efficacy of pLent-GATA4-

CRISPR and pLenti-GATA6-CRISPR.

Figure 32 Gel electrophoresis of pLenti-GATA4-CRISPR isolated by ethanol precipitation..

Figure $33 \mathrm{Gel}$ electrophoresis of packaging plasmids digested by EcoRI.

Figure 34 Development of mCherry fluorescent protein following lentiviral particle transduction over the course of 72 hours 


\section{Abstract}

In recent times, cattle embryology has been under the spotlight of investigation due to its apparent economic values. This is especially relevant in the case of New Zealand, owing to its high percentage of livestock export. Specifically, the period of peri-implantation development has been of particular relevance. During this stage, the developing zygote will establish 3 key lineages - epiblast, hypoblast and trophoblast. Previous studies have elucidated that a significant number of embryos die prior to implantation, therefore highlighting the importance of correctly establishing these 3 lineages to overall embryonic survival.

However, while embryological stages of the preimplantation embryo have been extensively studied in their eutherian cousin, mice, the molecular regulation of that of cattle remains much less addressed. Whereas the regulation of bovine embryo development is orchestrated by many transcriptional regulators, or genetic regulatory networks (GNP), we aimed to focus our studies on 2 key transcriptional regulators, GATA4 and GATA6. During early embryogenesis, both these transcriptional factors are known molecular regulators that drive the establishment of the hypoblast lineage in mice. By and large, while their respective expression has been documented in cattle embryos, functional studies towards these markers have not yet been performed.

Latest advances in molecular biology have given us novel methods to study the mechanism of bovine embryogenesis. To this end, the continuing perfection of CRISPR technologies in the last decade - in particular its delivery through lentiviral vectors, has established an ability to generate stable, targeted knock-out mutants. Therefore, it is aimed in this thesis to design and test lentiviral particles that induce knock-out mutants of GATA4 and GATAT6, to test their efficacy in primary cell cultures (bovine cumulus cells) and to functionally analyse the effect of GATA4 and GATA6 knockdowns in early bovine embryos. 


\section{Acknowledgement}

First and foremost I'd like to thank my supervisor Associate Professor Peter Pfeffer, who made this research project possible in the first place. Not only is he a knowledgeable, experienced expert in his field, Peter's professionalism and optimism have always served, personally, as a source of inspiration, particularly in times of need, i.e. when experiments fails with no apparent reasons. I am grateful of his constant help, guidance and support along this project.

Secondly, I'd like to thank fellow lab students, Kate Isaac, Jevon Upton and Nicole Waldron for helping each other out in the lab. Thank you for making this a positive experience for me despite the experimental setbacks. Special thanks to Kate Isaac for showing me how to aspirate cattle ovaries and proving me with bovine cumulus cells on numerous occasions. I wish you all the best for your future careers.

I thank also the many postgraduate students on TTR level three for helpful conversations with lab procedures, and just general banters, especially Aanchal Singh, Brittany FlorenceBennet and Linlin Liu.

Furthermore, I'd like to thank the administrative team from SBS and faculty of science, who works behind the scene to make the learning process as easy as possible for students. 


\section{LIST OF ABBREVIATIONS}

Abbreviations are applied without definition in reference to the National Centre for Biotechnology Information (https://www.ncbi.nlm.nih.gov/gene/). Other abbreviations used in the dissertation are listed below.

AJ Adherens junctions

AVH Anterior ventral hypoblast

ART Assisted reproductive technologies

BSA Bovine serum albumin

cDNA Complementary deoxyribonucleic acid

COC Cumulus-oocyte complex

CRISPR Clustered regularly interspaced short palindromic repeats

DAPI 4',6-Diamidino-2-phenylindole

DMSO Dimethyl sulfoxide

DNA Deoxyribonucleic acid

DPBS Dulbecco's phosphate-buffered saline

DSB Double-strand DNA breaks

EGA Embryonic genome activation

Epi Epiblast

ExE Extraembryonic ectoderm

FITC Fluorescein isothiocyanate

GJ Gap junctions

GRN Gene regulatory networks

HBS HEPES-buffered saline

HSBB Hank's buffered salt solution 
HDR Homology-directed repair

ICM Inner cell mass

IgG Immunoglobulin $\mathrm{G}$

IVM/IVF/IVC In vitro maturation/fertilisation/culture

MAPKKK Mitogen-activated protein kinase kinase kinase

NHEJ Non-homologous end joining

PAM Protospacer adjacent motif

PBS Phosphate-buffered saline

PDGFA Platelet-derived growth factor subunit A

PDGFRA Platelet-derived growth factor receptor A

PE Primitive endoderm (hypoblast)

PLC Phospholipase C

qPCR Quantitative polymerase-coupling reactions

RL Rauber's layer

RNA Ribonucleic acid

TE Trophectoderm

TF Transcription Factor

TJ Tight junctions

TU Titration units 


\section{Chapter 1 Literature Review}

\subsection{Introduction}

Understanding the reproductive processes in cattle during the preimplantation stage is important for optimisation of reproductive success, and for exploring new reproductive technologies. Specifically, conception rate in cattle is projected to be $c a$. $90 \%$, yet the calving rate is estimated to be between 40 to $50 \%$. About $20-50 \%$ of the embryos are lost by Day 7 after insemination and about $30 \%$ of the embryonic loss occurs between Days 8 and 27 , respectively (Diskin, Murphy, \& Sreenan, 2006). This is particularly relevant to the New Zealand economy; since the country's export relies heavily on its agricultural sectors, including dairy and beef/sheep-derived products, which accounts for $38 \%$ of the exports of New Zealand, and projected to be on a steady rise. The challenge hence remains to increase the production efficiency in these sectors. Furthermore, lactation and the production of beef is reliant on efficient reproduction in cattle. As a result, there is therefore a huge interest in increasing cattle's reproduction efficiency by minimising embryonic loss during the preimplantation period.

Preimplantation embryonic development is also prominent for setting up the developmental programme that later influences the phenotypes of offspring after birth. Additionally, alterations in the maternal environment have been shown to affect the calves' behaviour, cardiovascular function and growth rate in a number of species (Feuer \& Rinaudo, 2012). The importance of understanding preimplantation development is further highlighted by the growing prevalence of assisted reproductive technologies (ART) in cattle, which aims to mimic maternal environment in vitro. While ART in cattle has been shown to be hugely economically successful (Thomasen, Willam, Egger-Danner, \& Sørensen, 2016), ART is not fully optimised, with a lack of knowledge of some important process such as regulatory mechanisms involving key-lineage establishments. This is underscored by abnormalities that include abnormal gene expression (Driver et al., 2012), an altered methylome (Niemann et al., 2010), higher lipid content (Crosier, Farin, Dykstra, Alexander, \& Farin, 2001) and perhaps, as a result, embryonic death in vitro. Current published work has demonstrated that, at Day 14 , a large number of retrieved embryo from the uterus have significant loss of epiblasts in the blastocysts and thus are unviable (Berg, van Leeuwen, Beaumont, Berg, 
\& Pfeffer, 2010). These examples highlight the need to understand preimplantation development in cattle embryos.

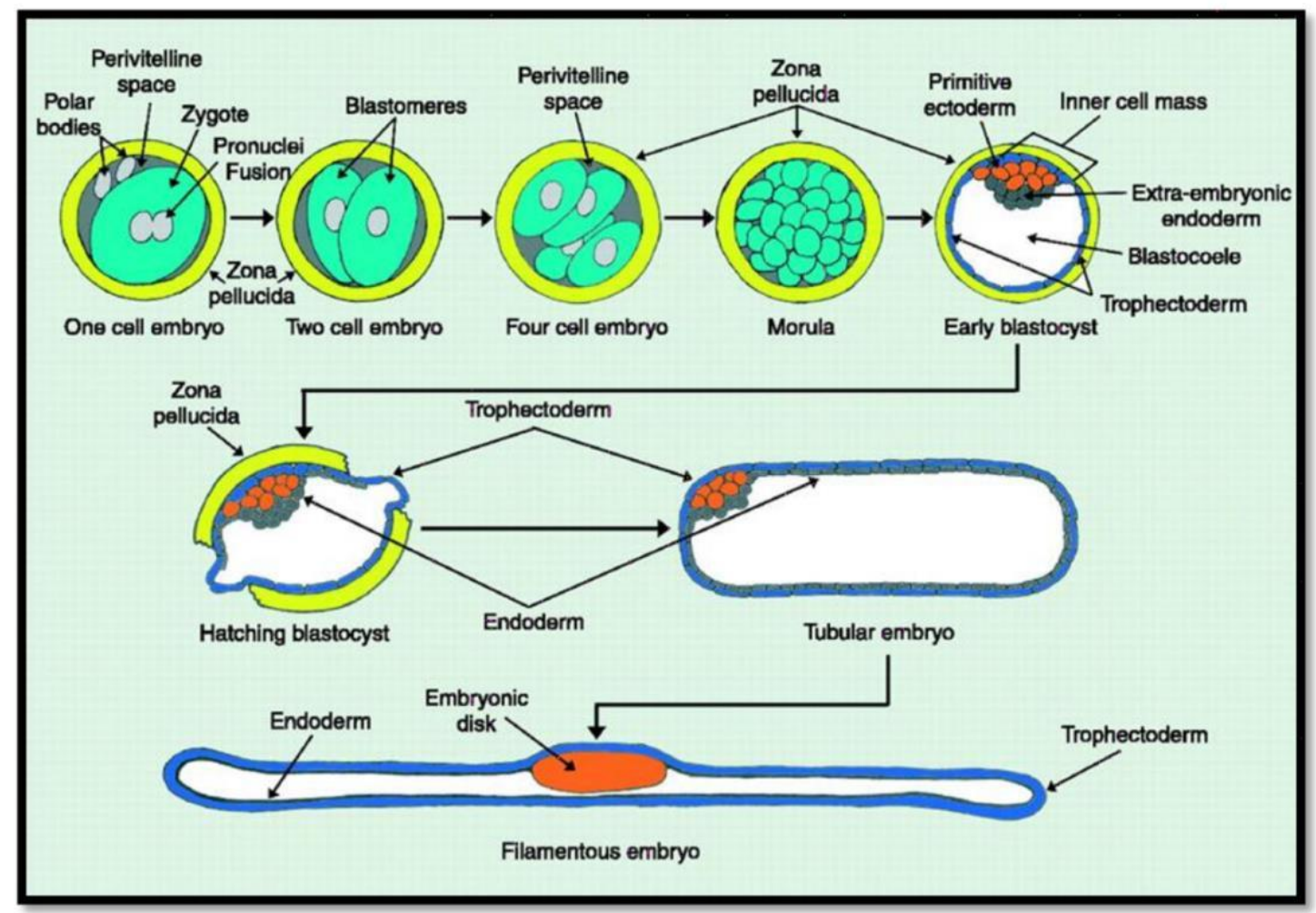

Figure 1 Macroscopic Overview of Bovine Embryo development to the peri-implantation period. (Bazer, Spencer, Johnson, Burghardt, \& Wu, 2009) 


\subsubsection{Overview of cattle preimplantation development}

Due to the high percentage of embryonic loss at the second week of gestation (D. K. Berg et al., 2010; van Leeuwen, Berg, \& Pfeffer, 2015), this period of development has drawn much scientific attention. Morphologically, the developmental events up to this point in cattle are similar to those of other species (Figure 1). Fertilisation of the MII oocyte occurs in the upper third of the bovine oviduct (Hunter \& Wilmut, 1984), a process which is followed by rounds of cellular mitosis. The developing embryo stays within the oviduct until Day 4-5 post fertilisation, and then the embryo enters the uterine cavity (Betteridge \& Flechon, 1988). Compaction occurs around Day 5-6, at which point the total volume of the embryo decreases and individual boundaries between cells become obscured. This process involves the acquisition of tight junctions and the establishment of polarities in the outer cells of the embryo (Pfeffer, 2018). At this stage, the signalling for first lineage divergence initiates, where most outer cells are instructed into the trophectoderm lineage (trophoblast/TE/TB), while the inner cells remain pluripotent and give rise to the inner cell mass (ICM).

Trophectoderm is an extra-embryonic lineage that, in further development, gives rise to the extra-embryonic components of the placenta. The correct differentiation and establishment of this lineage is, consequently, of great importance for embryonic survival (Red-Horse et al., 2004).

In mice, trophectoderm differentiation is thought to start as early as the 8 cell stage, since each cell at this stage has undergone polarisation, in a PLC-PKC (Phospholipase C - Protein Kinase C) dependent manner (Zhu, Leung, Shahbazi, \& Zernicka-Goetz, 2017). In other eutherian mammals, such as humans, cattle and rabbits, polarisation takes place significantly later and is carried out in a less synchronised fashion (Pfeffer, 2018). Such advanced timing of polarisation would be assumed to have an effect on early lineage establishment, since the division of polarised cells would more likely be asymmetric (Figure 2).

Concomitantly with trophectoderm establishment, blastocyst formation takes place, at which stage the embryo creates a cavity referred to as the blastocoel. At this point, the ICM and TE can be readily identified under light microscopy in bovine embryos (Figure 2). Afterwards, the ICM undergoes a second event of differentiation to form epiblast and hypoblast. The epiblast lineage is thought to be the precursor of foetal tissues, contributing to the embryo proper, while the hypoblast lineage will later give rise to mainly extraembryonic tissues, 
including the yolk sac. In cattle, by Day 9, hypoblast cells migrate to the periphery of the ICM. At Day 11, the hypoblast cells will start to cover the inner surface of TE (MaddoxHyttel et al., 2003).

Hatching occurs approximately coincidently with ICM differentiation into epiblast and hypoblast at Day 8 - 9 (Maddox-Hyttel et al., 2003). This is the process whereby the embryo escapes the zona pellucida: a protein-rich capsule surrounding the oocyte. A number of secretory events take place subsequently, such as the secretion of urokinase-type plasminogen activator (PLAU) which chemically digests the zona (D. A. Berg \& Menino, 1992). Additionally, the embryo undergoes rounds of expansion to aid the hatching process mechanically (Massip \& Mulnard, 1980). However, after hatching, the bovine embryo remains mobile within the uterus for another 12 days and apposition of the bovine embryonic trophoblast and maternal endometrium does not occur until approximately Day 20 (MaddoxHyttel et al., 2003; Maddox-Hyttel et al., 2003).

Around Day 13 - 14, the bovine embryo prepares itself for gastrulation (van Leeuwen et al., 2015), which is the separation of epiblast into three distinct germ layers. As mentioned above, the hypoblast will begin to line the inner surface of TE and epiblast, giving rise to the primitive yolk sac (Maddox-Hyttel et al., 2003). The TE cells continue to proliferate after hatching and, as a result, the developing conceptus will continue to grow in size. At Day 912 , the conceptus goes through structural changes from a sphere to an ovoid shape, and eventually to a tubular shape, as the TE elongates (Figure 1). To give a numeric impression of this massive change, the growing embryo is around $0.5 \mathrm{~mm}$ at Day 8 and grows to be $160 \mathrm{~mm}$ by Day 16.

It is worth mentioning that, at this stage, the conceptus is in coordinated communication with the maternal environment. Interactions between the maternal corpus luteum, uterine endometrium and the developing embryo are essential for the establishment of pregnancy. The lack of understanding between the embryo and the maternal environment contributes to the high failure rate of in vitro produced embryos. This is further underscored by the fact that elongation does not successfully occur under in vitro culture conditions (Blomberg, Hashizume, \& Viebahn, 2008; Machado et al., 2013; Shorten et al., 2018). One cytokines secreted from TE, interferon-tau (IFNT), has been shown to block the breakdown of the corpus luteum and therefore maintains the production of progesterone, to induce the maternal 
pregnancy state (Robinson, Hammond, Wathes, Hunter, \& Mann, 2008). In fact, early reports have stated that IFNT can be detected in the embryo as early as Day 6, when the morula is compacting (Kubisch, Larson, \& Roberts, 1998). Current consensus is that in cattle, the increased progesterone level changes the secretory profile of the bovine endometrium, or in other words, alters the histotroph (uterine milk) composition, and it is through this mechanism that an observed size increase of the conceptus at Day 16 is induced (Clemente et al., 2009).

At the stage around D10 in cattle embryos, the portion of TE cells directly on top of the epiblast, also known as Rauber's layer (polar trophectoderm) degenerates to expose the underlying epiblast. Rauber's layer (RL) begins to degenerate around Day 11-12 and disappears around Day 13-14 (van Leeuwen et al., 2015). RL has an important role in inducing gastrulation by secreting proteases (Furin), which travel by diffusion to the epiblast to induce Nodal expression to induce gastrulation. Comparatively, in mice, at the equivalent stage (around gastrulation), the embryo exhibits a structure homologous to Rauber's layer the extraembryonic ectoderm (ExE) (Valdez Magana, Rodriguez, Zhang, Webb, \& Alberio, 2014). While both are derived from polar trophoblast and induce epiblast gastrulation, ExE does not degenerate and plays an important role in inducing early implantation of the mouse embryo.

With the onset of elongation (Day 12 - 14), the epiblast rearranges from a circular to ovoid shape. Secondly, while the hypoblast at E10-11 is non-polar, around Day $12-14$, the hypoblast cells underneath the epiblast begin to lose its homogeneity, leading to eventually the formation of anterior ventral hypoblast $(\mathrm{AVH}) . \mathrm{AVH}$ is a key organiser region that induces the anterior-posterior axis patterning across species. A cavity forms in the epiblast region at the AVH stage, which is thought to be involved in the transition from the multilayered epiblast cells to the single or double-layered, flat, epithelium-like embryonic ectoderm. The AVH stage embryo may remain directly exposed to the maternal milieu for days (van Leeuwen et al., 2015). Such cavity formation is observed at equivalent stages in mice, which give rise to the amniotic cavity (Christodoulou et al., 2018; Sheng, 2015).

As stated above, the majority of studies carried out on early embryogenesis have used the mouse as a model system. Thanks to the recent advances of molecular biology methods ,embryology studies on a number of different species has been carried out 
( Kuijk et al., 2012; Negron-Perez, Zhang, \& Hansen, 2017). These studies have provided valuable insights into the molecular divergence across mammalian embryonic development.

This evolutionary divergence underpins the interest and necessity for studying cattle embryology. The details of such interspecies discrepancies will be discussed in the next section, with highlights on the first two lineage divergence events.

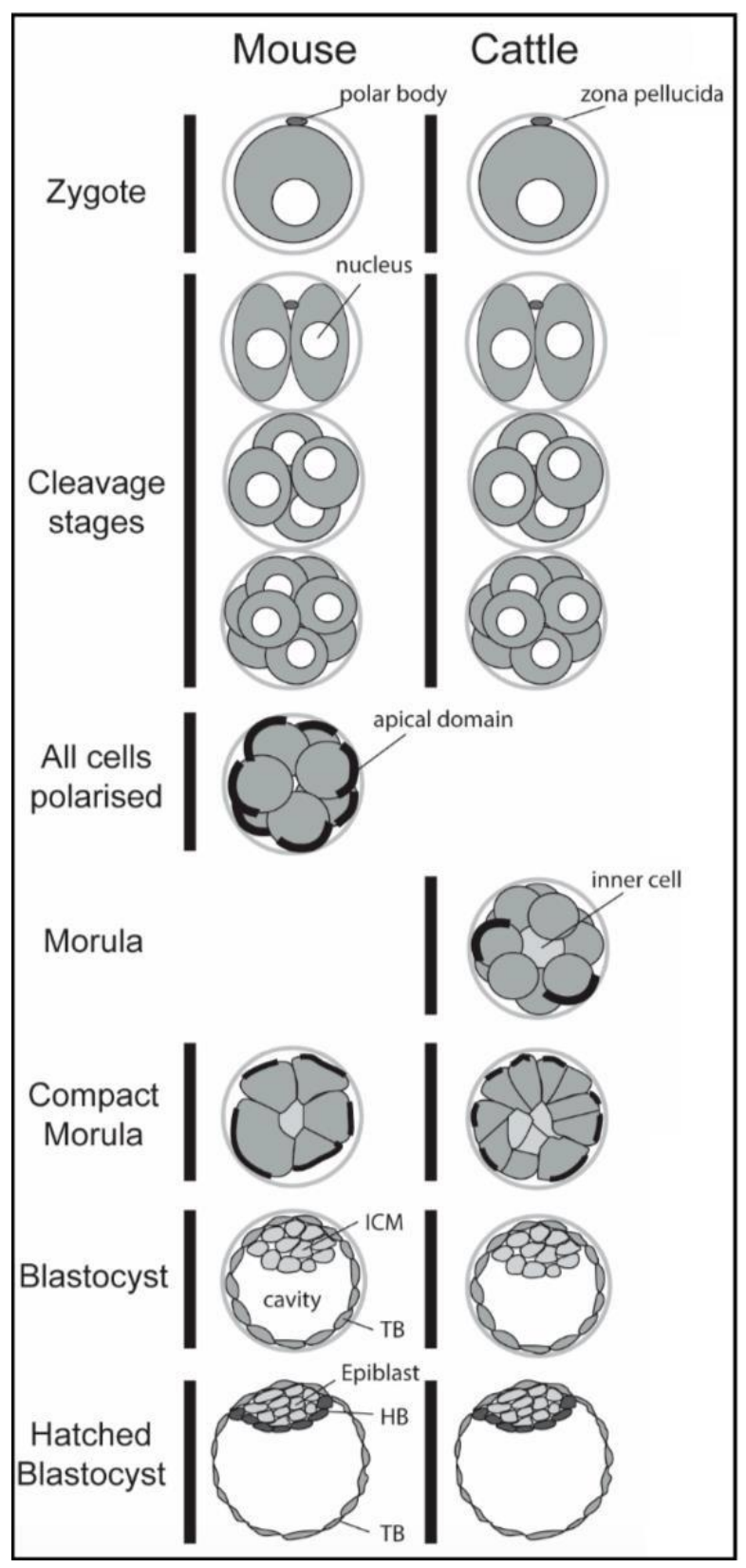

Figure 2 An Illustrated diagramme of development of bovine and murine embryos up to the peri-implantation stage. Note that embryos at equivalent stages are found at different time points. Mouse embryos undergo maternal attachment as early as Day 4 post fertilisation, when the embryo is a fully formed blastocyst. Compare to cattle, whose blastocyst formation occurs from Day 6. TB = trophoblast (trophectoderm). (Pfeffer, 2018) 


\subsubsection{Overview of First Lineage Divergence Event}

In the mouse embryos, several transcription factors (TF) have been discovered as stagespecific regulators for each of the three early lineages - epiblast, hypoblast and trophoblast. The main factors implicated in promoting pluripotency, i.e. in the ICM and later epiblast, are Pou5f1, Nanog and Sox2. TFs involved in trophoblast have also been discovered, namely Cdx2, Tead4, Gata3 and Eomes (Boroviak et al., 2015; Guo et al., 2010; Home et al., 2017). They have been extensively studied in the mouse model, the knock-out and knock-downs of which have been shown to induce phenotypic effects on a range of related cellular processes during the establishment of the first lineage, such as skewed ratio of TE vs ICM and changes in the subcellular localisation of functional proteins, e.g. tight junction proteins (TJ). These examples will be discussed in detail below.

In mice, $C d x 2$ transcription is activated as early as the 8-cell stage, primarily via the YAPTEAD4 signalling pathway (Nishioka et al., 2009), though several other factors may be debatably involved (Pfeffer, 2018). The presence of intercellular junctions in the individual totipotent cells provides the functional basis for protein scaffolding and distinct subcellular localisation. The net result of which is the expression of $C d x 2$ in the outer cells (Figure 3). At this stage, $C d x 2$ starts to instruct these cells towards differentiation into the trophoblast lineage, by promoting the expression of downstream trophectoderm TFs. Meanwhile, other cells express OCT4 (from the Pou5f1 gene) to maintain their pluripotency. In mice, one of the downstream effects of CDX2 is to inhibit the expression of Pou5f1 - a mechanism that is not found in cattle (D. K. Berg et al., 2011). Globally, this marks the first cell fate determination, whereby the ICM and the TE are formed; Pou5fl is restricted to the ICM population while $C d x 2$ is restricted to the TE. The functional roles of these two TFs are reflected by a number of genetic studies. The knock-out of Pou5f1 results in unviable embryos unable to form ICM (Le Bin et al., 2014; Nichols et al., 1998). Conversely, the knock-out of $C d x 2$ results in mutant embryos forming a blastocoel cavity with abnormal localisation of intracellular junction proteins, which eventually is not able to maintain the TE lineage (Strumpf et al., 2005). 
Concurrently, TEAD4 and SOX2 interact with $C d x 2$ and Pou5f1, respectively. Sox2, another pluripotency factor, is initially present in the oocyte, then decreases in amount around Embryonic Genome Activation (EGA) and increases later once more at the morula/early blastocyst stage in the ICM (Avilion et al., 2003). It can bind to the positive cis-regulatory regions of several genes, including the promotor element of Pou5f1, thereby establishing a positive feedback loop of pluripotency establishment. Sox2 deficient mutants can form an ICM but are unable to develop epiblast cells (Avilion et al., 2003; Lodato et al., 2013). Tead4 is expressed prior to $C d x 2$ and is required for both $C d x 2$ expression and TE maintenance, through binding to cis-regulatory elements (Figure 3). Tead4 is similarly limited to the outer cells of the developing embryo. Knock-out mutant of Tead4 have disturbed or no TE differentiation (Nishioka et al., 2009; Yagi et al., 2007).

The genetic factors implicated in the differentiation between ICM and TE of the cattle embryos are conserved to an extent, with also some notable and important differences (Kuijk et al., 2012; Pfeffer, 2018; van Leeuwen et al., 2015). The most prominent difference lies in the regulation of $C d x 2$ and Pou5f1 (OCT4). While CDX2 can be considered as marker proteins for the equivalent lineages between cattle and mice, expression of the pluripotency promoting gene, Oct4, is distinct in mice than other species. In mice, a silencer element is present in the regulatory region of the Oct4 gene. This element binds to the AP2 factors of the trophectoderm (if present), and thereby represses the expression of Oct4, limiting the expression of Oct4 to ICM. While Oct4 can be detected in all of the cells of the early cattle blastocyst. This particular divergence on the molecular level is perhaps reflective of the need of mouse embryos for rapid implantation, which in turn, requires rapid establishment of the placental lineage (D. K. Berg et al., 2011). This corresponds to the survival strategy of the early implantation and much shorter gestation time of the mouse species. It is worth noting that the repression of $O c t 4$ by $C d x 2$ is not reciprocal: Oct4 knock-out mouse embryos display normal localisation of ICM and TE markers until the late blastocyst stage (Ralston et al., 2010; Wu et al., 2013).

Genetic knock-out studies for non-mouse eutherian models have been relatively limited. However, with the advances in CRISPR technologies, functional studies on specific lineage markers genes in other mammals are becoming increasingly prevalent. OCT4 knock-outs 
have shown that it has dispensable role during the first lineage decisions, but induces defects in the second lineage divergence (discussed in detail below) (Kilian Simmet et al., 2018). Other differences between the two species is the differential requirement of the TF discussed above, which may be crucial for mice but not so in cattle. For example, knock-down studies through siRNA of TEAD4 by $80 \%$ has no effect on cattle embryos for TE establishment in terms of $C d x 2$ positive cells or the ratio of ICM to TE cells (Sakurai, Takahashi, Emura, Hashizume, \& Sawai, 2017). Similarly, $C d x 2$ deficient embryos can form blastocysts though the pattern of maintenance is disturbed, and eventually are unable to elongate (Berg et al., 2011). EOMES is not significantly expressed in the cattle TE, therefore implicating that it may be dispensable for cattle TE development (Berg et al., 2011; Ozawa et al., 2012). 


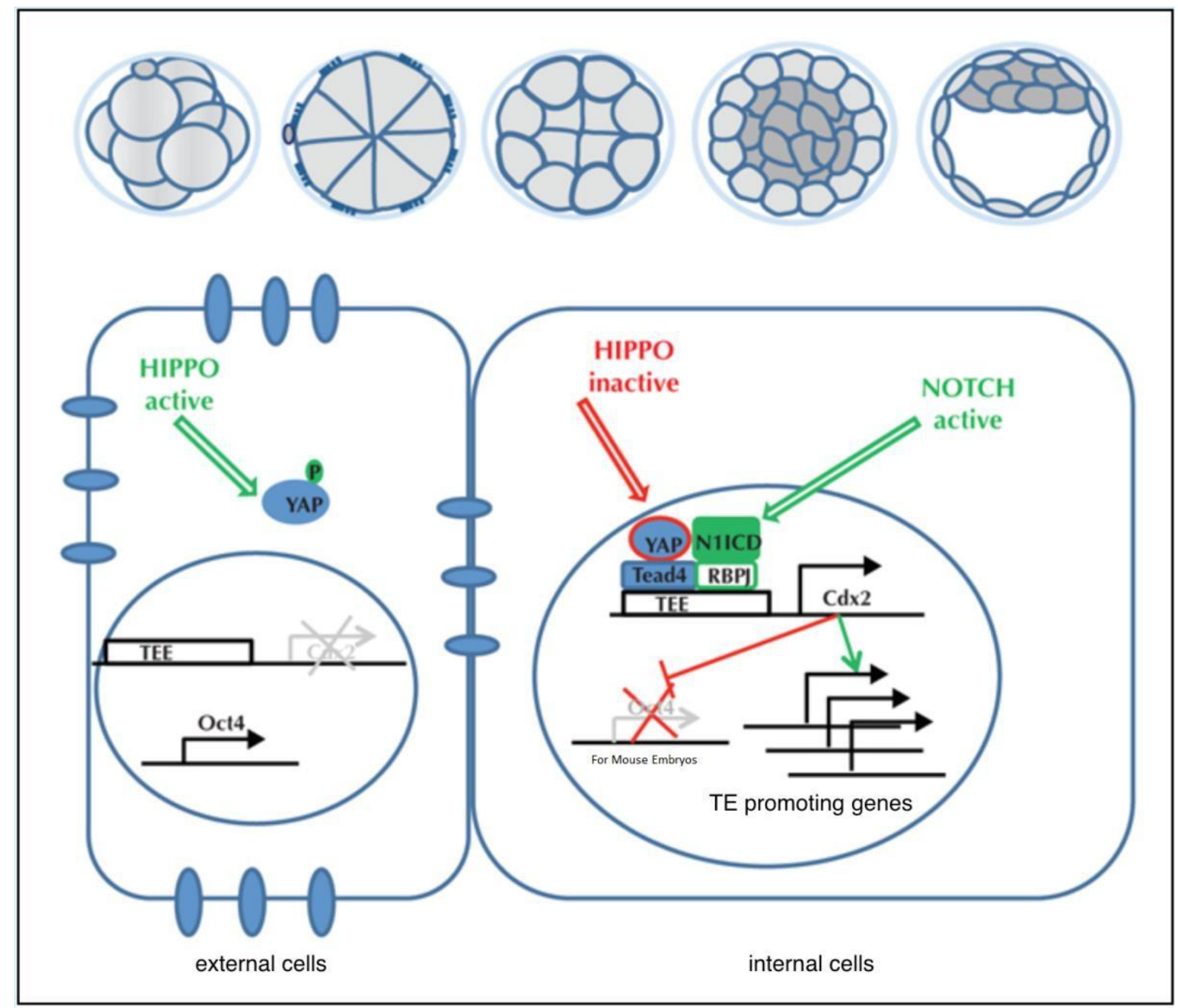

Figure 3 Illustrated diagramme summarising the molecular mechanism underpinning the first lineage divergence event. Adapted from (Duranthon, 2016) with permission. 


\subsubsection{Differentiation into the Hypoblast Lineage}

\subsubsection{The second lineage divergence}

In eutherian mammals, the second lineage establishment event is the differentiation of the ICM into hypoblast and epiblast. Different to the first lineage establishment event, the progenitor lineage, ICM, first co-expresses the factors for both of the two daughter lineages (epiblast and hypoblast). Then the ICM resolves into a salt-and-pepper expression pattern (Figure 4). Now the TFs for the epiblast and hypoblast lineages are found in a mutually exclusive manner within the ICM. Eventually, the cells sort into two distinct compartments - an epiblast cluster (Epi) and a hypoblast epithelium (also known as Primitive Endoderm in mice).

In mice, the formation of epiblast and hypoblast is dependent on NANOG and GATA6 the central factors of their respective gene regulatory networks (GRN) (Chazaud \& Yamanaka, 2016). Cell tracing experiments have demonstrated that such process takes place asynchronously, ranging from E3 - E3.75 (Bessonnard et al., 2014). NANOG have been implicated to maintain totipotency soon after EGA (Guo et al., 2010), which takes place E1.5. Current consensus for mice is that such specification takes place mainly through selective mRNA degradation (Chazaud \& Yamanaka, 2016). However, the reciprocal suppression of GATA6 and NANOG on each other further promotes the segregation of the two lineages (Chazaud \& Yamanaka, 2016).

The specific effects of these two factors have been closely examined in mice through knock-out mutants. In Gata6--- mutants all ICM cells express NANOG without any hypoblast specific markers, therefore indicating the complete acquisition of epiblast lineage (Bessonnard et al., 2014; Schrode, Saiz, Di Talia, \& Hadjantonakis, 2014). In contrast, in Nanog-/ mutant embryos, all ICM cells express GATA6 (Frankenberg, Shaw, Freyer, Pask, \& Renfree, 2013), indicating the loss of the epiblast lineage. Comparatively, neither Gata6 nor Nanog knock-out mutants of the bovine embryo have been reported.

Other markers for hypoblast differentiation in the mouse are SOX17, PDGFRA, HNF4a and GATA4. In mice, these four transcriptional factors are expressed after the hypoblast specification event. After the "salt-and-pepper" expression pattern, any experimental 
perturbations that decreases PE cell numbers is not compensated by an increase in epiblast cell numbers, and vice versa. The aforementioned TFs interact with each other to promote the differentiation into hypoblast (Chazaud \& Yamanaka, 2016). The expression dynamics have been studied extensively in mice - there is a gradual and temporal sequence of activation for these four factors and earlier markers are expressed more ubiquitously than later ones (Artus, Piliszek, \& Hadjantonakis, 2011; Pfeffer, 2018; Plusa, Piliszek, Frankenberg, Artus, \& Hadjantonakis, 2008). While these later hypoblast markers seem to be expressed in a similar fashion at equivalent stages of cattle embryos (Kuijk et al., 2012). However, their interactions and functional roles remain unaddressed in cattle.

With the advancement of gene editing technologies, more and more functional studies are carried out on specific genes during early embryo development of different species. For example, a recent study has elucidated the functional role of Oct4 in the second lineage divergence event. Oct4-^- mutant mouse embryos develop normally up to the early blastocyst stage, where it develops the normal "salt-and-pepper" phenotype. However, as development progresses, the embryo cannot maintain GATA6 expression, and fails to be viable due to the lack of the hypoblast lineage (Frum et al., 2013; Le Bin et al., 2014). The observed effect is attributed to the role of OCT4 in inducing FGF expression.

Yet, a recent study published in 2018 has carried out a similar experiment, to produce bovine Oct4-/ mutants. They observed that bovine Oct4 KO mutants fail to express Nanog to a significant level (Kilian Simmet et al., 2018). This effect closely mimic the recently discovered effect of Oct4 KO in human embryos (Fogarty et al., 2017). It has been documented that FGF/MAPK signalling is not essential for GATA6 expression in cattle (discussed in detail in the next section), as compared to mice (Kuijk et al., 2012), suggesting a direct effect of Oct4 on maintaining pluripotency (i.e. epiblast establishment). Accumulating evidence is beginning to reveal the vast mechanistic differences between mouse and bovine embryos - as well as similarities between bovine and human embryos, during the first (Berg et al., 2011) and second lineage (Kilian Simmet et al., 2018) establishment events. These studies support bovine embryogenesis as an alternative model for human embryogenesis.

It is worth mentioning that, in the aforementioned paper (Kilian Simmet et al., 2018), the bovine KO mutants are carried out using donor cell somatic nuclear transfer (SCNT), which 
requires the application of the CRISPR machinery, large-scale library screening of donor cells and the need for micromanipulation techniques, which is a laborious and expensive procedure. The experiment encountered further difficulties due to the low efficiency of KO generation in donor cells, which was attributed to the nature of donor cells (fibroblast), whose differentiated status implied inaccessible chromatin. The need to develop new strategies for generating bovine $\mathrm{KO}$ embryos is clearly exemplified. 


\subsubsection{Role of FGF and FGFR family proteins}

Likewise, the mechanistic knowledge underpinning the establishment of the hypoblast lineage has been closely mapped out in the mouse as model system. In the mouse embryo, signalling molecules of the MAPK pathways are responsible for the differentiation of ICM cells to hypoblast (Kang, Piliszek, Artus, \& Hadjantonakis, 2013). FGF4 acts in the embryo as a ligand for both FGFR1 and FGFR2 (Molotkov, Mazot, Brewer, Cinalli, \& Soriano, 2017), in a paracrine fashion, to direct exit from pluripotency.

The current consensus in mice states that, during the event of the first lineage establishment, the first round of cells that occupy the ICM expresses higher level of FGF4, while the daughter cells, that is, cells that enter the ICM in the next round of cellular division, expresses FGFR2 (Kang et al., 2013; Morris, Graham, Jedrusik, \& Zernicka-Goetz, 2013; Morris et al., 2010). Signalling through FGFR1/2 leads to the phosphorylation of the MAPKKK pathway. The MAPKKK pathway is a series of protein kinases which is activated sequentially (MAPKKK-MAPKK-MAPK). MAPK promotes the transcription of GATA6 while repressing the expression of Nanog. Such difference in TF expression is maintained through the reciprocal inhibition: GATA6 blocks the expression of pluripotencypromoting markers, such as NANOG, thus these cells are instructed to become the hypoblast lineage. The initial cells that occupy the ICM, which are now marked with a higher expression of FGF4, will express NANOG, a pluripotency-promoting marker, due to the low level of MAPK activity and low GATA6 expression, which are committed to the pluripotent epiblast lineage (Morris et al., 2010). This results in the "salt and pepper" pattern of hypoblast and epiblast, which now express exclusively their lineage-specific factors in the differentiating ICM cells. 


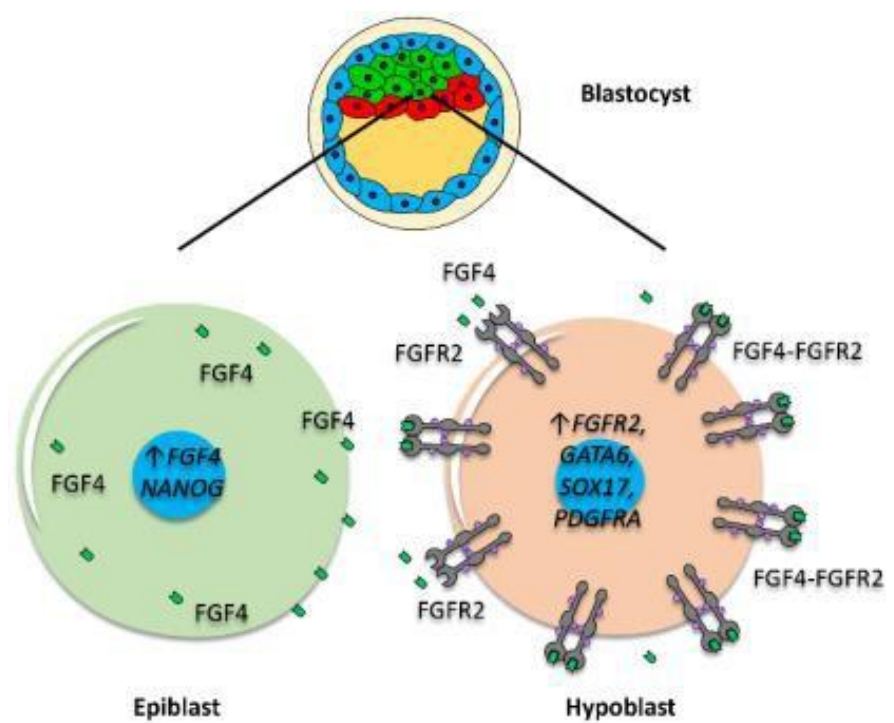

Figure 4 Illustrated image of the second lineage divergence event in eutherian embryos.

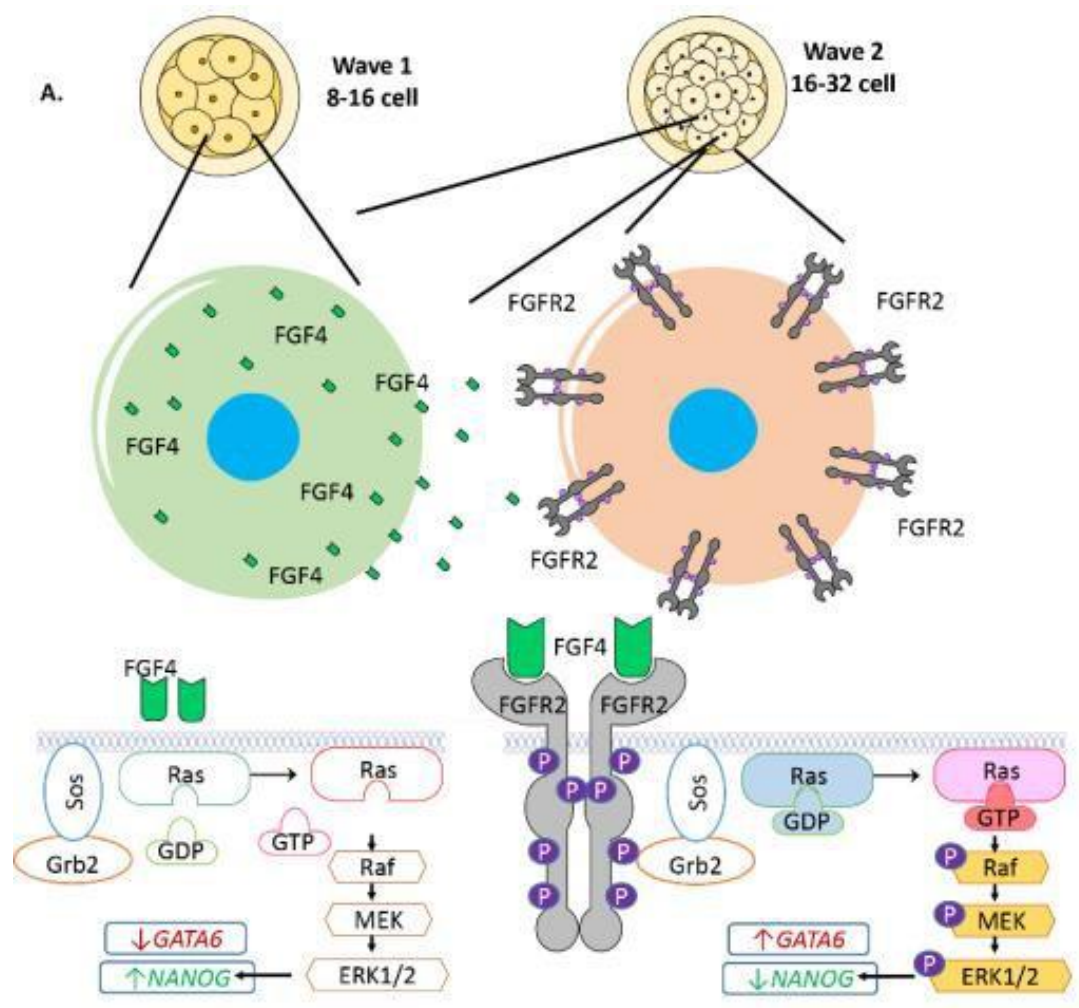

Figure 5 Role of FGF signalling in mouse embryos during the second lineage divergence event in mouse embryos. FGFR2 are tyrosine kinase receptors which selfphosphorylates upon FGF4 binding. The phosphorylation of residues results in altered conformations and mediates series of protein-protein interactions. This collectively leads to the phosphorylation and activation of the MAPKKK signalling pathway. 
Since the expression of GATA6 is dependent on FGF4 signalling, it is therefore expected that when FGF4 is inhibited, the ratio of epiblast over hypoblast will increase. Indeed, perturbation of FGF4 signalling reduces or complete depletes the ICM of hypoblast development. For example, earlier studies have shown that in mice, disruption of GRB2, an adaptor protein that facilitates the activation of ERK, one of the main MAPK proteins, activation through protein scaffolding (Figure 5), would cause the blastocysts to exhibit a total loss of hypoblasts (Chazaud, Yamanaka, Pawson, \& Rossant, 2006), thus demonstrating the crucial role of Fgf4 signalling in mice hypoblast development.

Chemical genetics studies targeting MAPK in both mice (Brinkhof et al., 2015; Ewart W. Kuijk et al., 2012) and cattle(Ewart W. Kuijk et al., 2012) have demonstrated that, in both species, attenuation of FGF4 signalling drastically reduces or completely depletes the hypoblast development. Specifically, when embryos are treated with a MAPK inhibitor, the cell differentiation ratio is skewed towards more Nanog positive cells, i.e. future epiblast. When treated with an Fgf4 agonist, more hypoblast is formed in the developing cattle embryo (Yang et al., 2011). Furthermore, MEK, one of the main MAPKK proteins, when inhibited in both mouse and cattle embryos lead to loss of population heterogeneity and leads to an ICM consisting of only Nanog-expressing cells (Kuijk et al., 2012).

In comparison, the role of FGF signalling in bovine embryos seems to be more elusive. Firstly, mouse embryos with MEK signalling inhibited develop into blastocysts with solely NANOG-expressed cells. When cattle embryos undergo the same treatments, hypoblast precursor cells were not fully ablated, therefore suggesting a compensatory mechanism present (Kuijk et al., 2012). The same group reported that inhibition of FGF signalling upstream of MEK, through the presence of small-molecule inhibitors, did not have an effect on the hypoblast to epiblast ratio. This suggests that the segregation of the two lineages is independent of FGF signalling and not entirely dependent on the MAP kinase pathway. MAPK has been previously demonstrated to inhibit the expression of NANOG in mouse embryonic stem cells (Hamazaki, Kehoe, Nakano, \& Terada, 2006). Therefore, it is plausible to assume that FGF4-induced GATA6 expression in cattle embryos is the result of an indirect effect of activated MEK (and downstream MAPK) on the repression of NANOG (Figure 6). 


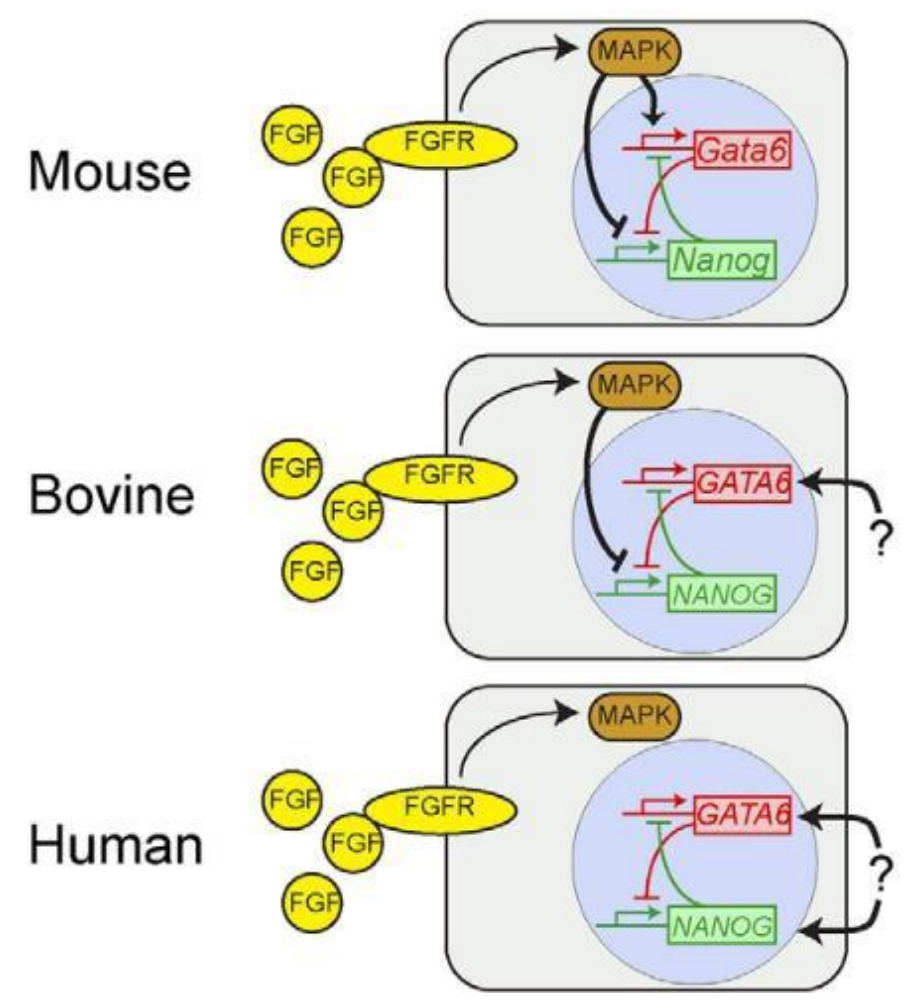

Figure 6 Illustrated imaged of the hypothesised role of FGF and MAPK signalling on fate decision across mouse, bovine and human embryos. In mouse, FGF signalling pathways results in MAPK activation. Activated MAPK will lead to the expression of GATA6 and repression of Nanog. GATA6 and NANOG reciprocally inhibit each other, leading to the "saltand-pepper" expression pattern. In bovine embryos, the promotion of GATA6 expression is hypothesised to be secondary to MAPK's repression of NANOG. The primary/direct mechanism that promotes GATA6 expression in cattle is unknown (question mark). In human, the mechanisms regulating NANOG and GATA6 expression has not yet been addressed. Adapted with permission from (Kuijk et al., 2012) 


\subsubsection{Other possible mechanisms of hypoblast establishment}

As a result of such differences for FGF signalling across species, a number of other signalling pathways have been proposed to be alternative signalling pathways for hypoblast establishment. PDGFA, through its receptor PDGFRA and MAP2K1/2, is required for hypoblast maturation by preventing apoptosis in mice (Chazaud \& Yamanaka, 2016). Treatment of exogenous PDGFA ligand on mouse embryos did not produce similar effect as exogenous FGF treatment.

Canonical WNT signalling prevents ß-Catenin degradation and hence allows the latter's nuclear translocation to activate target genes. WNT pathway is dispensable in mice prior to the gastrulation stage with no observable effect on epiblast to hypoblast ratio when inhibited. In bovine embryos, it has been reported that treatment of CHIR99021, a small-molecule inhibitor for WNT signalling, from the zygotic stage, but not the morula stage, will induce in fewer epiblast cells with no effect on the number of hypoblast precursors (Kuijk et al., 2012).

Alternatively to WNT signalling, the bias in lineage determination may be attributed to the history of the blastomeres the during the first lineage event (see above chapter; (Yamanaka, Ralston, Stephenson, \& Rossant, 2006)). In mice, cell tracing experiments have confirmed the theory that cells internalising at later time points will encourage its fate as hypoblast precursor cells (Morris et al., 2013; Morris et al., 2010); no similar experiment has been applied to cattle embryos. It could be argued that blastomeres internalising at these later times could be subject to more YAP signalling (Figure 3), which prevents SOX2 expression. FGF4 synthesis is dependent on SOX2 expression. However, given the evidence that FGF4 is likely to be a secondary mechanism for hypoblast establishment in cattle (Kuijk et al., 2012), it is likely that another underlying pathway is responsible for sustaining GATA6 (and repressing NANOG) expression.

To this end, immunohistochemistry and cell history tracing experiment in the cattle embryos have shown interesting dynamics of GATA6/NANOG protein distribution through the blastocyst stage - contrary to the mouse equivalent stages, where GATA6 and NANOG are quickly shut off in the trophoblast after early blastocyst stage (Artus et al., 2011). In cattle, GATA6 is maintained until late blastocyst stage in the trophoblast, whereas NANOG is not 
detectable in the trophoblast at any stage of blastocyst development (Denicol et al., 2014), in a manner reminiscent of human embryos (Figure 7). These findings fit well into a model, which suggests that the extended expression of hypoblast precursor markers in the outer trophoblast precursors maintains their plasticity into the hypoblast lineage. Further cell lineage tracing studies combined with chimera embryo studies should provide interesting insights regarding this proposed model.

However, to date GATA6 knock-out bovine embryos have not been documented in published literature. This is in part due to the lack of available methodologies, with the exception of the newly developed CRISPR technologies. Traditional genetic studies are laborious and require expensive equipment. However, the harvest of CRISPR technologies provides the potential of circumventing these limits, which will be discussed in detail below. 


\begin{tabular}{|c|c|c|c|c|c|c|c|}
\hline \multicolumn{4}{|c|}{ mouse GATA6 } & \multicolumn{4}{|c|}{ mouse NANOG } \\
\hline$E$ & $M$ & L & $\mathrm{H}$ & $E$ & $M$ & L & $\mathrm{H}$ \\
\hline \multicolumn{4}{|c|}{ human GATA6 } & \multicolumn{4}{|c|}{ human NANOG } \\
\hline$E$ & $M$ & $\mathrm{~L}$ & $\mathrm{H}$ & $\mathrm{E}$ & $M$ & L & $\mathrm{H}$ \\
\hline \multicolumn{4}{|c|}{ cattle GATA6 } & \multicolumn{4}{|c|}{ cattle NANOG } \\
\hline $\mathrm{E}$ & $M$ & L & $\mathrm{H}$ & $\mathrm{E}$ & $M$ & L & $\mathrm{H}$ \\
\hline
\end{tabular}

Figure 7 Illustrated diagramme of GATA6 and NANOG expression in different mouse, human and cattle blastocyst stages. Adapted with permission from (Pfeffer, 2018).

Blastocyst stages include E, early; $M$, mid; L, late; H, Hatched. Colour-coded histogrammes representing red, epiblast; yellow, hypoblast; blue, trophoblast. Note the extended expression of GATA6 in human and bovine trophoblast, and the lack of NANOG expression in respective trophoblast. 


\subsection{Developing Methodologies for Embryonic Gene Editing}

\subsubsection{Overview and Origin of CRISPR}

Bacteria and archaea-bacteria employ CRISPR and CRISPR-associated protein (Cas9) as a unique adaptive immune system to fight against foreign DNA, such as invading virus (Doudna \& Charpentier, 2014; Sampson, Saroj, Llewellyn, Tzeng, \& Weiss, 2013).

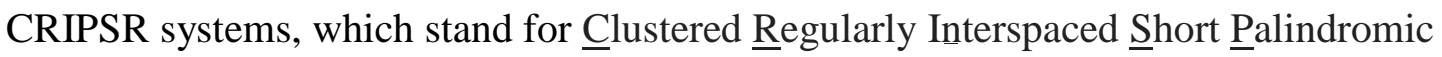
Repeats, are a series of different compositions of ribonucleic hybrids. The CRISPR-Cas systems share several key common mechanistic features across the two classes and six major types (type I - VI) (Doudna \& Charpentier, 2014):

1. They provide immunity through 3 distinct stages of workflow - acquisition of spacer region, CRISPR-Cas9 expression and interference.

2. They use small crRNA encoded in the CRISPR locus to guide targeted, sequence-specific interference of DNA sequences

In bacterial and archaeal genomes, the CRISPR locus encodes a series of trans-activated CRISPR RNAs (crRNA), Cas protein and CRISPR repeat-spacer array (all together referred to as Cas operon) (Jennifer A. Doudna \& Emmanuelle Charpentier, 2014; Sampson et al., 2013). Namely, in this spacer array, regularly interspaced repeat sequences and spacer sequences are found. Spacer region are acquired from foreign DNA sources. Upon expression from the CRISPR locus, a long pre-CRISPR DNA construct is transcribed and processed into individual crRNA by cleavage. The now mature crRNA contains a spacer sequence and a repeat sequence, which directs Cas nuclease to execute cleavage of nucleic acid targets in a sequence-dependent manner (Figure 8).

It should be stated that, through the stages of acquisition, expression and interference, the different type of CRISPR-Cas9 system also exhibits a great array of biological mechanisms in crRNA biogenesis and subsequent genetic knock-out (Doudna \& Charpentier, 2014). This section of literature review will only aim at given an overview of CRISPR functionality, with specific emphasis on its application in genetic engineering. 
Of the six types of CRISPR systems, type II CRISPR system entails the most simplistic workflow. This system requires only one protein, Cas9, therefore is aptly named the CRISPR-Cas9 system. With the help of an engineerable RNA component, the Cas9 protease can recognise, bind and cleave at the desired DNA sequences. Biochemically, Cas9 is a bilobular protein, made up of a larger $\alpha$-helical domain and a nuclease domain lobe (Jinek et al., 2014). In the native organisms where the type II CRISPR system is found, the RNA component is made up of two short, variable crRNA sequence and a tracrRNA with known sequences, that forms a duplex prior to binding to Cas9 (Jinek et al., 2014; Wang, La Russa, \& Qi, 2016). By designing the sequence of the crRNA, the CRISPR-Cas9 system can used to cleave any site upstream of a PAM sequence (protospacer adjacent motif), the exact sequence of which depends on the Cas protein used. Translation of the CRISPR-Cas9 system into the laboratory allowed the fusing of the two oligos RNAs into a single sgRNA (single-guide RNA) (Doudna \& Charpentier, 2014).

Once the Cas9 complex is formed, it scans the genomic material by associating and disassociating along DNA strands until a PAM sequence is encountered. The binding of PAM sequences with the Cas9 complex induces a conformational change that unwinds the DNA around 10 nucleotides upstream of the PAM sequences, termed the seed region (Szczelkun et al., 2014). If the sgRNA matches the seed region, the formation of a probeDNA heteroduplex will occur. The separation of the heteroduplex complex renders itself into a metal-ion dependent site for Cas9's endonuclease activities. The HNH domain of the Cas9 nuclease lobe cleaves the target strand, while the other strand is cleaved by the RuvClike domain of the $\alpha$-helical lobe.

When applied to eukaryote systems, the effect of Cas9 activities will lead to a doublestranded break (DSB) at a targeted locus (Jennifer A. Doudna \& Emmanuelle Charpentier, 2014). The DSB will then activate the repair machinery of the cell, through either errorprone non-homologous end joining (NHEJ), or homology-directed recombination (HDR). If NHEJ were to occur, the DSB will be joined back through cleaving the overhangs and religation, resulting in mutant populations with potential frame-shift mutations. HDR occurs when a homologous DNA sequence is available to be copied and pasted to replace the old sequences. HDR can also allow knock-in mutagenesis if a foreign template is additionally provided (Doudna \& Charpentier, 2014).. 

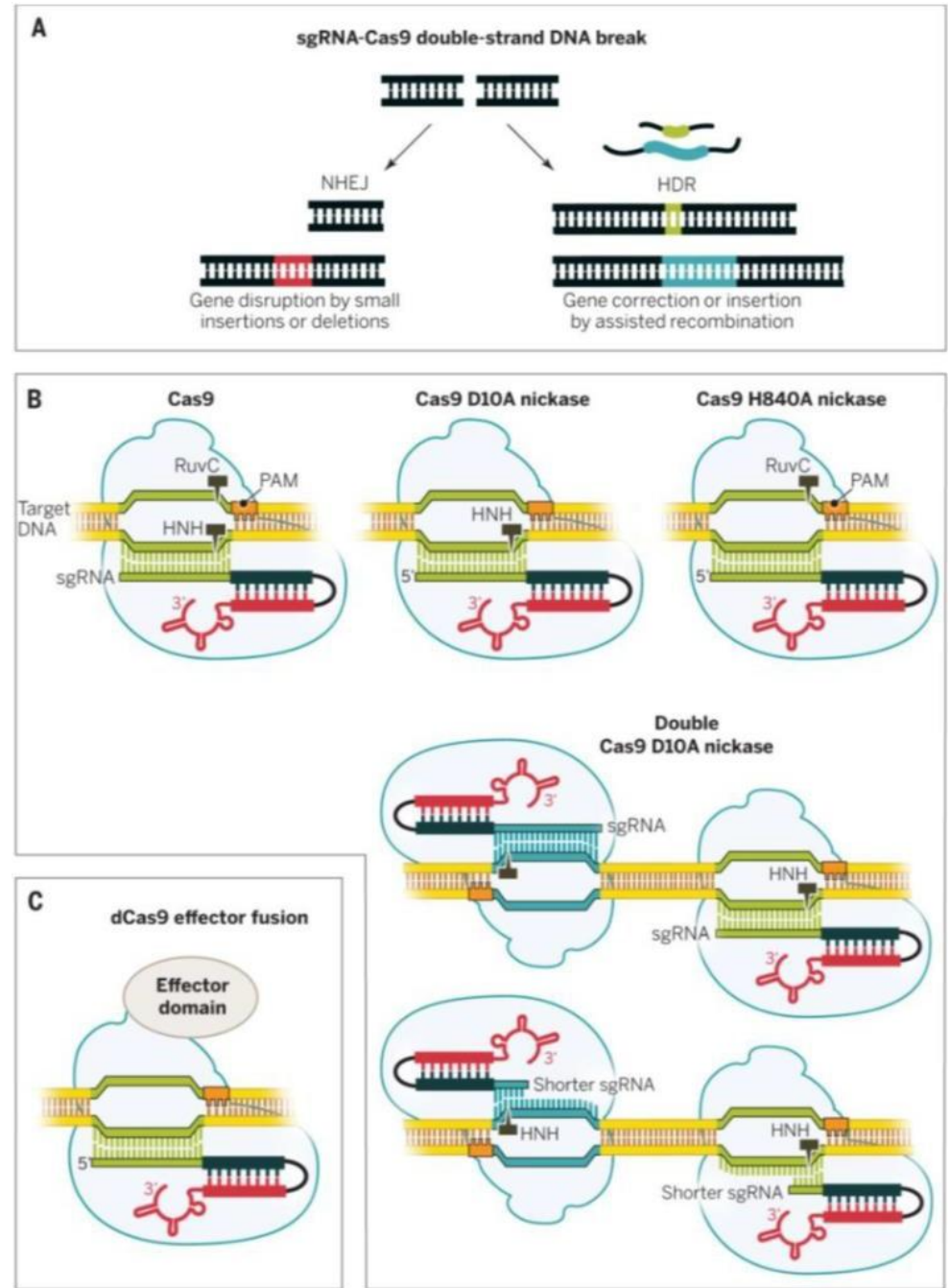

Figure 8 Illustrated summary of CRISPR-Cas9 system's application in genetic engineering. A. Indel mutations or gene correction (if a foreign probe is added) can occur as results of the cellular DNA repair system. B. Engineered Cas9 can induce, in addition to double strand breakage (DSB), nickase activity on either strand of DNA. A pair of Cas9 can be used targeting different loci to induce a staggered DSB. C. Increasing, Cas9 protein are exploited for their recognition ability only with no nuclease activity, which is conjugated to other effector domains, such as fluorescent proteins. Adapted from ( Doudna \& Charpentier, 2014) with permission. 


\subsubsection{Advantages of CRISPR}

To date, Cas9-mediated genetic technologies have been broadly applied in reverse genetics studies to determine the functions of specific genes. Over the last decade, several other programmable nucleases have been developed to facilitated genetic studies. Nevertheless, when compared to other classes of site-specific nucleases, such as Zinc finger nucleases (ZFNs) and transcription activator-like effector nuclease (TALENS), the CRISPR/Cas9 system exhibits a number of advantages (Lino, Harper, Carney, \& Timlin, 2018). Specifically, due to the particularly chemical make-up of CRISPR-Cas systems (ribo-nucleic hybrids), they can be readily and easily engineered to targeted genetic sequences on a caseby-case basis. This will allow high-throughput, less labourious studies at unprecedented rates (Doudna \& Charpentier, 2014).

As described above, different families of CRISPR system exhibit, respectively, mechanistic differences (Doudna \& Charpentier, 2014; Lino et al., 2018; Wang et al., 2016), albeit all can produce similar net chemical reactions, which is the eventual hydrolysis of phosphodiester bonds between desired nucleotides. CRISPR/Cas9 has the powerful advantage of targeting any 23-bp sequences that contains a short PAM motif, which can be on either the compliment or coding strand. In the case of Streptococcus pyogenes derived Cas9, the PAM motif is NGG, found on average once every 8 base pairs in the human genome due to its random and repetitive nature. This will thus allow the potential to target almost every gene in any organismal genome.

The CRISPR-Cas9 system is easily programmable to edit multiple genome loci with precision by introducing multiple sgRNAs at once. This allows for high-definition and highthroughput genetic screens that were infeasible before. In addition to generating insertion and deletion of sequences (INDELs), the Cas9-mediated machinery has also been applied to induce large-scale chromosomal rearrangements, aiming to mimic a genetic instability which is observed in many human disease states (e.g. cancer). As an example, by creating two DSBs through Cas9 lysis in different chromosomes will induce large-scale chromosomal translocation, which could not be easily achieved by other classes of engineerable nucleases (Brunet \& Jasin, 2018). 


\subsubsection{Short-comings and current research goals}

While exhibiting high efficiency in cell lines, the specific application of the CRISPR-Cas9 system still faces some obstacles towards its application in the field of embryology. Low efficiencies, in particular of gene $\mathrm{KO}$ events may be due to the epigenomic state of a target cell, e.g. when a gene is in densely packed heterochromatin (Simmet et al., 2018).

Studies on producing gene-edited animals have shown genetic mosaicisms within individual embryos (Yen et al., 2014; Zuo et al., 2017), whereby some of the cells or the developing blastocysts shows the desired genotype, while others remain unaffected. To this end, recent studies (Zuo et al., 2017) have demonstrated that such challenges can be overcome by using multiple targeting-RNAs of the same gene.

As mentioned frequently in recent reviews (Doudna \& Charpentier, 2014; Lino et al., 2018; Wang et al., 2016), the delivery of CRISPR-Cas9 into individual cells/nucleus, where it exercises its therapeutic effect, is still hindered to a significant extend. Notably, by the lack of appropriate pharmacological vector. Every type of delivery has its advantages and shortcomings, and some of these vectors may be quite specific or inapt depending on respective hosts (e.g. cells in a flask vs. live organisms). This is specifically relevant in the case of embryological studies. The early embryo is surrounded by an impermeable, glycoprotein-rich capsule, which necessitates alternate strategies.

Microinjection is by far one of the most common means of generating genetically modified animal models (Lino et al., 2018). However, whether be it the cytoplasm or perivitelline space, the process of microinjection requires expensive laboratory equipment (a micromanipulator), specialised instrument skills, as well as being itself, a laborious procedure.

In addition to the direct injection of the CRISPR machinery, there are several other methods that have become available for the pharmacological delivery of the CRISPR-Cas9 system. Of them, lentiviral vectors have become popular for embryo modification due to their ability to target even non-dividing cells. In fact, recent studies have demonstrated a synergistic efficiency of knock-out mutagenesis by combining microinjection and lentiviral vectors (Kabadi, Ousterout, Hilton, \& Gersbach, 2014). In other words, the injection of CRISPRencoding lentivirus into the perivitelline space of the bovine oocytes produce the highest efficiencies (Tessanne et al., 2012). We propose here an alternative strategy, in which the 
zona pellucida, is removed through attenuated protease digestion. The CRISPR-Cas9-sgRNA complex can then be delivered by soaking embryos in a solution of high-titre CRISPRconstruct-containing lentiviral particles, bypassing the need for microinjections.

It is the intention for this master's research project to produce lentiviral particles that functionally target bovine GATA6 and bovine GATA4, in order to provide the methodological basis for their genetic studies in bovine embryos. These viruses can then be applied during bovine hypoblast development and hence used to address the interspecies molecular divergence, by comparing it to the mouse equivalent stages. While lentiviral plasmids that contain CRISPR-Cas9 are commercially available (Sanjana, Shalem, \& Zhang, 2014), they must first be tailored to incorporate the specific gRNA sequences that target the two genes of interest. We therefore aim to:

1. design and verify GATA4-targetting CRISPR-activating lentiviral plasmids

2. produce lentiviral particles from such lentiviral plasmid

3. test the efficiency of these lentiviral particles on HEK293, an immortalised cell line

4. test the efficiency and efficacy (of genetic knock-out) on primary bovine cells in terms of gene expression (qPCR) and protein translation (immunocytochemistry). 


\section{Chapter 2 Methods}

\subsection{Cell culture}

Cell culture work in this thesis was carried out in its entirety in a laminar flow hood (Alphatech, Czech Republic) with appropriate aseptic techniques. Both the flow hood and all instruments entering the flow hood are sterilised with $70 \%$ ethanol before and after use. Cells were grown in a water jacket incubator (VWR International, USA), maintained at $37^{\circ} \mathrm{C} / 5 \% \mathrm{CO}_{2}$.

\subsubsection{Media}

A defined type of media was applied for all aforementioned experiments, namely Dulbecco's modified eagle medium (DMEM), with 10\% heat-inactivated FCS (foetal calf serum), $1 \%$ weight/volume PS (penicillin-streptomycin). All media solutions were sterilised by filtering through a $0.22 \mu \mathrm{m}$ filter (Millipore, Germany). Medium was prewarmed to $37^{\circ} \mathrm{C}$ in a heated water-bath prior to application.

\subsubsection{Thawing of cells}

Cell culture stocks were stored in liquid nitrogen in DMEM supplemented with 5\% DMSO (Sigma, USA). Prior to use, cells in vials were removed from storage and rapidly warmed till just thawed. It was aimed to avoid leaving cells to incubate in freeze media to avoid DMSO toxicity. Once thawed, cells were mixed into $10 \mathrm{~mL}$ of growth media and recovered through centrifugation for 3 minutes at $180 \mathrm{x} g$ in a table-top centrifuge (Eppendorf, Germany). The resultant supernatant was carefully decanted, and the pellet of cells was recovered through re-suspending in $10 \mathrm{~mL}$ of growth media. Finally, the cell suspension was_then transferred into appropriately sized growth plates. 


\subsubsection{Passaging cells}

In this body of work, cells were grown as adherent cultures. The cells were monitored daily and passaged into subcultures when reaching $60-80 \%$ confluency. The adherent cells were first washed by PBS to remove growth medium. Cells were then lifted using $0.25 \%$ Trypsin-EDTA (Life Technologies, USA), which was pre-warmed to $37^{\circ} \mathrm{C}$ prior to application. Lastly, cells were seeded in appropriately sized culture plates.

\subsubsection{Counting cells}

Prior to seeding, cells often need to be quantified so as to be plated at desired densities. To achieve this, suspensions containing cells of interest were diluted 1:2 in an equal volume of Trypan Blue (Sigma, USA). Cell counting was carried out using a haemocytometer, which was loaded with $10 \mu \mathrm{L}$ of the diluted suspensions.

\subsubsection{Freezing of cells}

Cells were frozen at appropriate quantities, ranging from 1 x 106 to 3 x 106 cells per cryovial in pre-prepared freeze medium. On the first night, cells were placed in a CoolCell ${ }^{\circledast}$ Cell Freezing Container (Biocision, USA), which in turn was left overnight in the $-80^{\circ} \mathrm{C}$ freezer. The use of $\mathrm{CoolCe}{ }^{\circledast}{ }^{\circledast}$ prevents the formation of ice crystals and therefore, its subsequent cytotoxic effects. The cryovials were transferred into the liquid nitrogen storage for long term storage after 24 hours. 


\subsection{DNA Cloning}

A collection of parental and derived plasmids was created in this thesis by DNA cloning mechanisms, which will be explained in detail in Chapter 3.

\subsubsection{Bacterial transformation}

\subsubsection{Preparation of electrocompetent cells}

The E. coli strain to be made competent was inoculated from a glycerol stock and grown overnight in $10 \mathrm{~mL}$ LB supplemented with ampicillin $(100 \mu \mathrm{g} / \mathrm{mL})$, at $37^{\circ} \mathrm{C}$ with rotation. This overnight culture was then added into $400 \mathrm{~mL}$ of the same media (LB with $100 \mu \mathrm{g} / \mathrm{mL}$ ampicillin) and grown until an OD600 of $0.35-0.4$ was reached. At this point, it was transferred to 8 sterile $50 \mathrm{~mL}$ tubes and cooled on ice for exactly 30 minutes. Cells were then centrifuged for 15 minutes at $2,700 \mathrm{x} \mathrm{g}, 4^{\circ} \mathrm{C}$. Cell pellets were resuspended in $200 \mathrm{~mL}$ ice-cold sterile $\mathrm{ddH}_{2} \mathrm{O}$ by gentle pipetting. The process of resuspension was done gently in view of the fragility of electrocompetent cells. Cells were pelleted again and resuspended for a second time in $500 \mu \mathrm{L}$ ice-cold glycerol. The electrocompetent cells were aliquoted in $1.5 \mathrm{~mL}$ solutions into a test tube at a concentration of $2-3 \times 1010$ cells $/ \mathrm{mL}$. Finally, cell aliquots were then snap frozen in a metal tube block which had been prechilled at $80{ }^{\circ} \mathrm{C}$ and stored at $-80{ }^{\circ} \mathrm{C}$ until needed.

\subsubsection{Transformation of electrocompetent cells}

Aliquots were removed from $-80{ }^{\circ} \mathrm{C}$ storage and thawed on ice. Plasmid DNA of around $10-50 \mathrm{ng}$ was added into the mix and transferred into an ice cold sterile 2 $\mathrm{mm}$ gap electroporation cuvette. Cells were electroporated at $2.5 \mathrm{kV}, 25 \mu \mathrm{F}, 100 \Omega$, after which $900 \mu \mathrm{L}$ of LB was immediately added to the cuvette and gently inverted to mix. Cells were incubated at $37^{\circ} \mathrm{C}$ with rotation during one hour for recovery. Finally, cells were plated on LB agar plates supplemented with $100 \mu \mathrm{g} / \mathrm{mL}$ ampicillin and grown overnight. 


\subsubsection{Plasmid isolation}

\subsubsection{Miniprep by ethanol precipitation}

Transformed DH5 $\alpha$ were grown overnight in $3 \mathrm{~mL}$ LB broth supplemented with ampicillin $(100 \mu \mathrm{g} / \mathrm{mL})$ at $37^{\circ} \mathrm{C}$ with rotation. $1 \mathrm{~mL}$ of this culture was transferred into a $1.5 \mathrm{~mL}$ microcentrifuge tube for miniprep and centrifuged at $11,000 \mathrm{x}$ g for 1 minute. Supernatant was removed and discarded while the cell pellet was resuspended in $100 \mu \mathrm{L}$ of Alkaline Lysis Solution I (See appendix). $200 \mu \mathrm{L}$ of Alkaline Lysis Solution II (See appendix) was then added, with the tube inverted 5 times to mix. 200 $\mu \mathrm{L}$ of Alkaline Lysis Soltion III (See appendix) was added and the solution was inverted to mix for 5 times. The mix was then centrifuged at 16,000 $\mathrm{x}$ g for 4 minutes. Resulting supernatant was transferred to a fresh $1.5 \mathrm{~mL}$ tube and $1 \mathrm{~mL}$ of $100 \%$ ethanol was added and centrifuged $\left(16,000 \mathrm{xg}, 4\right.$ minutes at $\left.4^{\circ} \mathrm{C}\right)$. The supernatant was then again removed, and the pellet was washed with $1 \mathrm{~mL} \mathrm{70 \%} \mathrm{ethanol.} \mathrm{The} 70 \%$ ethanol was removed with the tube left to air dry for 3 minutes. The DNA pellet was resuspended in $30 \mu \mathrm{L}$ of molecular biology grade $\mathrm{H}_{2} \mathrm{O}$ containing $1 \mu \mathrm{L}$ of RNase- A and finally incubated at $37^{\circ} \mathrm{C}$ for 30 minutes.

\subsubsection{Midiprep and maxiprep protocol}

Midipreps and maxipreps were prepared with the QIAGEN Plasmid Midi (or Maxi) Kit (QIAGEN, Netherlands), while closely following the manufacturer's protocols (See appendix). DNA content was measured on a Nanodrop ND-1000 Spectrophotometer. 


\subsubsection{Lentiviral packaging plasmids}

A commercially available, second-generation lentiviral plasmid (Addgene, USA) were used for lentiviral vector productions in this thesis. In this set of lentiviral production system, fewer plasmids are used when compared to the 3rd generation lentiviral vectors (which requires 4 plasmids). The 2 nd generation was considered advantageous, due to the more traditional nature of the calcium phosphate method of transfection. The 3 plasmids contained within the lentivirus production system included 2 packaging plasmids, and the lentiviral vector.

\subsubsection{Plasmid pMD2.G}

pMD2.G is a packaging plasmid that encodes VSV-G (Vesicular stomatitis Indiana virus $G$ ), an essential envelope protein for the successful assembly of the respective lentivirus. This envelope protein mediates the viral entry into target cells and is enhanced by an adjacent CMV promoter. Additionally, this plasmid contains the SV40 viral origin of replication, which promotes the large quantity of plasmid replication through the encoded large $\mathrm{T}$ antigen. An ampicillin-resistance gene is also encoded as a selection marker. Restriction sites are as labelled (Figure 9).

\subsubsection{Plasmid psPAX6}

psPAX6 is another packaging vector, through the employment a CMV promotor and TATA box, encodes other crucial components for lentiviral packaging - namely Group specific antigen (Gag), Protease, Reverse transcriptase (PoI), Tat/Rev and Revresponse element, respectively. The increased expression of these protein components is required for the proper functioning of the lentiviral system. Similar to $p M D 2 . G$, this plasmid also contains the SV40 origin of replication, allowing interaction of the host cell machinery for increased replication of plasmid. An ampicillin-resistance gene is included as selection marker. Restriction sites are as labelled (Figure 9). 

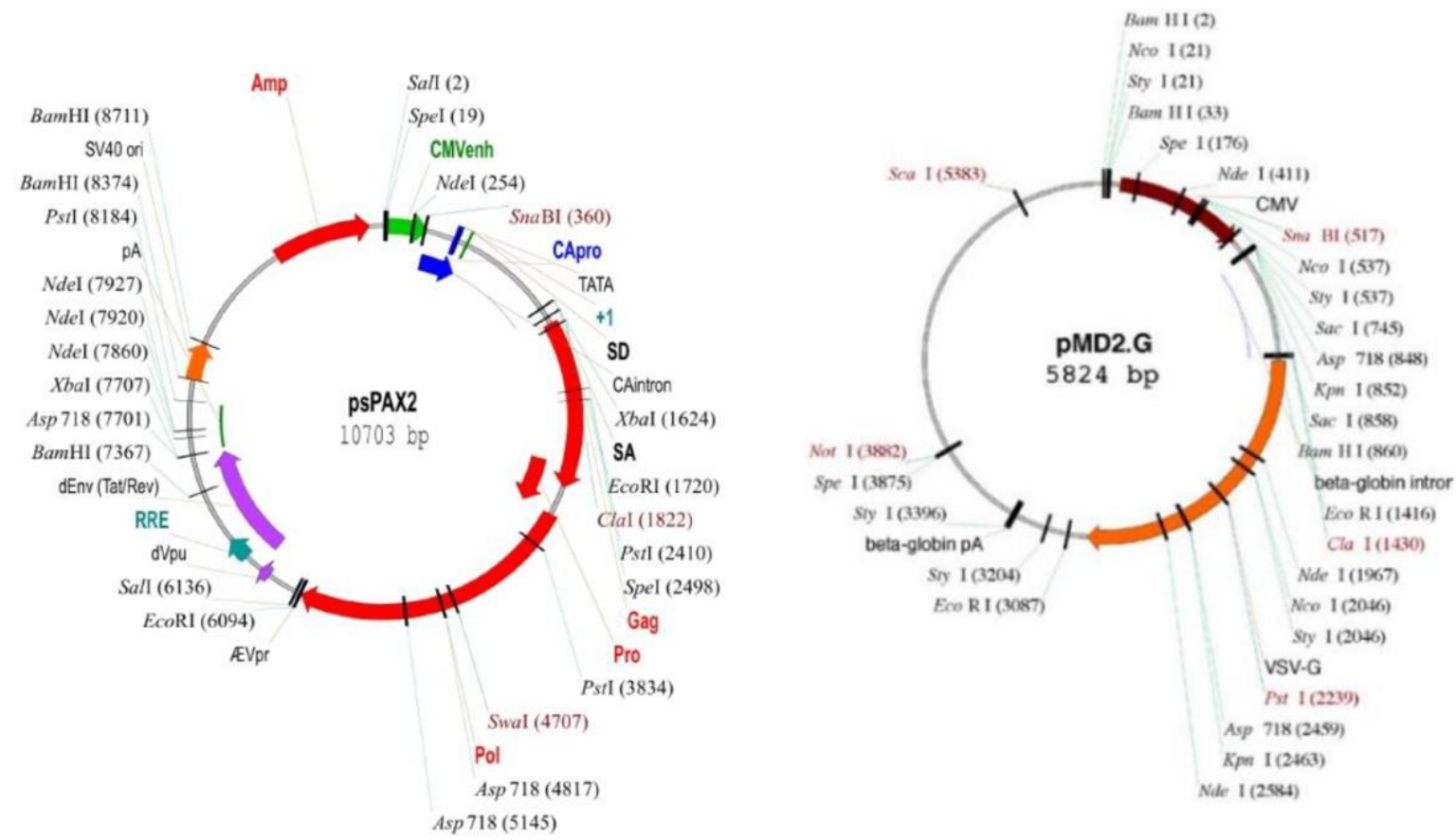

Figure 9 Restriction map of psPAX2 and pMD2.G 


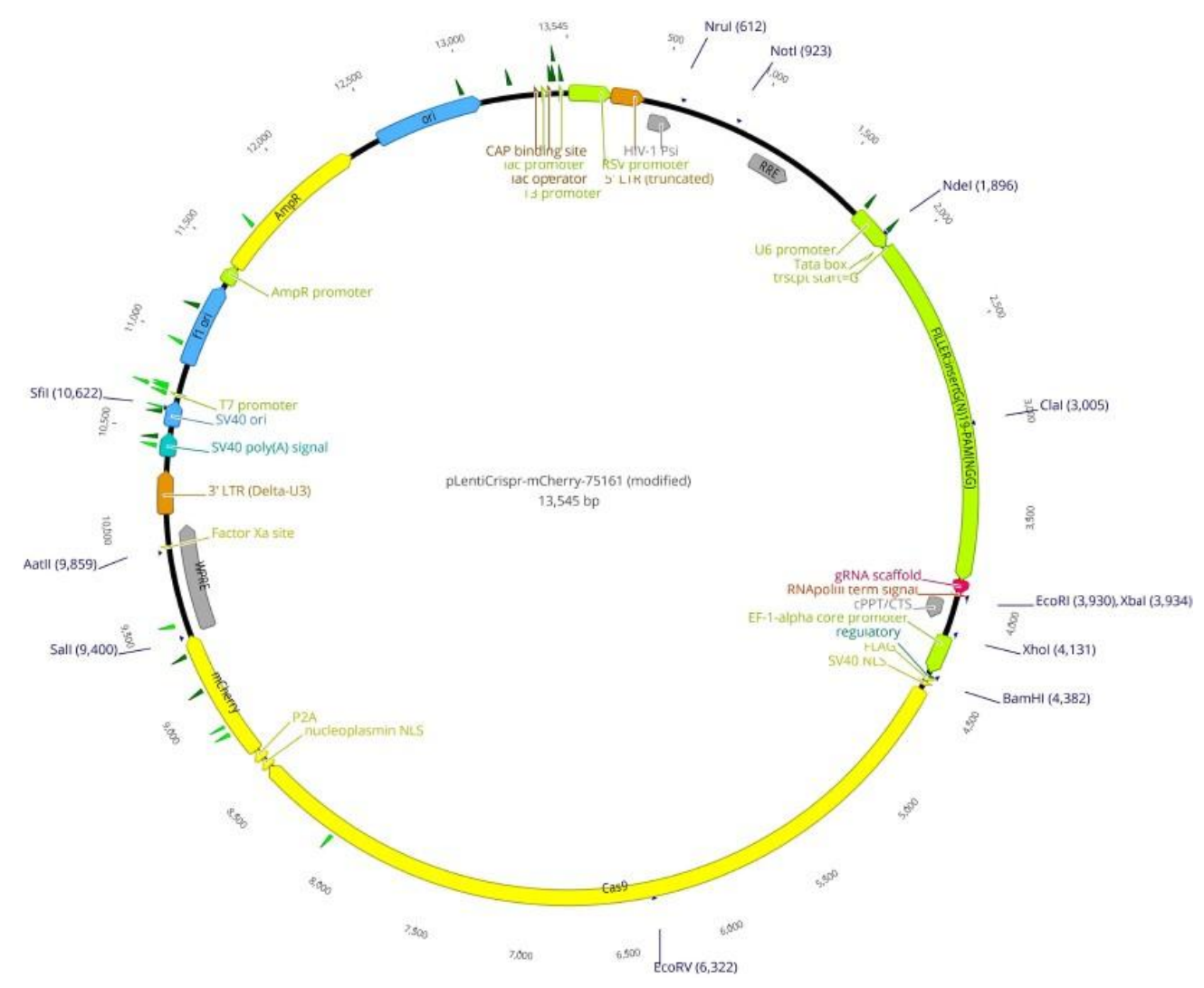

Figure 10 Restriction map of pLenti-CRISPR-mCherry

\subsubsection{Plasmid pLenti-CRISPR-mCherry}

pLenti-CRISPR-mCherry (Figure 10) is a commercially available, all-in-one plasmid, which encodes the Cas 9 protease, and an excisable filler sequence flanked by 2 BsmBI restriction sites. A fluorescent marker protein, mCherry is fused to the end of Cas9. Both proteins are promoted by an EFS promoter sequence. Like the packaging plasmids, this CRISPR plasmid contains the SV40 origin of replication to increase replication of plasmid by the large T antigen expressed in the HEK293T/17 cell line. The psi element and flanking long terminal repeats (LTRs) facilitates the package of Cas9 and sgRNA into resultant lentiviral particles, when co-expressed with the packaging plasmids ( $p M D 2 . G$ and $p s P A X 6)$. 


\subsubsection{Creating pLenti-CRISPR-bGATA4-mCherry}

pLenti-CRISPR-mCherry was used as the backbone vector from which bGATA4targetting plasmid was designed. sgRNAs complimentary to bGATA4 were designed via an online database, CHOPCHOP v2 (Labun, Montague, Gagnon, Thyme, \& Valen, 2016). This programme allowed selection of sequences with ranked for offtarget binding sites. Subsequently, the oligos were ordered from a commercial supplier (Invitrogen).

\subsection{Gel electrophoresis}

To analyse or isolate DNA following digestion, agarose gel electrophoresis was performed to separate DNA by size. Different percentages of agarose $(0.5 \%, 1 \%$ and $2 \%$ ) were applied depending on the anticipated product size. Ethidium Bromide (Bio$\mathrm{Rad}, \mathrm{A}$ ) was added to the gel at $0.5 \mathrm{ug} / \mathrm{mL}$ for visualising DNA bands under the transilluminator. To extract DNA following digestion, separated DNA bands of anticipated sizes were excised from the gel manually with a razor. DNA was then isolated using Wizard SV Gel and PCR Clean-up System (Promega, Auckland), following the manufacturer's instructions.

\subsection{Fluorescence Microscopy}

To quantify the transfection and transduction efficiency, fluorescence microscopy was used to visualise cells that expressed $m$ Cherry as a result of either the lentivirus or the lentiviral plasmid integration. Samples were photographed under the TXRED filter and the proportion of fluorescence was counted via ImageJ (Schneider, Rasband, \& Eliceiri, 2012) to quantify transformation and transduction efficiencies. 


\subsection{Lentiviral production}

\subsubsection{Calcium phosphate transfection}

HEK293/T (ATTC, USA) were plated overnight in the appropriate medium until above $80 \%$ confluency was reached. To transfect target cells, a transfection mix of associated DNA and calcium, in the form of chloride salt, was added into the culture dish. The following table obtained through the commercial supplier's manual (Addgene) was closed followed.

\begin{tabular}{|c|c|c|c|}
\hline ID & Volume & ID & Volume \\
\hline 15-cm dish & & 10-cm dish & \\
\hline $\begin{array}{l}\text { Transfer vector } \\
(60 \mu \mathrm{g})\end{array}$ & $\begin{array}{l}\text { Typically } \\
\text { around } 50 \mu \mathrm{L}\end{array}$ & $\begin{array}{l}\text { Transfer vector } \\
(20 \mu \mathrm{g})\end{array}$ & $\begin{array}{l}\text { Typically } \\
\text { around } 150 \mu \mathrm{L}\end{array}$ \\
\hline $\begin{array}{l}\text { psPAX2 (45 } \\
\mu \mathrm{g})\end{array}$ & $\begin{array}{l}\text { Typically } \\
\text { around } 20 \mu \mathrm{L}\end{array}$ & $\begin{array}{l}\text { psPAX2 (15 } \\
\mu \mathrm{g})\end{array}$ & $\begin{array}{l}\text { Typically } \\
\text { around } 10 \mu \mathrm{L}\end{array}$ \\
\hline $\begin{array}{l}\text { pMD2.G } \\
\text { envelop plasmid } \\
(18 \mu \mathrm{g})\end{array}$ & $\begin{array}{l}\text { Typically } \\
\text { around } 30 \mu \mathrm{L}\end{array}$ & $\begin{array}{l}\text { pMD2.G } \\
\text { envelop } \\
\text { plasmid ( } 6 \mu \mathrm{g})\end{array}$ & $\begin{array}{l}\text { Typically } \\
\text { around } 10 \mu \mathrm{L}\end{array}$ \\
\hline $2.5 \mathrm{M} \mathrm{CaCl}_{2}$ & $150 \mu \mathrm{L}$ & $2.5 \mathrm{M} \mathrm{CaCl} 2$ & $50 \mu \mathrm{L}$ \\
\hline $\begin{array}{l}\text { Molecular } \\
\text { Biology Grade } \\
\text { Water }\end{array}$ & $\begin{array}{l}\text { Make up to } 1.5 \\
\mathrm{~mL}\end{array}$ & $\begin{array}{l}\text { Molecular } \\
\text { Biology Grade } \\
\text { Water }\end{array}$ & $\begin{array}{l}\text { Make up to } 1.5 \\
\mathrm{~mL}\end{array}$ \\
\hline Total Volume & $1.5 \mathrm{~mL}$ & Total Volume & $0.5 \mathrm{~mL}$ \\
\hline
\end{tabular}

After the reagent mix is prepared accordingly, it was added dropwise into an equal volume of $2 \mathrm{x}$ HBS solution and incubated at room temperature for 15 minutes prior to introduction into the appropriate cell culture media. The cells were then incubated at $37^{\circ} \mathrm{C}, 5 \% \mathrm{CO}_{2}$ for 6 hours before the media was removed by aspiration and replaced with fresh DMEM with 10\% FCS. 


\subsubsection{Collection of lentiviral particles}

Subsequent to transfection, lentivirus-producing cells were monitored every day for fluorescent markers, as well as phenotypic changes in cell shape ("ballooning" of cell, which is a sign of viral infection), both of which are indicative of virion production. The media contained lentiviral particles were collected 48 hours post-transfection, replaced with fresh media and collected again 72 hours post-transfection. The supernatant was filtered through 0.45 micron filters and stored at $-20{ }^{\circ} \mathrm{C}$ for up to one month.

\subsubsection{Concentration of lentiviral particles}

Supernatant solutions containing lentivirus were concentrated though ultracentrifugation. The harvest solutions were centrifuged at 70,000 x g, room temperature for 3 hours. Pellets containing concentrated lentiviral vectors should be observed. Then, depending on the scale of production, a second round of centrifugations were carried out by overlaying the viral pellets with more harvest solutions. Viral pellets were then resuspended in $100 \mu \mathrm{L}$ of $1 \times$ HSBB and transferred into a screw-cap microcentrifuge tube. A further $100 \mu \mathrm{L}$ of $1 \times$ HSBB was applied to "rinse" the centrifuge tube, in view of collecting any remaining viral particle, which was pooled with the previous viral suspension to give rise to a total of $200 \mu \mathrm{L}$. The concentrated viral suspension was finally vortexed for 15 minutes and briefly centrifuged to clear. This part of the protocol was adapted from (Tiscornia, Singer, \& Verma, 2006).

\subsubsection{Calculation of the biological titre}

In order to calculate the biological titre, in the form of transducing units per mL, of the lentiviral particles, transduction assays were carried out. The biological titre was calculated by first seeding $0.3 \times 106$ cells in a 6 -well plate. Serial dilutions of the concentrated stock (undiluted, half-dilution and 10-1) and the undiluted supernatant were added into each well. Cells were monitored hereafter daily and, after 3 days, the cells were analysed via fluorescent microscopy and numerically addressed in the following formula: 
Biological Titre $\left(T U . \mathrm{mL}^{-1}\right)$
$=\frac{\text { Percentage of fluorescent posituive cells } \times \text { Number of cells at the time of transduction }}{\text { Volume of transduction reagent }(\mathrm{mL}) \times \frac{1}{\text { Dilution factor }}}$

\subsubsection{Purification of lentiviral particles}

To achieve in vivo quality, the concentrated viral stock was subject to purification through ultracentrifugation. The solution containing viral particles was layered on top of $1.5 \mathrm{~mL} 20 \%$ sucrose and centrifuged at $50,000 \mathrm{x} \mathrm{g}, 20^{\circ} \mathrm{C}$ for 2 hours. After that, the viral pellet was recollected in $200 \mu \mathrm{L}$ of $1 \times \mathrm{HBSS}$ as per the concentration step. Finally, the suspensions were vortex and centrifuged briefly to clear.

\subsection{Bovine embryo production}

\subsubsection{Ovary Aspiration}

To collect oocyte complexes from ovaries through aspiration, collected ovaries from a local abattoir were strained by hand over sink. The ovaries were then washed with warm saline through agitation using hand in wide-mouthed thermos. Ovaries were washed again with fresh saline in the repetitive manner until there was no blood present in the saline.

Aspiration media prepared was prewarmed and poured by approximately $2 \mathrm{~mL}$ per $15-\mathrm{mL}$ tube to collect the oocyte complex. Clear, yellow follicles of $3 \mathrm{~mm}$ to $10 \mathrm{~mm}$ in size of diameter were selected for collection. To aspirate, the aspiration needle was inserted into the follicles while moving the needle in circular motions to extract all the follicular fluid. The pressure of the aspiration pump was also monitored during aspiration to be within $40-50 \mathrm{~mm} \mathrm{Hg}$ to ensure complete collection and reproducibility. If blood was aspirated, the tubes were then to be changed immediately. This process was repeated on all selected follicles. 


\subsubsection{In Vitro Maturation of Bovine Oocytes}

IVM media were prepared a day prior to use. On the day of IVM, cysteamine was thawed and added into the media. Droplets containing $c a .40 \mu \mathrm{L}$ of IVM media were put down in a 10-cm dish, the number of which is respective to the number of oocytes to be transferred in the next step. Usually, 10 droplets per dish were prepared in the following fashion. After which, the dishes were then placed in an incubator at $38.5^{\circ} \mathrm{C}$, $5 \% \mathrm{CO}_{2}$ for 2 hours to equilibrate.

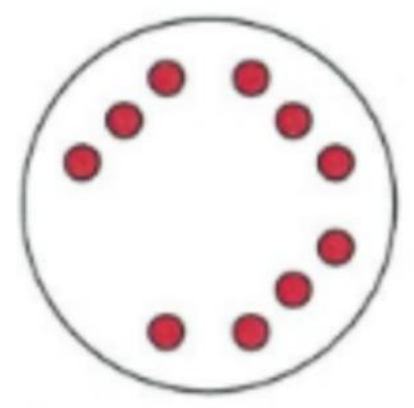

Figure 11 Layout of IVM plate preparation

\subsubsection{Oocyte transfer to IVM drops}

To transfer oocytes into IVM drops, tubes containing aspirated oocytes as well as dishes for collection were placed on a warm box to keep oocytes viable. In a serial and gradual manner, the cells were transferred through a number of media. Firstly, the sediment of the aspiration media from the earlier step containing oocytes, alongside other cell types and debris, is poured into dish. Then, the dish was placed on a warm stage under a microscope and oocytes were searched and picked out using a grid plate. The oocytes were picked up to be transferred into a dish with H199 medium supplemented with $10 \%$ FCS. Each oocyte was afterwards transferred into a new dish containing B199 medium supplemented with 10\% FCS. Finally, oocytes were transferred immediately to prepared IVM plates. The plates were incubated at $38.5{ }^{\circ} \mathrm{C}$, $5 \% \mathrm{CO}_{2}$ for 22-26 hours to achieve oocyte maturation. 


\subsubsection{In Vitro Fertilisation of Bovine Oocytes}

\subsubsection{IVF plate preparation}

Drops containing $30 \mu \mathrm{L}$ of IVF and PPHH medium were placed in each plate. 10 drops were made per plate and each drop was used to lodge 5 oocytes.

\subsubsection{Sperm preparation}

A Percoll gradient was first prepared in a $15 \mathrm{~mL}$ centrifuge tube accordingly: $1 \mathrm{~mL}$ of $45 \%$ percoll solution was added, which was underlaid with $1 \mathrm{~mL}$ of $90 \%$ Percoll solution. Sperm straws were removed from liquid nitrogen storage and thawed in room temperature for 10 second, then in $35^{\circ} \mathrm{C}$ waterbath for 30 seconds. The thawed semen was aspirated and gently layered on top of the Percoll gradient. Sperm motility was checked to be above 50\% under a compound microscope. The Percoll gradient tube was centrifuged at $700 \mathrm{~g}$ for 20 minutes. The oocytes are prepared during the centrifugation.

Immediately after the centrifugation, samples were removed, and the supernatant was carefully aspirated. Sperm pellet was resuspended in $1 \mathrm{~mL}$ of HSOF and spun down again at $200 \mathrm{~g}$ for 10 minutes. After centrifugation, the supernatant was removed, and the sperm pellet was finally resuspended in $200 \mu \mathrm{L}$ of IVF and PPHH medium prior to quantification through cell counting.

\subsubsection{Oocyte preparation}

Oocytes were transferred from IVM drops and transferred into a $35 \mathrm{~mm}$ dish containing drops of HSOF. Oocytes complexes were then pipetted up and down to loosen cumulus cells, but not completely stripped off. Oocytes were then washed by transferring to a new plate of HSOF drops. Oocytes were finally transferred to a third plate containing IVF and PPHH medium and returned to incubator at the $38^{\circ} \mathrm{C}$ incubator.

\subsubsection{Oocyte fertilisation}

Sperm preparations were diluted 1 in 20 then $10 \mu \mathrm{L}$ of which is added to each $40 \mu \mathrm{L}$ drops with previously prepared oocytes. IVF plates were checked under microscope for the presence of sperm and motility. Cumulus cells were collected from the droplets and transferred to a $35 \mathrm{~mm}$ dish containing DMED. 


\subsection{Immunohistochemistry}

All staining procedures were carried out at RT unless otherwise stated. Cells were adhered overnight onto a glass cover slide treated with poly-D-lysine, prior to staining. Cells were fixed with PBS with 4\% (v/v) PFA and permeabilised with PBS with $0.5 \%$ (v/v) Triton X-100. Sample was blocked with PBT with 10\% (v/v) PBS. Cells were the incubated with primary antibodies overnight at $4^{\circ} \mathrm{C}$. Afterwards, cells were washed with washing buffers (PBT once and PBT/3\%BSA) prior to introduction of secondary antibody. Cells were finally washed again in PBT/1\%BSA and stained with DAPI and eventually mounted onto slide.

\section{9 qPCR}

\subsubsection{RNA isolation}

For RNA extraction, the Trizol ${ }^{\mathrm{TM}}$ Reagent was applied while closely following the manufacturer's protocol. $1 \mathrm{~mL}$ of Trizol ${ }^{\mathrm{TM}}$ and chloroform was added into pelleted cell. $10 \mu \mathrm{g}$ of glycogen was also added at this point to help locate RNA pellet. Sample was centrifuged at 12,000 x g for 15 minutes, after which the upper aqueous was transferred to a fresh low-bind tube. 500 $\mu \mathrm{L}$ of ice- cold isopropanol was added and left at $-20^{\circ} \mathrm{C}$ for 2 hours. Afterwards, the RNA was precipitated by spinning at $18,000 \mathrm{x} g$ for 15 minutes at $4{ }^{\circ} \mathrm{C}$. The pellet was washed a second time by $70 \%$ ethanol and spun down at $18,000 \mathrm{x}$ g for 15 minutes at $4^{\circ} \mathrm{C}$. Finally, purified RNA was resuspended in $28 \mu \mathrm{L}$ RNase-free water.

\subsection{2 cDNA synthesis}

Purified RNA was subject to DNase treatment prior to cDNA synthesis. Briefly, sample was treated with RNase-free DNase in DTT, murine RNase inhibitor and DNaseI reaction buffer at appropriate concentrations and incubated at $37^{\circ} \mathrm{C}$ for 60 minutes. RNA was then precipitated and washed as described above. 
50 pmol oligo-dT $14 \mathrm{VN}$ primer and $10 \mathrm{nmol}$ of dNTP was added to $1 \mu \mathrm{g}$ of RNA and appropriate amount of water to make up $10 \mu \mathrm{L}$ of reaction volume. Then, the sample was incubated at $65^{\circ} \mathrm{C}$ for 5 minutes to anneal reverse transcription primers. cDNA synthesis was carried out via the commercially available Superscript III kit while closely following the manufacturer's protocol (Invitrogen). The sample was incubated at $40^{\circ} \mathrm{C}$ for 10 minutes, $50^{\circ} \mathrm{C}$ for 1 hour the $85^{\circ} \mathrm{C}$ for five minutes before qPCR. A RT- control was set up with the RNA only samples from the previous step, with no reverse transcription.

\subsubsection{Quantitative real-time PCR}

cDNA solution from previous was diluted 1 in 5 with T0.1E (10mM Tris, pH7.5, 0.1 mM EDTA). Technical triplicates with 2 original concentration and 1 half concentration of samples were set up of both the cDNA solution and the RT'- samples for each gene. TaKaRa mastermix containing taq DNA polymerase and SYBRG in appropriate buffer was added into the solution alongside primers for the genes of interest.

The conditions for PCR was as follow: an initial denaturation at $95^{\circ} \mathrm{C}$ for 3 minutes then 40 cycles of $95^{\circ} \mathrm{C}$ for 10 seconds and $60^{\circ} \mathrm{C}$ for 35 seconds for DNA elongation and primer annealing. A dissociation curve was generated through $72^{\circ} \mathrm{C}$ for 90 seconds then from $72^{\circ} \mathrm{C}$ to $95^{\circ} \mathrm{C}$ at $1^{\circ} \mathrm{C}$ every 5 seconds. 


\section{Chapter 3 Results}

\subsection{Design of GATA4-targetting CRISPR-Cas9 systems}

One of the first objectives of this Master's project was to design and verify GATA4targetting CRISPR-Cas9 lentivirus for bovine embryos. A second-generation lentiviral plasmid, pLenti-CRISPR-mCherry (Addgene, MA, USA), was ordered and used as the parental plasmid.

This second-generation lentiviral backbone contained an excisable 2 kilobase-pair region, flanked by 2 BsmBI (New England Biology, Genesearch, New Zealand) digestion sites. The cleavage by this enzyme would result in 3-prime overhangs (sticky ends) downstream of the cleavage site. In our case, the overhangs of the two BsmB1 sites were not complementary, therefore, they could not anneal to each other, as illustrated in Figure 12. Such noncompatibility promotes the insertion by donor oligo, which is the sgRNA sequence.

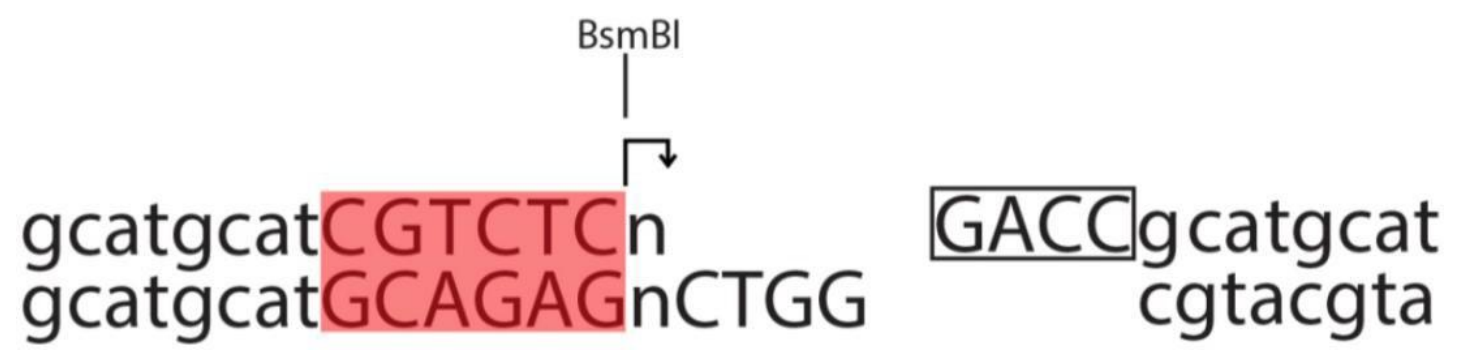

Figure 12 Illustrated image of digestion site. The digestion of BsmBI results in two overhangs with non-compatible ends and cannot be self-ligated back. 


\subsection{Design of sgRNA targeting bovine GATA4}

As discussed in chapter 1, the successful application of CRISPR-Cas9 based technology relies on a sgRNA. However, the immense size, big-data nature of the organismal genome and the random, repeating nature of the eukaryote genomic sequences make it a significantly labourious process to manually design appropriate sgRNA. As a result, several bioinformatics tools have in recent years become readily available to assist the design of active and specific sgRNAs, with less potential for off-target effects.

To this end, one of those online resources, CHOPCHOP, has been frequently applied in many current publications as a useful prediction tool for sgRNA design (Chari, Mali, Moosburner, \& Church, 2015; Cui, Xu, Cheng, Liao, \& Peng, 2018; Labun et al., 2016; Xu et al., 2015). Since we are aiming to produce loss-of-function mutants, i.e. null mutants, the sgRNA must target within the protein-encoding sequence of the gene. By searching on this database, 3 different sgRNAs that target the protein-coding regions of GATA4 were designed and relevant oligo-RNAs were ordered from a commercial supplier (Table 1).ChopChop4 sgRNA was selected to use from this point on as a first attempt. 


\begin{tabular}{|l|l|l|}
\hline Name of oligo & Sequence & Targeting locus \\
\hline Chopchop4_fwd & caccGAGATTGGGGTGTCGCGCCG & $\begin{array}{l}\text { Exon } 1 \\
\text { nucleotide \#883 } \\
-\# 864\end{array}$ \\
\hline Chopchop4_rv & aaacCGGCGCGACACCCCAATCTC & $\begin{array}{l}\text { Exon } 1 \\
\text { nucleotide \#723 } \\
\text { - \#704 }\end{array}$ \\
\hline Chopchop5_fwd & caccCGCGAGCAGTACGGGCGAGC & $\begin{array}{l}\text { Exon } 1 \\
\text { Nucleotide } \\
\# 357 \text { - \#338 }\end{array}$ \\
\hline Chopchop5_rv & aaacGCTCGCCCGTACTGCTCGCG & \\
\hline Chopchop6_rv & aaacGCGCCGTGCATGAAGGCACC & \\
\hline
\end{tabular}

Table 1 Oligo sequences designed to target bovine GATA4 


\subsection{Production of lentiviral plasmid}

To produce the plasmid containing both Cas9 and the desired oligo-RNA sequence targeting bGATA4, the $p$ Lenti-CRISPR-mCherry plasmid needed to be modified through a series of directed deletion and insertions. The lentiviral plasmid was digested with BsmBI for 3 hours at $55^{\circ} \mathrm{C}$.

The digested solution was run on a gel to separate the digested plasmid from the spacer region (Figure 13). The upper band, which corresponds to the excised plasmids, is cut from the gel with DNA recovered using a gel extraction kit, Wizard Gel Clean-up Kit (Promega, New Zealand).

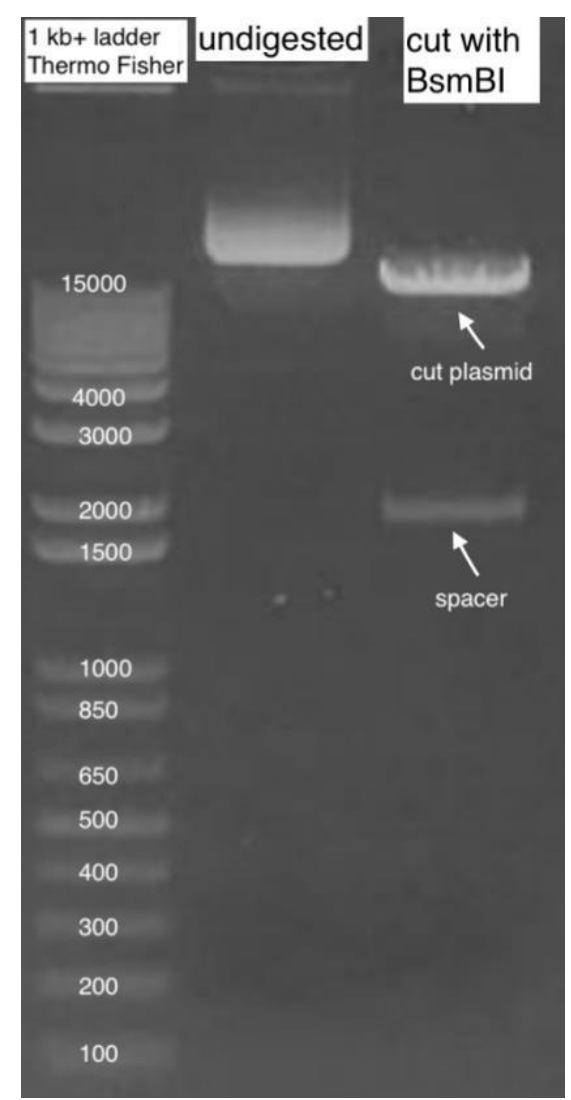

Figure $13 \mathrm{Gel}$

Electrophoresis of pLentiCRISPR-mCherry digested with BsmBI. White arrows showing assumed DNA product corresponding to their anticipated molecular size. 
Meanwhile, to prepare for the successful ligation of the desired oligo to the "filler-free" plasmid, the forward and the reverse strand of bGATA4-oligo were annealed. The doublestranded oligo now contains the overhangs compatible with the respective sticky ends from the previous BsmBI digestion. The resulting solution mixture was then to be introduced into a line of chemically competent DH5alpha bacteria for transformation.

However, many ligation and transformation attempts failed, as a result of which, several experiments were carried out to analyse the experimental parameters.

\subsubsection{Bacterial transformation competency}

We hypothesised that the purchased competent bacterial cells were of insufficiently high chemical competency.

We therefore aimed to prepare electrocompetent bacteria from these cells (see Methods section). We tested these self-made electrocompetent cells with pUC19, a test plasmid, achieving colony formation units (cfu) of up to $109 \mathrm{cfu} / \mu \mathrm{g}$ (Figure 14). However, they were still unable to take up ligated plasmids as show by the low number of viable colonies (Figure 15). The use of pUC19 plasmid served as a positive control to demonstrate all the chemicals (e.g. ampicillin-LB plates) used in this experiment were not the cause for the failed transformation.

After such an attempt, a new line of chemically competent bacteria, OneShot ${ }^{\mathrm{TM}} E$. coli (Thermo Fisher Scientific, New Zealand) was purchased and subsequently gave rise to a much higher efficiency of transformation, around $109 \mathrm{cfu} / \mu \mathrm{g}$ (Figure 15). This allowed me to get a sufficient number of colonies for further analysis. 


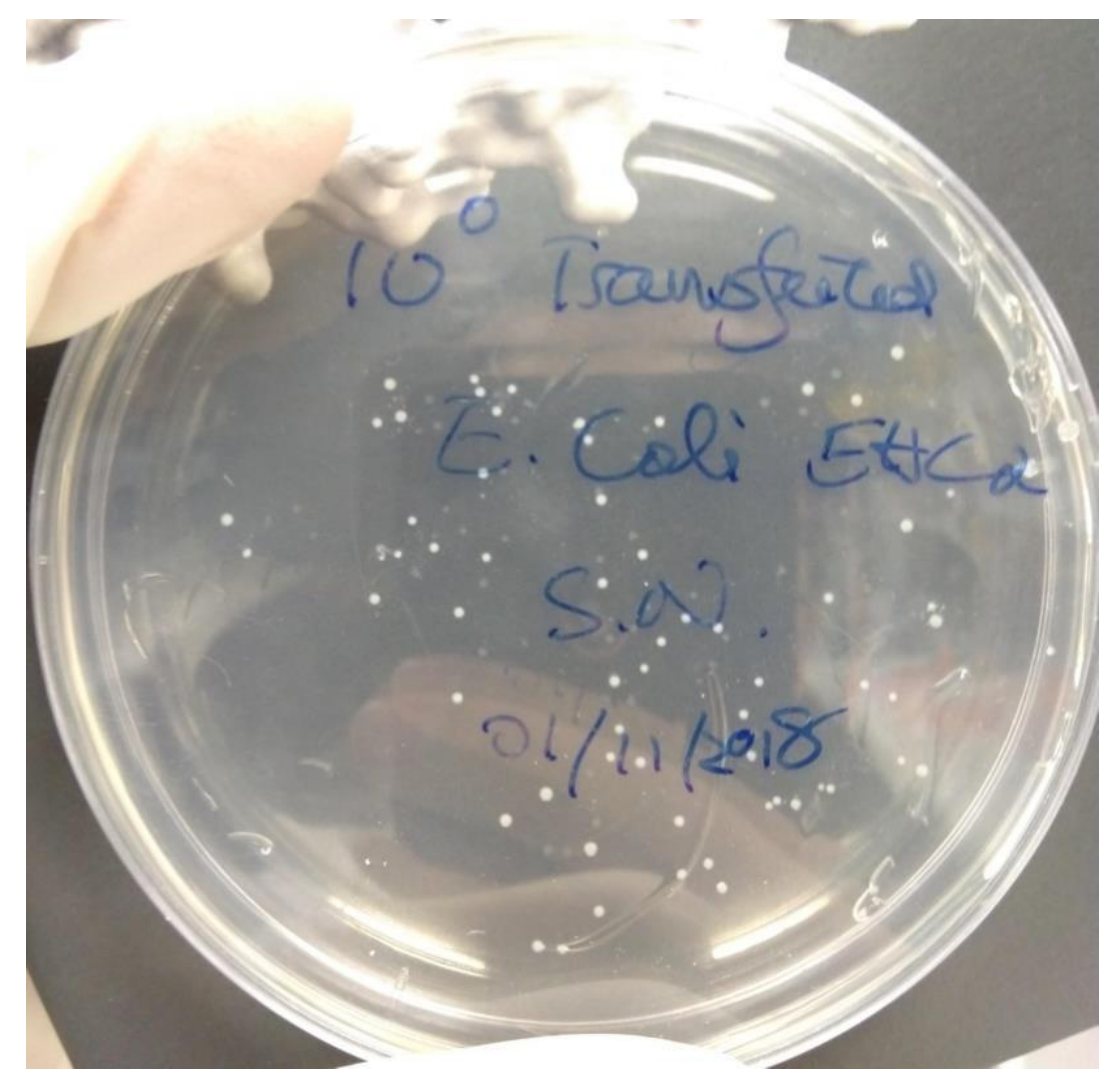

Figure 14 Self-prepared chemically competent cells tested with trial plasmid pUC. The plasmid contains an ampicillinresistant gene, which worked on our ampicillin-LB plates. 


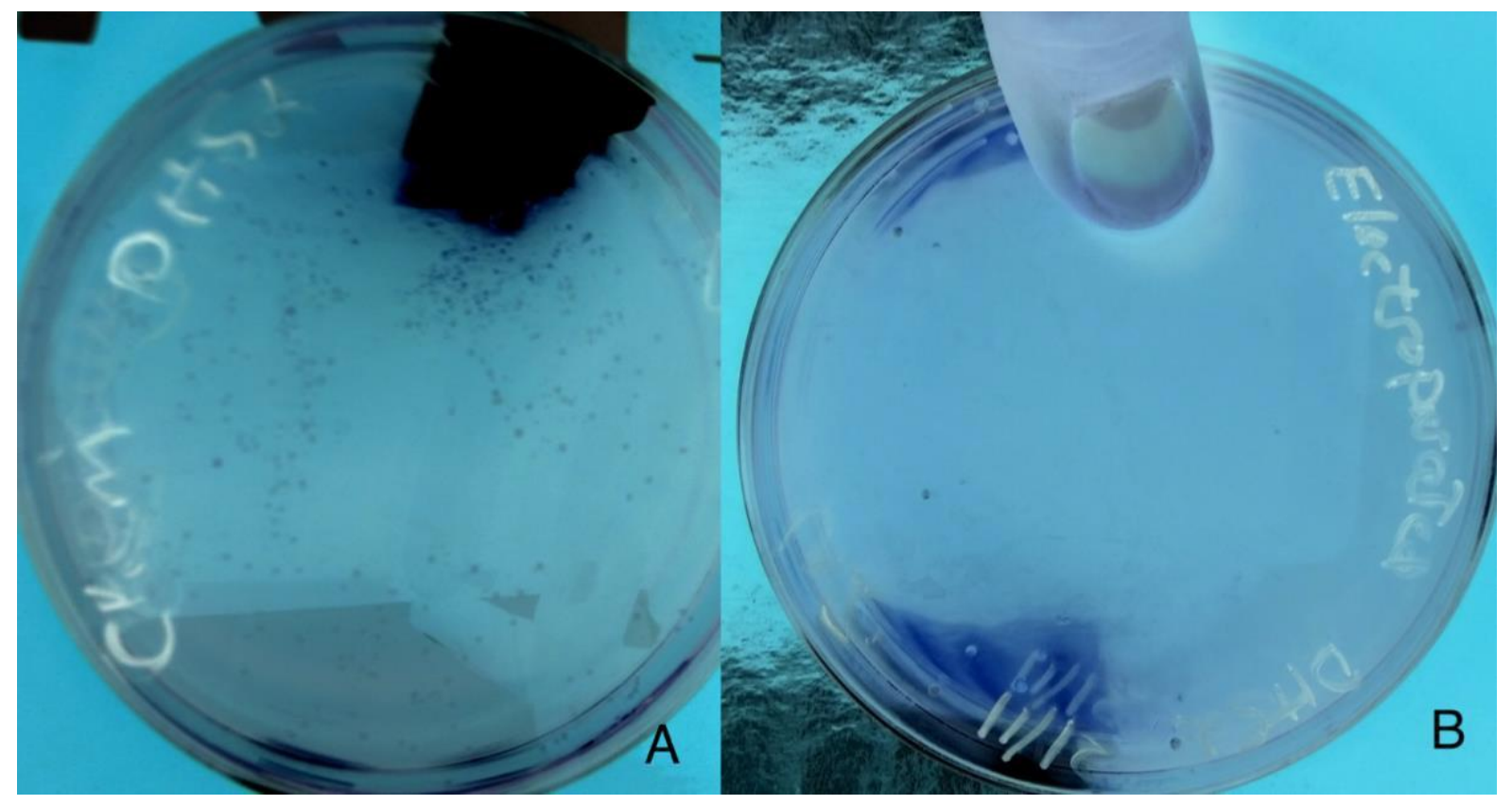

Figure 15 LB ampicillin plates with (A) OneShot chemically competent bacterial or (B) self-made electrocompetent bacteria following transformation of pLenti-GATA4-CRISPR. While the same amount of plasmid DNA was used, the overall transfection efficiency differed greatly with the latter generating only 6 surviving colonies. 


\subsection{Verification of Lentiviral Plasmid}

Resulting transformed colonies needed to be analysed for the correct removal of the $2 \mathrm{~kb}$ base-pair spacer region and insertion of the bGATA4 oligos before lentiviral production. Antibiotic-resistant colonies could contain a plasmid arising from an exision/ligation combination where:

1. The $2 \mathrm{~kb}$-base-pair spacer region was not successfully excised by BsmBI (thus no ligation took place, and this would correspond to the parental vector).

2. The spacer region was excised but self-ligated

3. The bGata4 oligos was successfully integrated into the lentiviral plasmid backbone.

In theory, scenario 2 was less likely since the removal of the spacer region relies on BsmBI, which leaves 5-prime overhangs, being non-compatible for ligase-catalysed end joining. It is still possible if the overhangs had been removed due to contaminating DNase activities.

To test these possibilities, restriction enzyme digestions were performed to differentiate between these possible outcomes. The lentiviral plasmid has a number of sites recognisable by commercially available restriction sites. We selected two enzymes that flank the spacer region, BamHI-HF and NdeI (New England Biology, Genesearch, New Zealand). The different possible situations can be deduced by observing the size of the products.

1. If scenario 1 were to happen, the digestion would yield two bands of $2 \mathrm{~kb}$ and $11 \mathrm{~kb}$ lengths

2. If scenario 2 were to occur, a $600 \mathrm{bp}$ and an $11 \mathrm{~kb}$ band are able to be visualised

3. In the case of scenario 3 , a $620 \mathrm{bp}$ band and an $11 \mathrm{~kb}$ band should be observed 


\subsubsection{Verification by Restriction Digest - Incomplete BsmBI digestion}

The small size of the desired product (620bp) implied that, a high yield of plasmid DNA is required to be successfully visualised. Initial attempts showed only a single band. This is either because there was only a single band, or because there was too little DNA present and therefore a very small band could not have been seen. The possible low yield could be attributed to technical errors as these minipreps were carried out using ethanol precipitation methods (Section 2.2.2.1). Therefore, subsequent experiments were carried out using Miniprep Spin Column (QIAGEN, New Zealand). The results, as shown in Figure 16, indicated that the spacer region had not been successfully cut out by BsmBI.

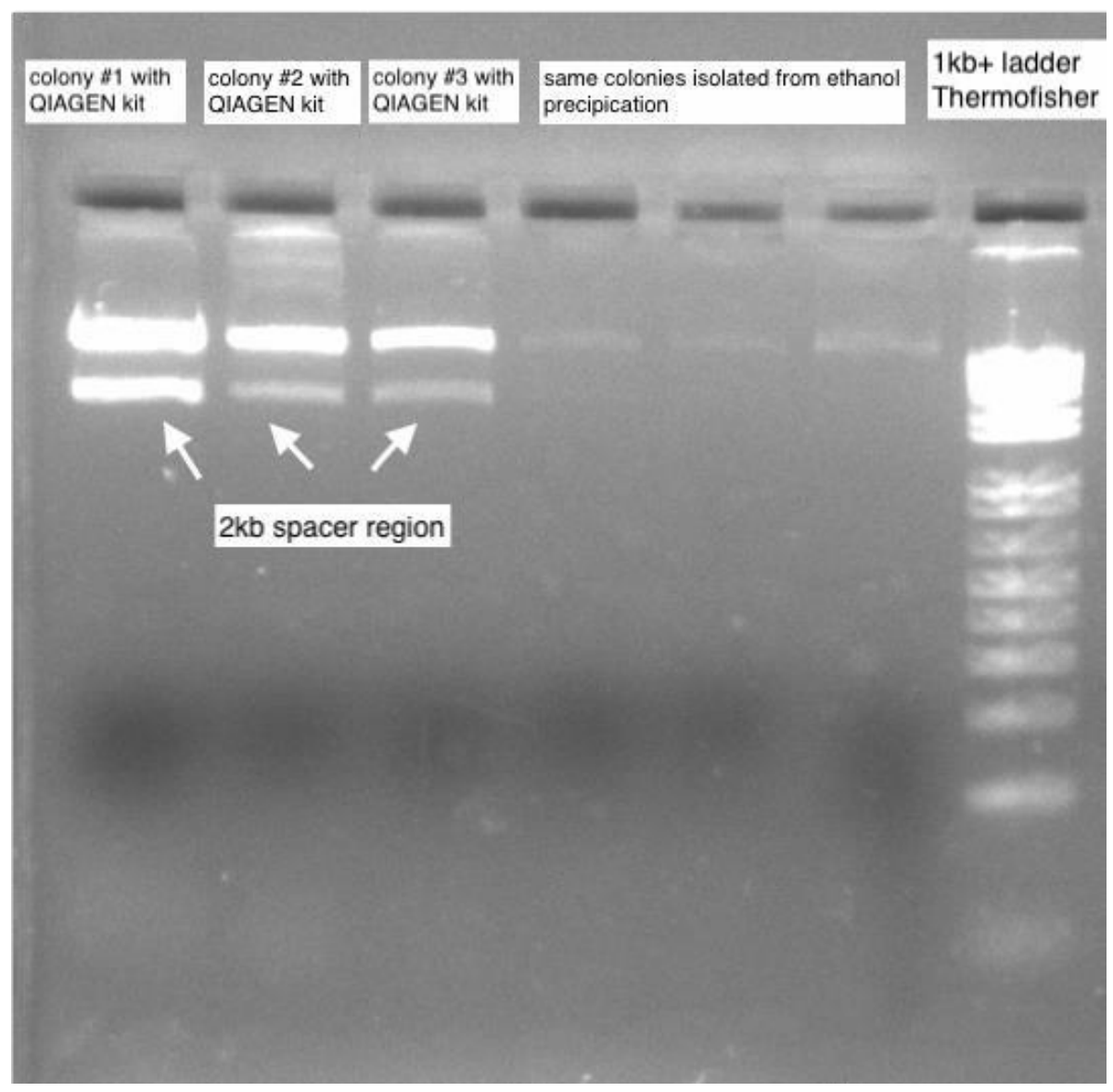

Figure $16 \mathrm{Gel}$ electrophoresis of ligated plasmid from overnight bacterial culture. White arrows show the presence of a $2 \mathrm{~kb}$ band that suggests the presence of undigested (by BsmBI) parental plasmid. 
To troubleshoot, we reviewed the experimental parameters and thereafter, decided to digest the parental plasmid overnight (24 hours) instead of the 3-hour digestion period suggested by the commercial supplier. The experiment was repeated from the start (digestion with BsmBI - extraction - miniprep - digestion with BamHI and NdeI).

\subsubsection{Digestion by BamHI-HF and Ndel}

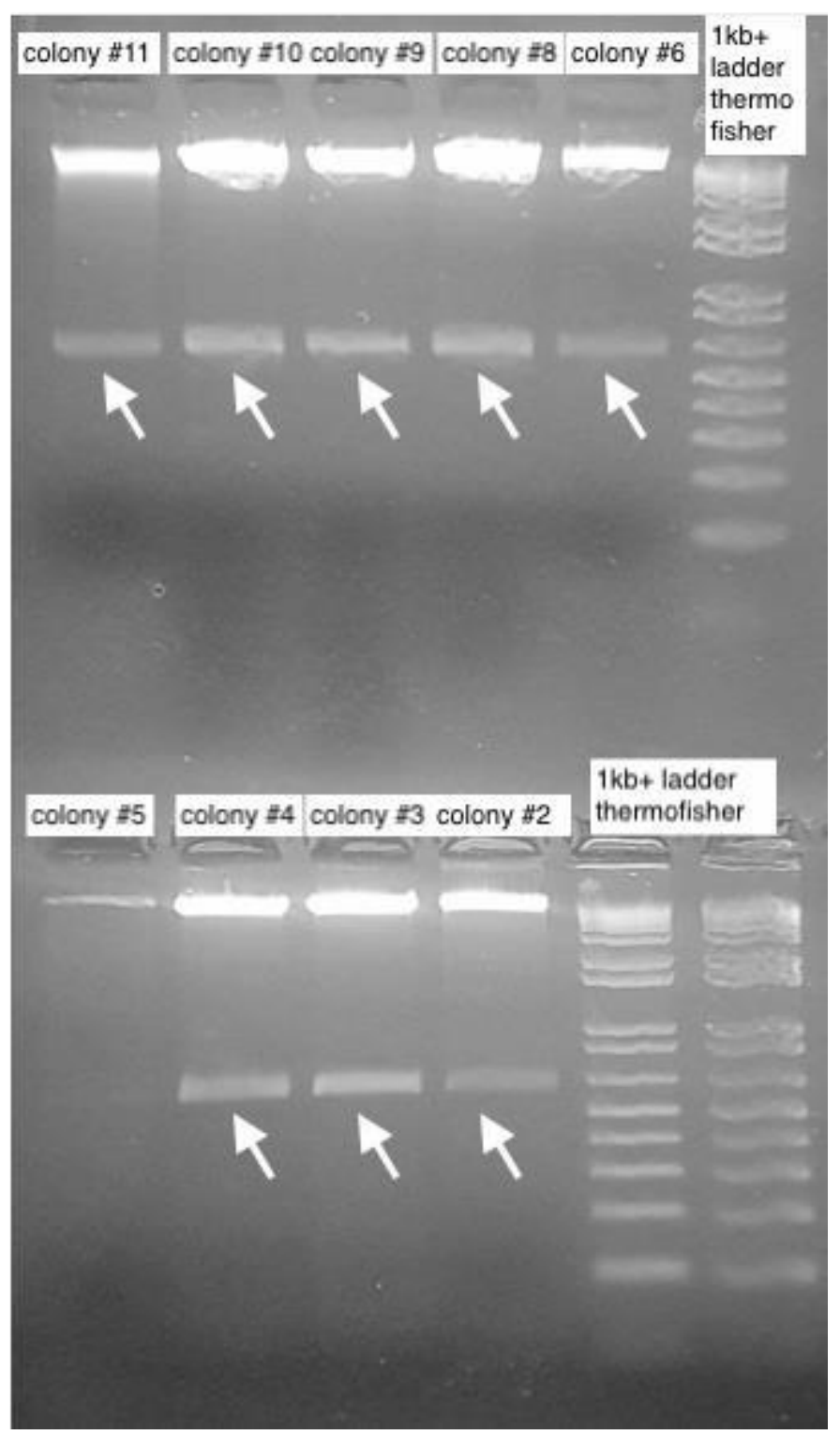

Figure $17 \mathrm{Gel}$

electrophoresis of ligated plasmids from miniprep plasmid extractions. White arrows indicating the band corresponding $600 b p$ molecular weight DNA strands, suggesting complete BsmBI digestion. 
Figure 17 demonstrates the successful digestion of $\mathrm{BsmBI}$ as there is now a band of a size around 600bp. However, due to the resolution of gel electrophoresis when separating DNA by size, it is still unclear whether scenario 2 or scenario 3 occurred. In other words, it is unknown whether the $c a .600 \mathrm{bp}$ band contained the $20 \mathrm{bp}$ gRNA sequence or not.

To address this issue, we digested the plasmid with EcoRI and NdeI, which would give rise to $\sim 150 \mathrm{bp}$ product (or 130bp if the 20bp gRNA sequence is not present), and eletrophoresed this in parallel with with a similarly digested lentiviral CRISPR plasmid containing a 20bp GATA6 gRNA (pLenti-GATA6-CRISPR) as a positive control. pLenti-GATA6-CRISPR was previously constructed and verified through sequencing by a former student in the Pfeffer Lab (Upton, 2019).

\subsubsection{Digestion by EcoRI and Ndel}

It is shown in Figure 18 that the digested products are of the same size to the positive control (pLenti-GATA6-CRISPR), therefore it is very likely that the ligation reaction was successful. Subsequently, the plasmid was sent off to the Waikato Sequencing Facility to be sequenced for a definitive verification.

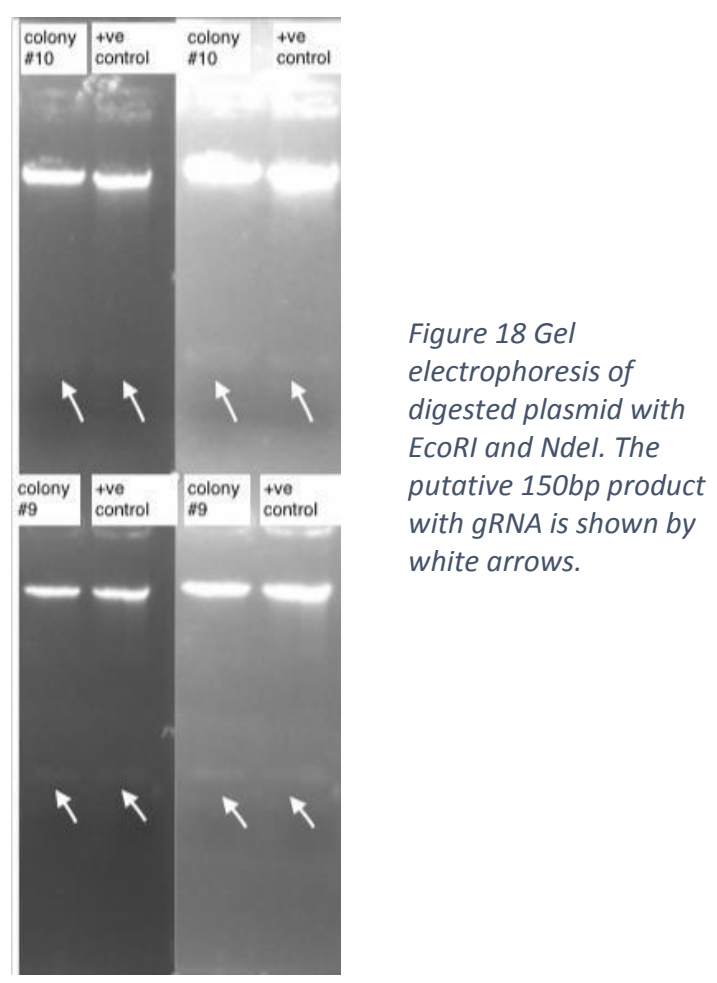




\subsubsection{Verification by sequencing}

The sequencing primer was designed to hybridise around 30 base pairs upstream of the gRNA sequence (ChopChop4) to ensure relative accuracy of reads (Figure 19). The sequencing data were realigned using Genious to compare any potential INDELs, or recombination events around the insertion site.

As it is demonstrated (Figure 19), ChopChop4 was successfully incorporated into the plasmid insertion site, with no observable INDEL or recombination events. The ChopChop4 sequence is completed conserved in the sequencing sample, with the exception of a missing $\mathrm{C}$ nucleotide. Closer inspection of the sequencing trace reveals that this is due to a reading error of the sequencing software as a clear C-peak is present (indicated by black arrows).

Altogether, these data suggest that when correctly assembled, these lentiviral plasmids have the potential of producing functional lentiviral particles, which are able to induce lysis at the sequence targeted by the ChopChop4 gRNA. The plasmid is now named pLenti-GATA4CRIPSR. We therefore next aimed to produce lentivirus particles from this construct, as well as from the previously constructed pLenti-GATA6-CRISPR plasmid. 


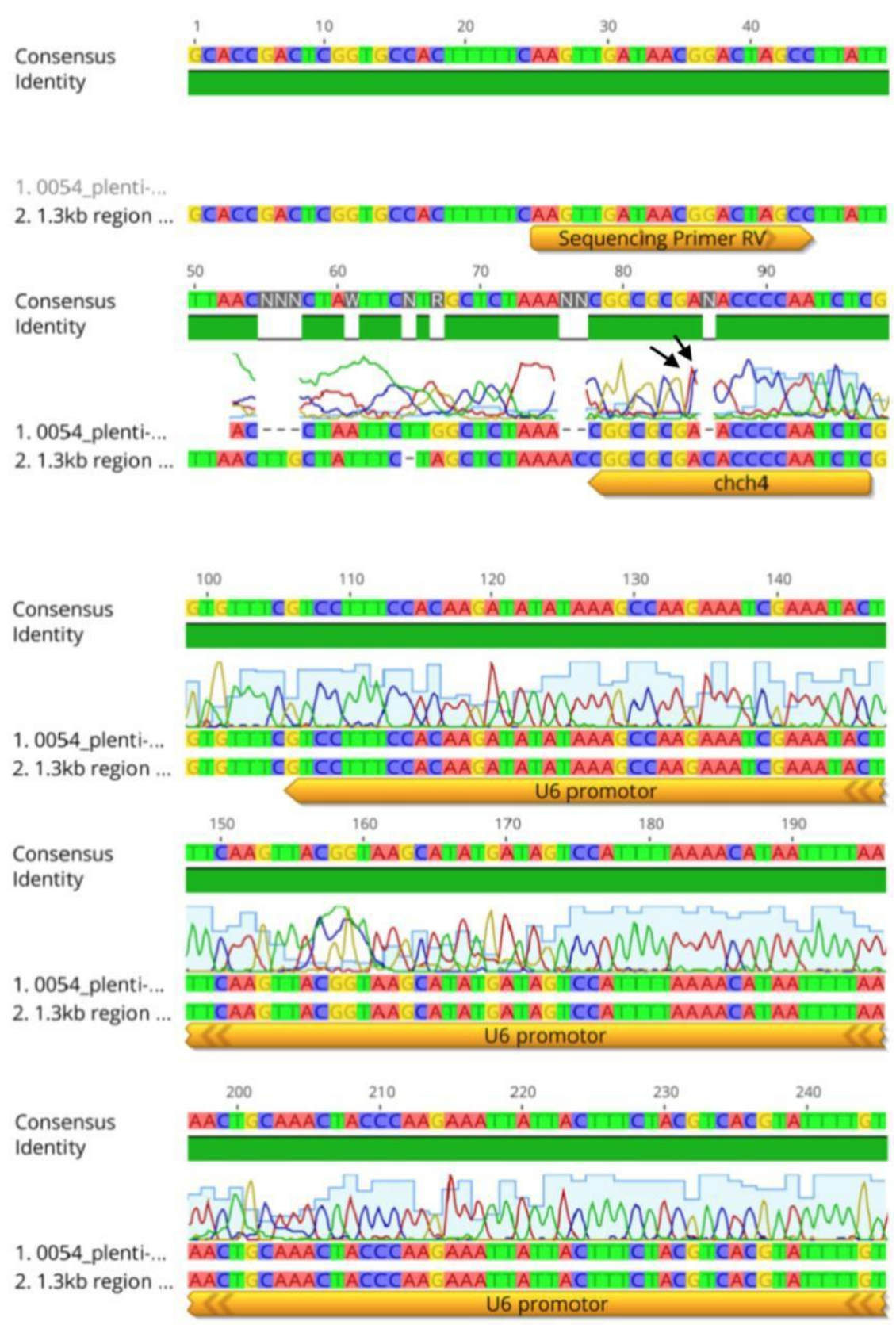

Figure 19 Sequencing data aligned using the Geneious software. Note that the identity is in agreement with the sequencing data and the hypothesised plasmid sequence after insertion based on the parental plasmid. Black arrow showing the omitted read of $C$ nucleotide due to a mis-read. 


\subsection{Transfection and Production of CRISPR-Cas9 Lentivirus}

\subsubsection{Adjustment of Transfection Reagent}

Next, we aimed to generate functional lentiviral particles through in vitro production and packaging. HEK293T cell line was selected as the basis for viral production. Initial attempts of transfecting the lentiviral plasmid and the two packaging plasmids were carried out using an available protocol from the parental plasmid's commercial supplier (Section 2.6.1). However, low transfection efficiency was initially observed, with only less than half of the cells $(<50 \%)$ expressing the fluorescent protein mCherry - a marker for successful lentiviral (transfer) plasmid transfection and transcription in the host cell (Figure 20).

Later attempts aimed to adjust the parameters of reagents used - namely the ratio of the 2 packaging plasmids to transfer plasmid, and the amount of calcium used. The amount of calcium was doubled, using $200 \mu \mathrm{L}$ of $2.5 \mathrm{M} \mathrm{CaCl}_{2}$ solution (compared to $100 \mu \mathrm{L}$ suggested), while a $35 \mu \mathrm{g}$ of transferring plasmid (compared to $20 \mu \mathrm{g}$ suggested) was used.

We observed that by increasing the ratio of transfer plasmid over packaging plasmids, the transfection efficiency increased (compare Figure 20 to Figure 21). Furthermore, increasing the amount of calcium chloride also ameliorated the efficiency of the reaction, albeit dose- dependent cytotoxic effects induced by high extracellular calcium levels.

Accordingly, a new, adjusted protocol was established. I altered the ratio of the plasmids to 1:3 by mass (packaging plasmid: transfer plasmid), compared to and doubled the calcium concentration suggested by the commercial supplier. With these modifications, transfection efficiencies of greater than $90 \%$ were reproducibly observed in our samples, analysed via ImageJ (Figure 21). 

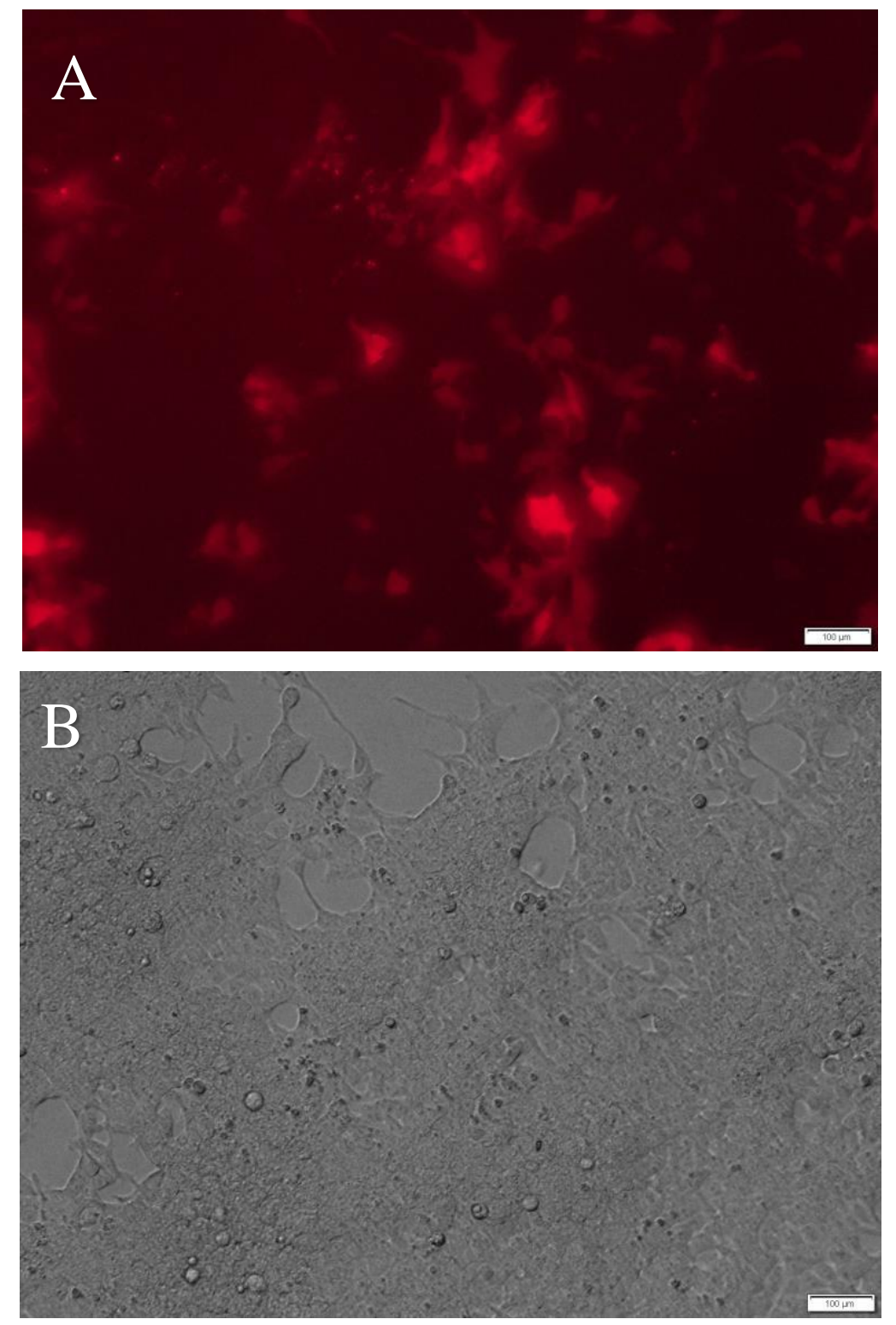

Figure 20 Plasmid transfection efficiency when carried out per the manufacturer's protocols (see 2.6.1). HEK293 cells transfected with pLenti-GATA6-CRISPR under (A) TREX filter and (B) brightfield. The transfection efficiency is visibly less than $50 \%$. 

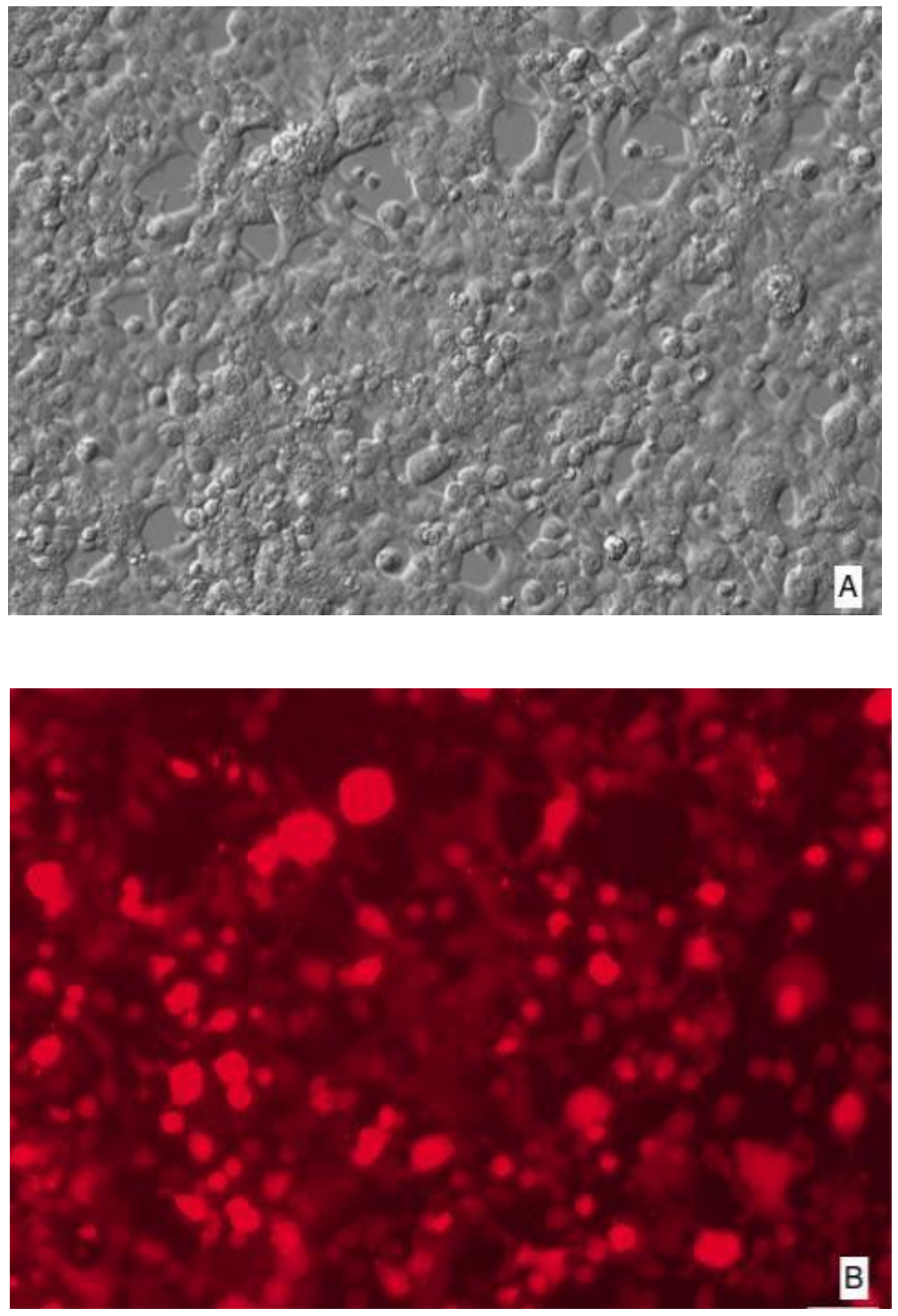

Figure 21 Fluorescent microscopy showing the effect of plasmid transfection 3 days after initial reaction in (A) brightfield and in (B) TREX. Around $90 \%$ of all cells express $m$ Cherry to a varying degree of intensity. 


\subsection{Biological Titre of CRISPR-Cas9 Lentivirus}

\subsubsection{Transduction by pLenti-GATA6-CRISPR and pLenti-GATA4-CRISPR of HEK293T}

I next harvested and determined the biological titre of the two CRISPR lentiviruses in vitro.

This is to see whether any functional viral particles are produced and what scale is the size of production.

Consistently, the production of the two lentiviruses was difficult and only resulted in titres of $104 \mathrm{TU} / \mathrm{mL}$ (Figure 22), despite the high rate of transfection seen in the previous section (Figure 21). Furthermore, it appears that the mCherry signal was a lot weaker than in the previous transfection experiment (Figure 21). Analysis of transduction efficiency is rendered difficult due to the fact that some of the red signal may be background fluorescence. It is difficult to set a "threshold intensity" over which cells would be considered "positive", which is a required setting if to be analysed by ImageJ.

We hypothesised that such global low intensity of mCherry signal may be the result of a low titre of lentivirus and thus low multiplicity of transduction, is the low titre may have been due to the large size of the lentiviral genome, as initial pilot experiments carried out by a masters student with a smaller virus succeeded in infecting bovine cumulus cells (Upton, 2019).

Nevertheless, genetic knock-out still could have occurred within some to the infected cells as the CRISPR construct is not/may not be required at high concentrations. Current literature suggests an intracellular concentration of $1.5 \mu \mathrm{M}$ to $3 \mu \mathrm{M}$ for $C$ elegans (Au et al., 2019), a figure that is likely to be different depending on the species. To test the possibility, we aimed next to infect bovine primary cells and test the efficacy of GATA4/6 knock-out, which should be able to bring further insight into the practicality of the two lentiviruses. 


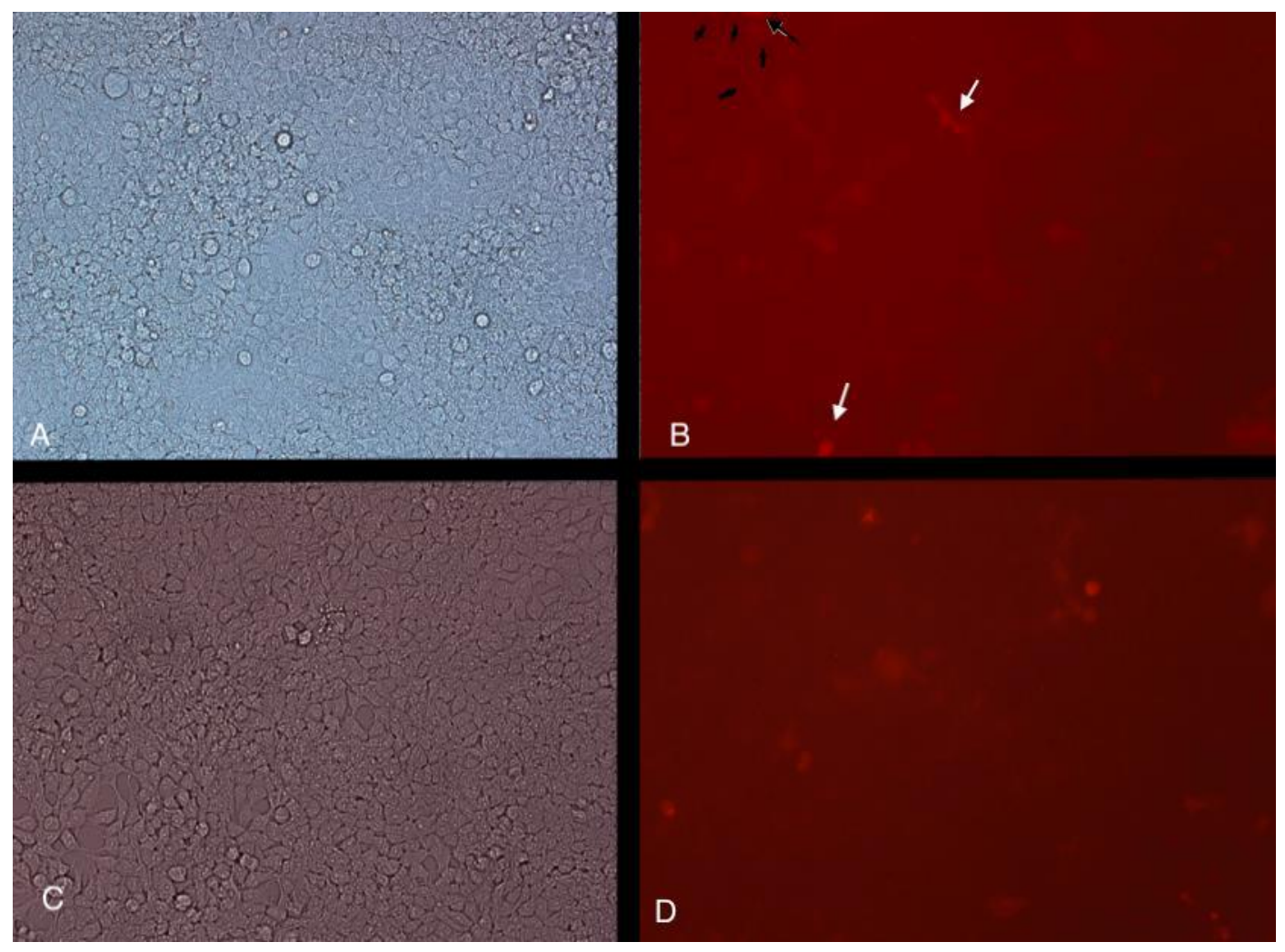

Figure 22 Biological titring of the pLenti-GATA4-CRISPR (A; B) and pLenti-GATA6-CRISPR (C; D). Note the "red cells" pointed out by the black arrows which conforms to cellular shapes, but it is hard to determine whether they are truly transduced cells nor not. Compare to white arrows that are pointing out stronger signals. 


\subsection{In vitro testing of CRISPR-Cas9-GATA6 lentivirus}

\subsubsection{In vitro culturing of bovine cumulus cell}

To address the efficacy of these GATA4/6-targeting CRISPR virus, we aimed to test it upon a type of bovine primary tissue cells that is known to express GATA6 and GATA4. Whereas the virus now has been proven able to invade cell lines and be expressed (at least weakly), the efficacy of the sgRNA-CRISPR complex remains unknown.

In cattle, the ovarian follicle contains layers of cumulus cells, which is a group of epithelial cells that surround the antral cavity. The cumulus cells juxtapositioned to the oocyte were an ideal candidate for such experiments due to the fact that they are readily available as by-products of IVF, and easily cultured in vitro. On searching the literature I found a published study which quantified the expression of GATA6 (Bai et al., 2009) in bovine cumulus-granulosa complexes. Whereas GATA4's expression has only been documented in mouse cumulus cells (Salmon, Handyside, \& Joyce, 2005).

Therefore, I next quantified the expression of GATA4 and GATA6 in bovine granulosa cells. To achieve this, these cells must be collected and cultured in vitro. The bovine cumulus cells were abundantly collected following IVF, which ensures that a uniform population of cumulus cells were collected. These primary cells readily survived and replicated in DMEM media and could be frozen and thawed. Their morphology is demonstrated in Figure 23. 


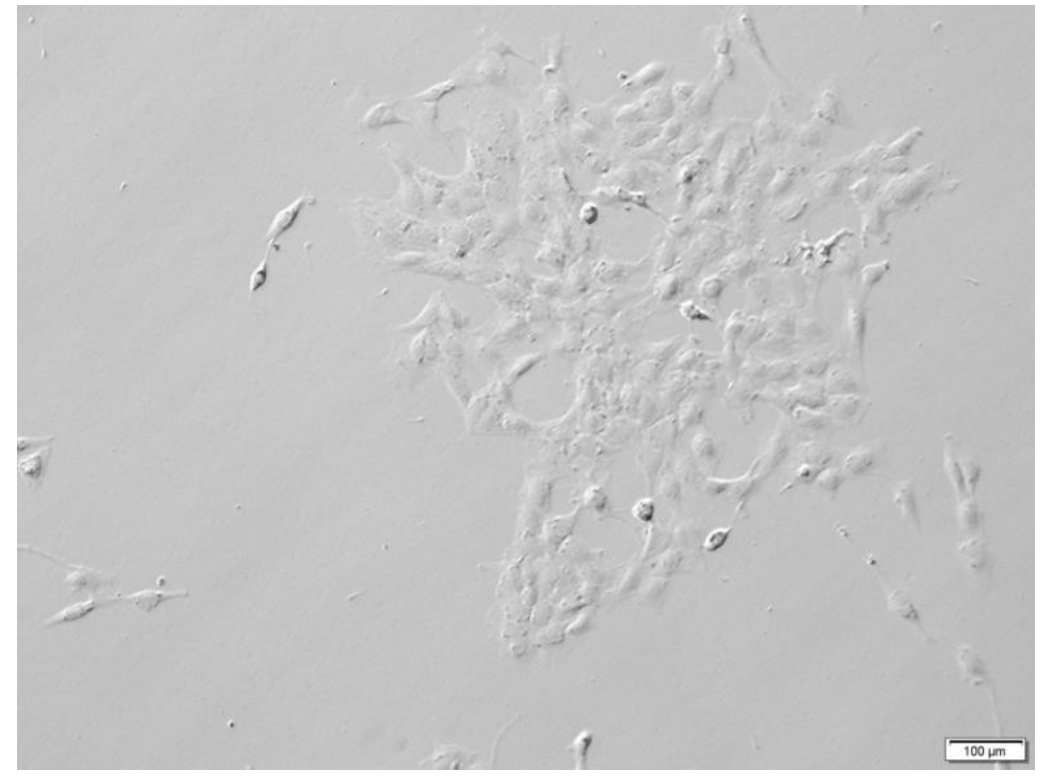

Figure 23 Light microscopy showing the morphology of bovine cumulus cells. 
3.7.2 Confirming the expression of Gata4 and Gata6 mRNA in bovine cumulus cells

Thereafter, I aimed to address whether bovine cumulus cells express GATA4 and GATA6 when collected post-IVF, and if so, the quantitative profile of their expression level. To achieve this, RNA extraction by ways of Trizol-precipitation was performed and subjected to reverse transcription quantitative PCR (RT-qPCR) analysis. Three series of qPCR reactions, one for GATA6 one for GATA4 and a third for a housekeeping gene, was performed with technical triplicates.

Melt-curve analysis suggests that for both those two reactions, the amplified products are as anticipated by the sets of primers, with no observable by-products, such as primer dimers. This is reflected by the single melt-curve peak for each reaction mixture and no signal at temperatures lower than $80^{\circ} \mathrm{C}$ (Figure $24 \mathrm{~B}$ and Figure 25B).

In both reactions, HPRT was used as a housekeeping gene. The relative expression level of GATA4 and GATA6 can therefore be derived through normalisation to HPRT expression levels. It is confirmed from these experiments that both Gata4 and Gata6 mRNAs are expressed to a detectable level (Figure $24 \& 25$ ), therefore suggesting their usefulness in our subsequent experiment, which aims to test their knock-out efficacies. 

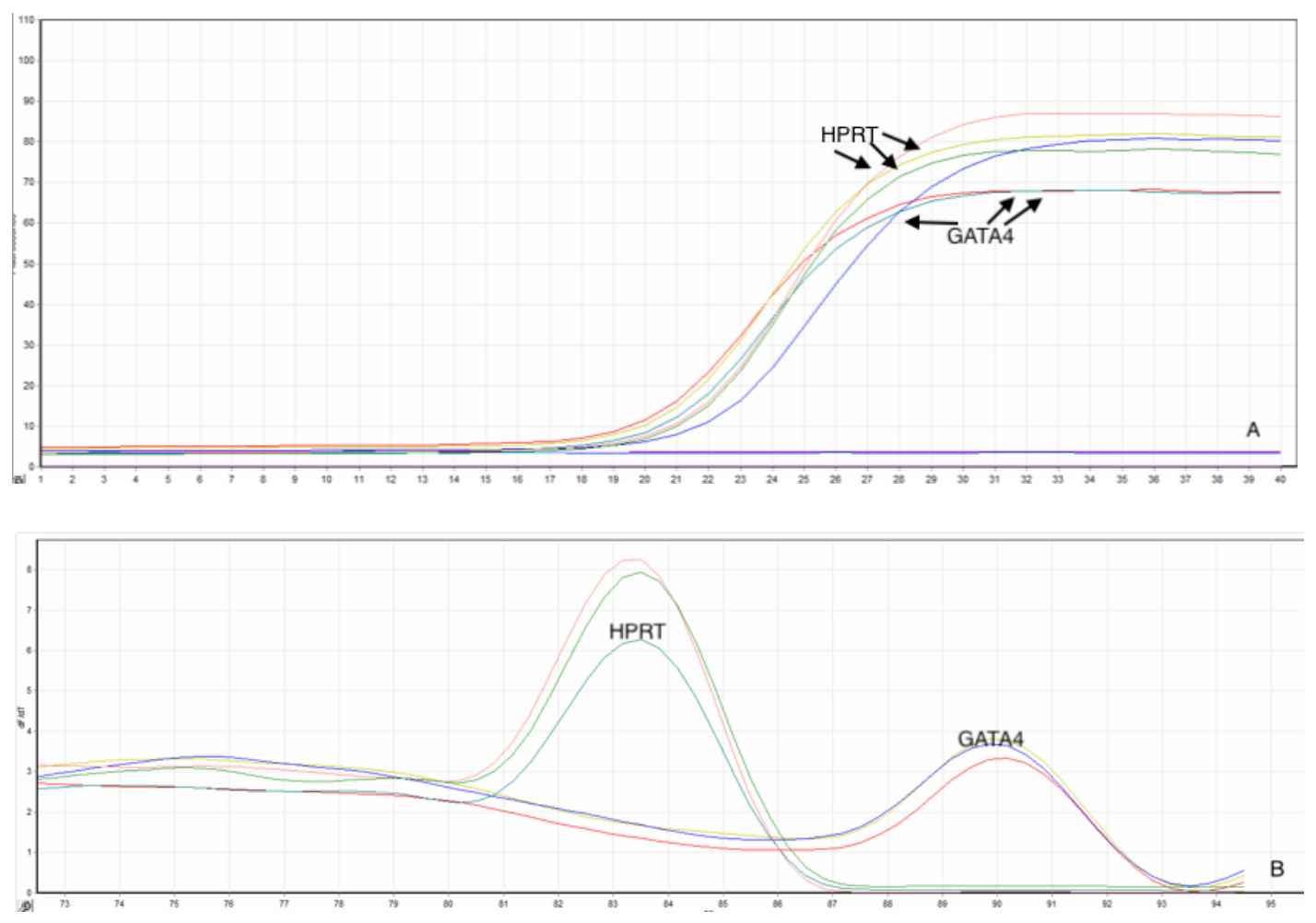

Figure 24 qPCR reaction with GATA4 and HPRT. (A) raw signal of SYBR over cycle numbers. (B) Melt curve of end-point products. Note that for each technical replicate there is an observed peak at the same temperature. 

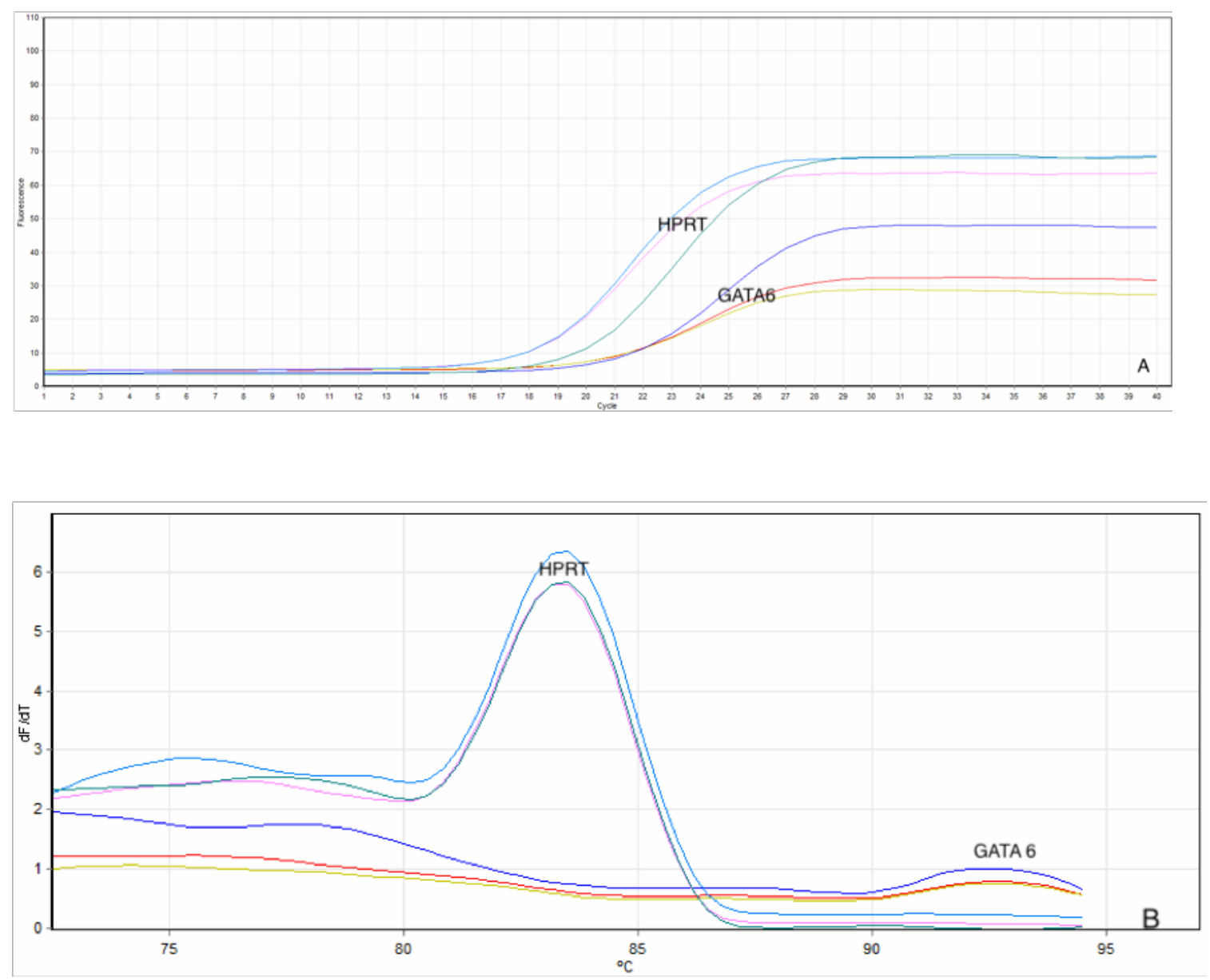

Figure 25 qPCR reaction with GATA6 and HPRT. (A) raw signal of SYBR over cycle numbers. (B) Melt curve of end-point products. 


\subsubsection{Low transduction efficiency of bovine cumulus cells}

Since we have established the potential usefulness of bovine cumulus cells as a test target for the gene deletion effects of the two novel lentiviruses, we then went on to address the knock-out efficacy of the two viruses. Treatment of the two CRISPR-activated viruses did not induce much observable mCherry signal from fluorescent microscopy. In fact, the signal is even weaker than the treated HEK293T cells (Figure 26 and 22). It could be argued that the primary cells are likely to have a slower metabolic profile and hence slower protein synthesis rate, which may explain the even lower mCherry expression level. Alternatively, the lower mCherry expression may be due to a lower success rate of lentivirus infection, due to the different, or lack of ligand recognition (VSV-G) required for successful cellular infection.

As discussed above, in view of the fact there is no consensus on the concentration of Cas9 required for successful genetic knockouts in bovine systems, it is possible that these viruses would be still effective in knocking down the expression level of GATA6 and GATA4. Therefore, a series of qPCR experiments were performed subsequently to address this question. 


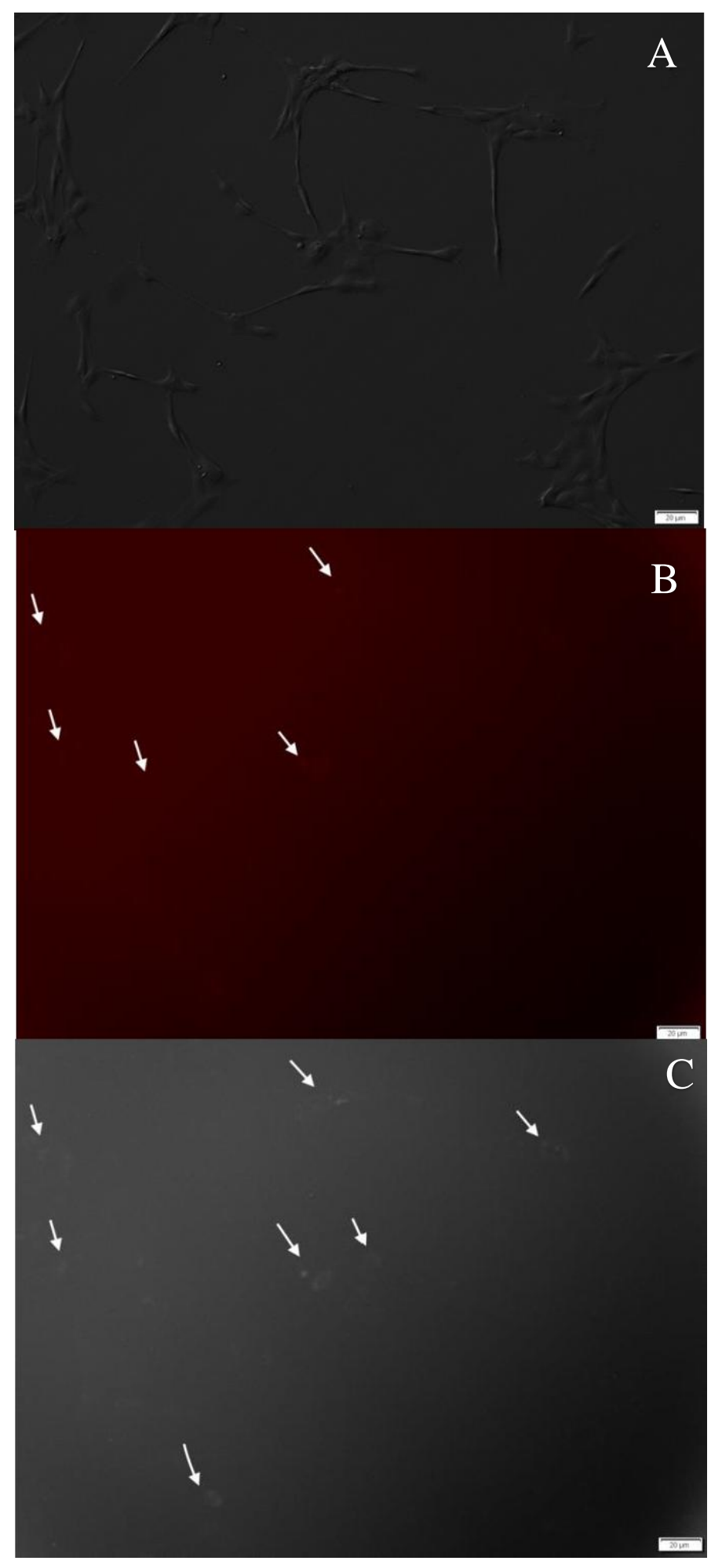

Figure 26 Fluorescent microscope of CRISPR lentivirus treated bovine cumulus cells in (A) Bright field (B)TRED (C)TRED and black-and-white filter. White arrows showing possible mCherry expression. 


\subsubsection{Effect of pLenti-GATA4-CRISPR and Effect of pLenti-GATA6-CRISPR on Gata4 and Gata6 mRNA expression level}

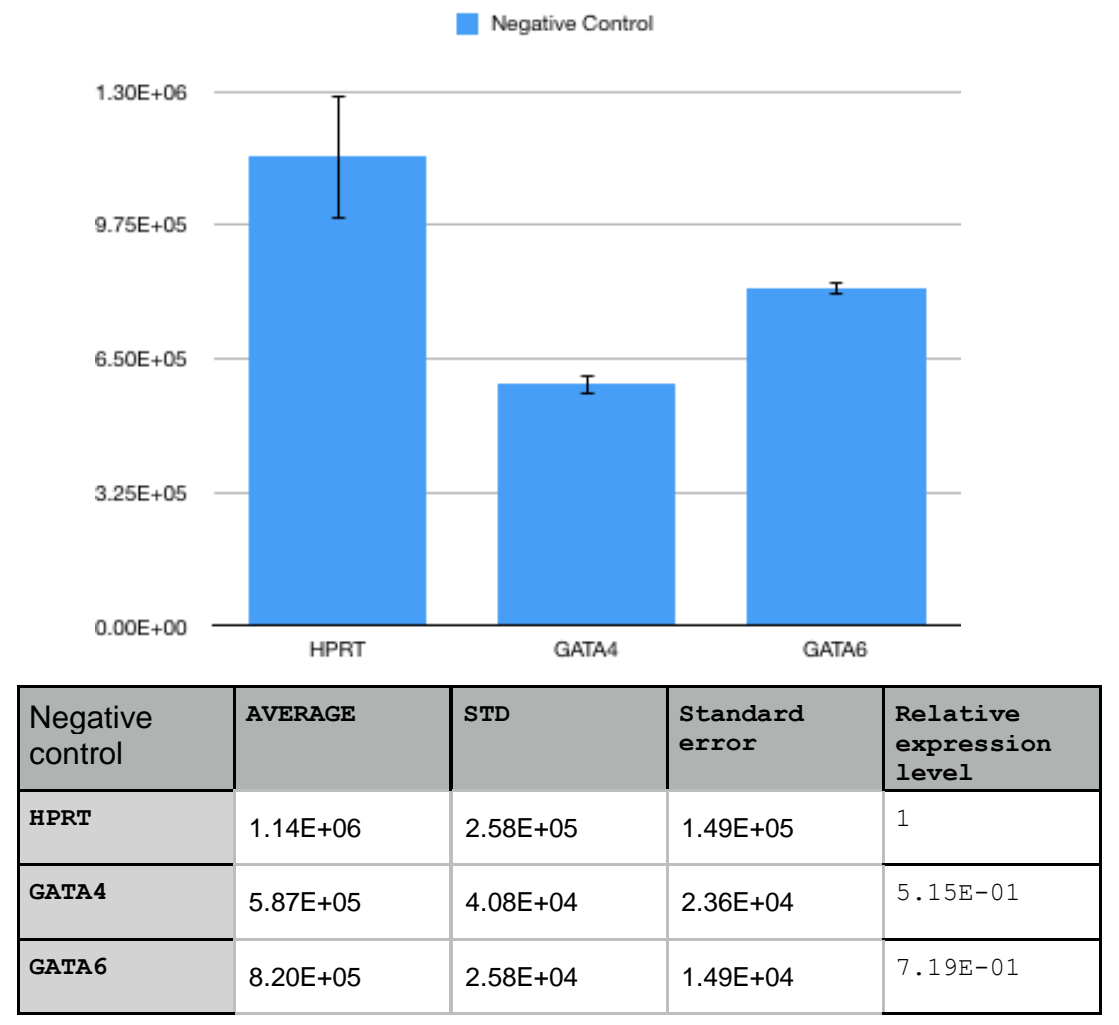

Figure 27 qPCR analysis of bovine cumulus cells with no virus treatment. Error bar showing standard error.

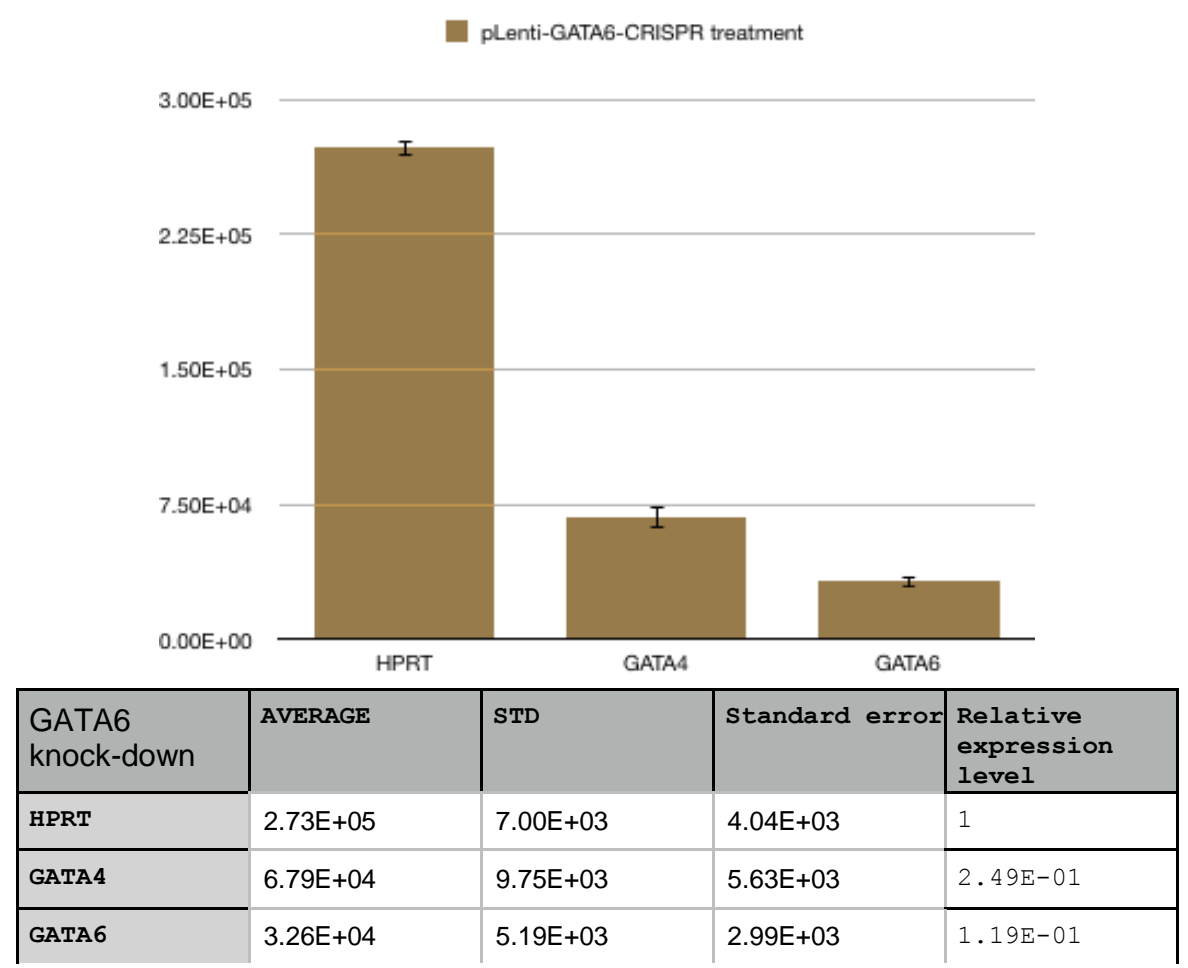

Figure 28 qPCR analysis of pLenti-GATA6-CRISPR treated bovine cumulus cells. Error bar showing standard error. 


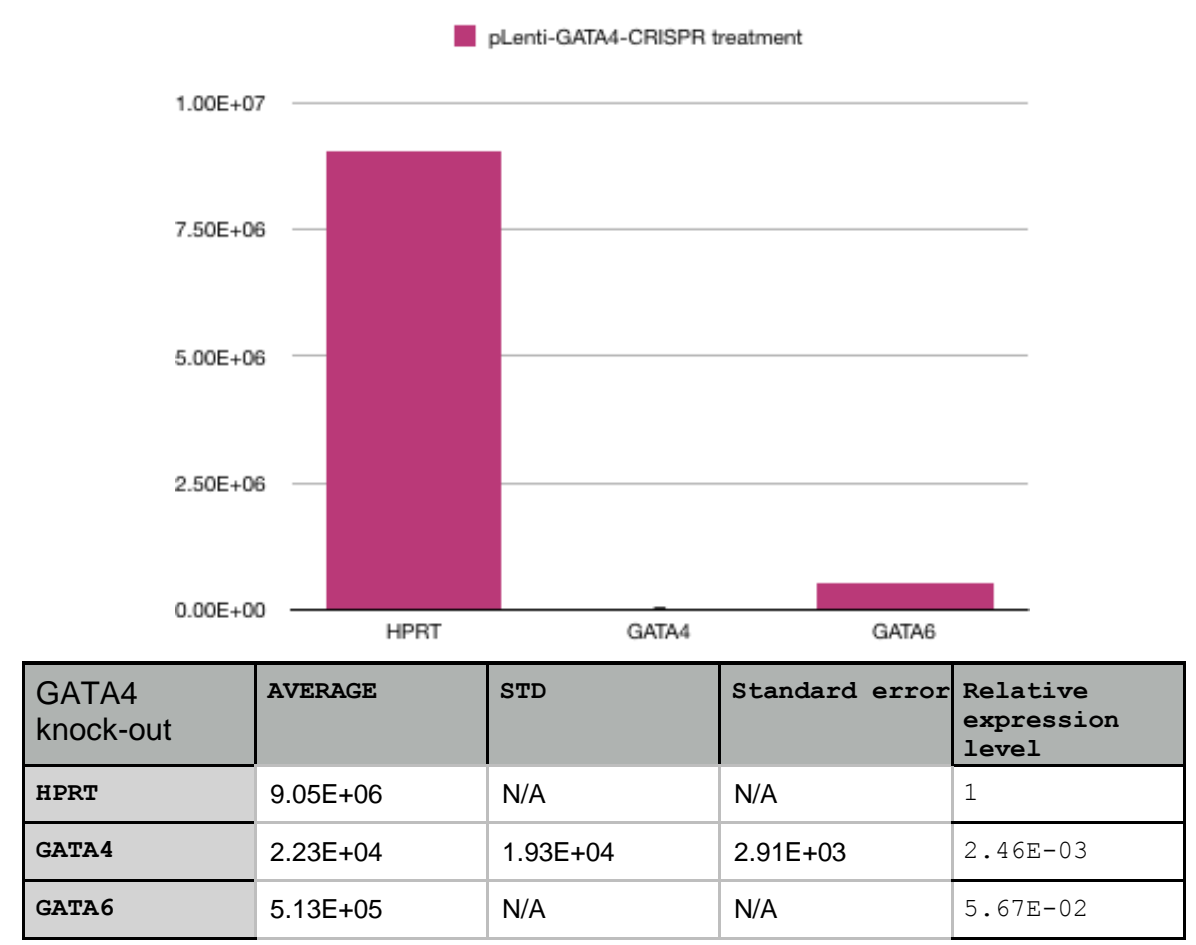

Figure 29 qPCR analysis of pLenti-GATA4-CRISPR treated bovine cumulus cells. Error bar showing standard error. Note that the standard error was not available for HPRT and GATA6 due to the low amplification efficiency in some of the technical replicates.

Next, we aimed to address the knock-out efficacy of the two CRISPR virus on bovine cumulus cells. By performing qPCRs on the untreated sample (Figure 27), pLent-GATA6CRISPR treated sample (Figure 28) and pLenti-GATA4-CRISPR treated samples (Figure 29), the expression level of the targeted gene can be quantified when compared to a housekeeping gene (HPRT). Melt curve analyses of these experiment (Figure 31 in Appendix) suggests the correct size of products amplified with no observable non-specific products.

It would appear that the two lentiviral vectors seem to have an effect on their respective gene expressions, as demonstrated by the relatively stable HPRT expression level, yet a decrease of GATA4 and GATA6 to HPRT ratio following treatment. Note that the experiments do not have a statistical significance due to the lack of repeats. Further experiments should be carried out to address whether these observed effects are indeed replicable or not. 


\subsubsection{Effect of the two viruses on protein expression level}

Thereafter, immunohistochemistry (IMC) was performed to probe for the presence of GATA6 protein. For our experiment, an antibody that exhibit activity for both mouse and cattle GATA6 protein was chosen. Primary cumulus cells were cultured and anneal onto a coverslip overnight, treated with a concentrated aliquot of CRISPR-bGATA6 lentivirus and left to grow overnight.

Subsequently, cells were stained for GATA6 and nucleus (DAPI) 24 hours afterwards. A negative control was also set up by receiving no viral treatment. Figure 29 demonstrates the abundant expression of GATA6 in native cumulus cells. Comparatively, the treatment of lentivirus did not induce in any observable attenuation of GATA6 expression level - since both treated and untreated cumulus cells positive for GATA6, as demonstrated by a DAPI counterstain (Figure 30). 


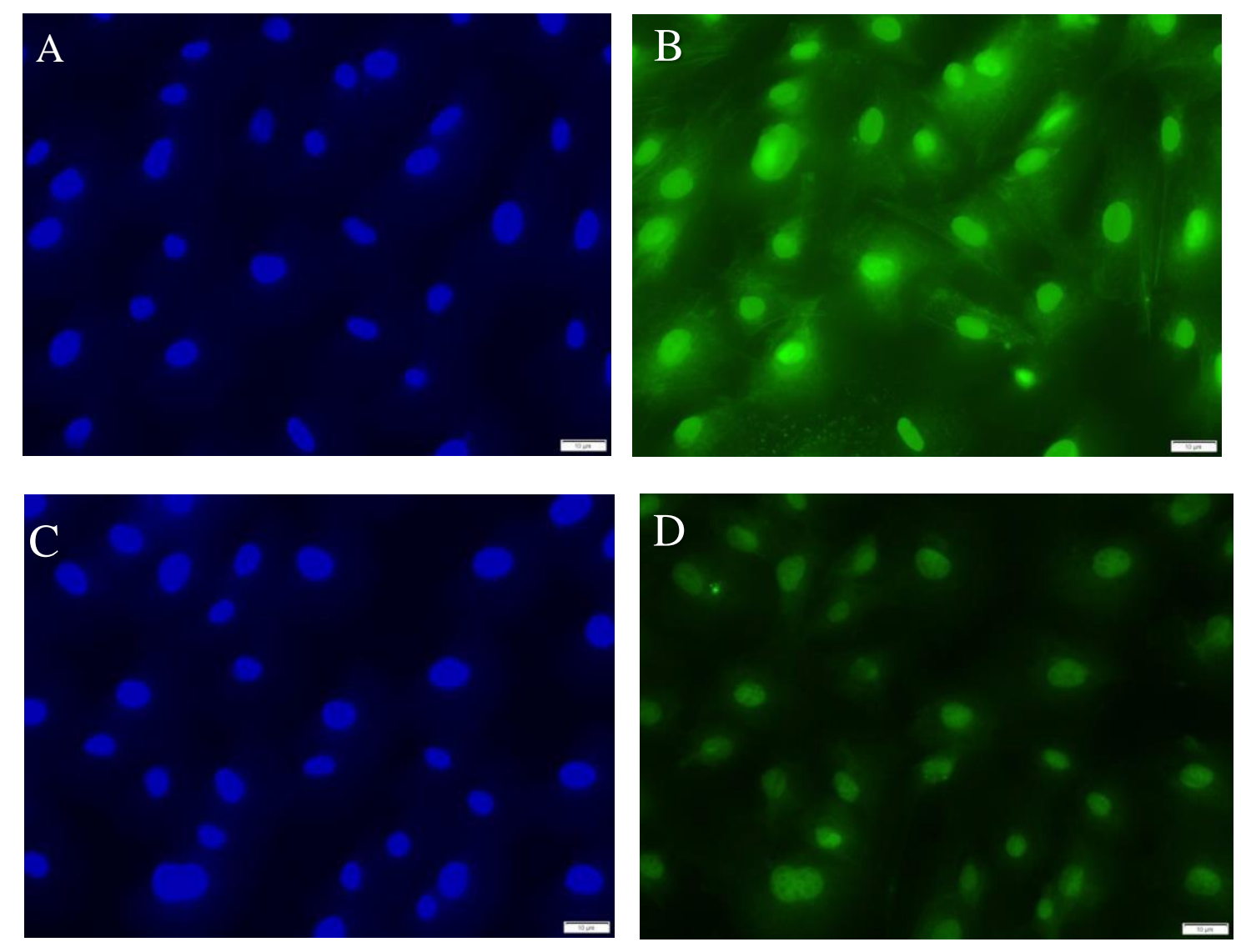

Figure 30 Immunohistochemistry of bovine cumulus cells stained with (A) DAPI (B) GATA6 (C) DAPI following lentiviral treatment (D) GATA6 following lentiviral treatment. This confirms the uniform expression of GATA6 expression in all cumulus cells, as well as no observable expression difference was induced by pLenti-GATA4-CRISPR treatment. 


\section{Chapter 4 Discussion}

\subsection{General Discussion}

Our current understanding of early mammalian development relies predominantly on data available from mouse embryo studies. However, recent studies on a number of other eutherian species have shown fundamental differences in the molecular regulation of early development. Additionally, studying the developing mechanism of early mammalian embryos across species allows insights on the fertility and development of humans. Specifically, the potential of studying cattle physiology in this thesis is underlined by increasing interests in producing genetically improved livestock, which can be immensely beneficial for the New Zealand economy (De Vries, 2006). Cattle, as one of New Zealand's most prominent sources of agriculture, contributed to an estimated amount of $\$ 6.5$ billion worth of red meat export during the 2017-2018 fiscal year (DairyNZ, 2018).

The use of CRISPR/Cas9 apparatus as a means of genetically editing is becoming more and more established as a revolutionary technique in molecular biology, due to its specificity and ease of application. While only a few applications of CRISPR/Cas9 system onto the generation of transgenic cattle has been recently documented (K. Simmet et al., 2018), research addressing the efficient lentiviral delivery of CRIPSR/Cas9 system into bovine early embryos is still not sufficient. The pharmacological delivery of CRISPR machinery during embryonic development therefore remains a relatively new field, with potential for optimisation and commercialisation.

Studies carried out in this thesis target two specific hypoblast-defining genes in cattle embryos, namely GATA6 and GATA4. These two zinc finger-containing transcription factors have been implicated to establish and maintain the bovine hypoblast lineage, in a fashion different to their mouse paralogous genes (Chazaud \& Yamanaka, 2016; E. W. Kuijk et al., 2012). Apart from the apparent economic value of optimising cattle reproduction, mounting evidence is suggesting that mice have an atypical preimplantation developmental pattern. The mice early embryogenesis promote the fast implantation and early genomic autonomy of the embryo, i.e. early embryonic genome 
activation (Pfeffer, 2018), which is likely a result of evolutionary selection. Therefore, we aimed within the body of this thesis to design, produce and verify two novel lentiviral systems that are capable of generating genetically modified cattle embryos. In theory, such vectors, when fully optimised, will serve as the functional basis for embryonic knock-out studies. These functional genetic studies which will provide extended knowledges of early mammalian embryonic development, that is not limited only to cattle. 


\subsection{Design and verification of pLenti-GATA4-CRISPR}

One of the main goals of this master's thesis was to generate functional CRISPRactivating lentivirus that targets bovine GATA4. To do so, the sgRNA must be designed first in silico. By using online platforms, namely CHOPCHOP (Labun et al., 2016), 3 pairs of sgRNAs were created and ordered from a commercial supplier in the forms of single-stranded oligo DNA. These sgRNAs have no predicted off-target effects in the bovine genome, and they were designed in view of targeting (hybridise) at the protein-coding regions of exon 1 of bovine GATA4. A number of alternative transcripts have been reported for bovine GATA4, but all of them contain exon one (O'Leary et al., 2016). By designing our sgRNA in that exon ensures that the presence of compensatory alternative transcript would be unlikely.

By way of targeting restriction digestions and DNA extraction, the lentiviral plasmid was cut and ligated to incorporate Chch4, one of the pairs of oligo DNA designed from the previous step. We then verified the sequence further by diagnostic digestions and gel electrophoresis. Together with the sequencing data, it was suggested that we have successfully produced a GATA4-targeting, CRISPR-activating lentiviral plasmid.

It is worth mentioning that, throughout the research project, I encountered difficulties in producing a sufficient amount of the CRISPR-activating plasmid. This was a reoccurring problem and is likely to be due to the low-copy nature of this plasmid within each replicating bacterium. In effect, during one point of the project, it was necessary to forgo the previously prepared glycerol stock and re-transform new OneShot ${ }^{\mathrm{TM}}$ bacteria with purified plasmids, as the overnight cultures from the old glycerol stock produced very limited amount of plasmid DNA (less than $10 \mu \mathrm{g}$ per maxiprep). Additionally, the maxiprep efficiency of pLenti-GATA4-CRISPR was ultimately ameliorated by doubling the volume of overnight culture, using $1 \mathrm{~L}$ instead of $500 \mathrm{~mL}$, the latter of which is suggested in the QIAGEN Maxiprep manual.

Overall, I provide here evidence that correct sequence verified pLenti-GATA4CRISPR plasmids were produced during this master's project. These lentiviral plasmids are stored in the form of glycerol stock and DNA stock for future 
applications, which should, in theory, be able to induce DNA cleavage at the sgRNAtargeted genomic loci.

\subsection{Production of pLenti-GATA4-CRISPR and pLenti-GATA6-CRISPR}

Subsequently, I aimed to produce functional lentiviral particles from the two, now verified, CRISPR-activating plasmids. I used the method of calcium-mediated transfection due to its economic advantages, compared to the lipofectamine-mediated method. After a small adjustment of calcium dosage, I continuously achieved transfection efficiencies of around $90 \%$, as analysed by the percentage of positive, mCherry-expressing cells.

However, when attempting to titre the biological activity of these two lentiviruses, the percentage of mCherry expressing cells is much lower than anticipated, demonstrating titres as low as 104 units/mL. In fact, the number is likely to be inaccurate as it is unclear exactly how many cells are expressing mCherry. As discussed, the transduction of these two viruses seems to induce very low signals of red fluorescence, as demonstrated in Figure 22. To analyse the percentage of mCherry expressing cells on ImageJ, it is required to set the threshold frequency, above which point a cell (as pixels) is considered to be "positive".

This is perhaps not surprising as it was formerly observed by a previous master's student that it was hard to produced high transduction efficiency of the parental plasmid (pLenti-CRISPR-mCherry). In fact, results present in this body of thesis is in agreement with his data (Upton, 2018).

Previous experiments by a master's student has shown the effectiveness of another lentivirus, pLL3.7 to infect bovine primary cells (Personal Communication,). pLL3.7 is a small lentivirus $(7.5 \mathrm{~kb})$ that expresses a reporter cassette of cytomegalo virus (CMV) element and a green fluorescent protein. It was proposed to use this lentivirus as a positive control in my work, however, due to the lack of glycerol stock and the seemingly degraded DNA stock, which repetitively did not produce any plasmid DNA from Midipreps, this experiment was not performed. 
Comparatively, the expression of mCherry is dependent on an EF-1 promotor, which is shared with Cas9, and a P2A element, which causes ribosomal skipping and cleavage between the two proteins. Stoichiometrically, it could be argued that mCherry requires a certain level of translation to be detected, and it does not imply that Cas9 is therefore not expressed at an adequate level. One easy way to address this problem is to design qPCR experiments that assay the expression level of Cas9 in these cells. As previously mentioned, there is no current literature that has addressed the required intracellular concentration of Cas9 required for successful genetic knockouts in bovine cells, whereas the number is suggested to be $c a .1 .5-3 \mu \mathrm{M}$.

Furthermore, in our experiments, we have noticed that the lentiviral plasmids are very sensitive to freeze-thaw cycles. This is especially the case for pPAX.2, one of the two packaging plasmids. It would appear the increased free-thaw cycles of this plasmid induced DNA rearrangement, as demonstrated by restriction enzyme digestions (Figure 33 in Appendix). It is common for lentiviral plasmids to go through nonspecific recombination in host cells, due to their highly repetitive sequences. Future experiments should bear this in mind and store lentiviral plasmids in small aliquots to prevent free-thaw cycles.

We have also noticed that lentiviral stocks are very prone to degradation by freezethaw cycles. Seemingly the transduction efficiency decreases significantly as the stock goes through freeze-thaw cycles. This is perhaps not surprising since after extensively reviewing present literature, there is in fact no agreed consensus on how to best store lentiviral particles. In fact, there have been reported titre losses from 5\% to $50 \%$ per freeze-thaw cycle (Krajden, Minor, Rifkin, \& Comanor, 1999; Ugai et al., 2002), and therefore some may suggest using the virus immediately after harvesting. These factors should be considered in the future.

In order to increase transduction efficiency, it was aimed to enhance virus-cell contact. Several reagents can increase the transduction efficiency, such as polybrene, which enhances the absorption of viral particle into the cells by neutralising the opposite electrostatic charges on the viral and cellular membrane (Davis, Morgan, \& Yarmush, 2002). It is even been documented that the application of polybrene would 
increase retrovirus gene transfer by 10 fold (Davis et al., 2002). However, in our experiments, we did not observe any increase in mCherry expression levels.

\subsection{Expression of GATA6 and GATA4 in bovine cumulus cells}

In order to verify the knock-out efficiency of these viruses, we aimed to test them upon primary bovine cells. Bovine cumulus cells are common by-products from IVF, and therefore could potentially be an ideal target of such experiment. Prior to our research, it was unclear how much GATA6 or GATA4 was expressed in bovine cumulus cells.

To determine this, I harvested cumulus cells post-IVF. This is to ensure that a uniform population of only cumulus cells, not the surrounding theca cells, are collected. It is observed in my experiments that bovine cumulus cells can be easily cultured in vitro with generic cell culture media (DMEM/ 10\% FCS) and grow as adherent cells.

Subsequently, our qPCR and antibody staining experiments confirm the expression of GATA6 and GATA4 to a comparable level to HPRT. These findings suggest that these primary cells are an ideal candidate to address GATA6 and GATA4 knock-out efficiencies. Alternatively, these cells have the potential of serving as donor cells for somatic nuclear transfer, to generate mutant bovine embryos.

It should be noted here that, these findings do not directly suggest the expression level of GATA6 and GATA4 by bovine cumulus cells in vivo, as it is unclear how "close" these isolated primary cells are, compared to bovine cumulus cells in their native milieu. The transcriptomic profile is likely to change since the cells are grown in vitro with supplied media (DMED/10\% FCS). 


\subsection{Efficacy of the two lentiviral vectors}

Lastly, experiments were carried out to address whether these two designed lentiviruses can induce GATA6 and GATA4 knock-out in bovine cumulus cells. qPCR experiments were carried out to samples treated with pLenti-GATA6-CRISPR and pLenti-GATA4-CRISPR, an untreated sample was also set up as negative control. Preliminary data demonstrated here suggests that the two viruses have an effect on the levels of transcription of the two targeted genes, respectively. The relative copy number of GATA6 and GATA4 decrease significantly as compared to the negative control. These data suggest that although there is a low level of mCherry expression, Cas9 is likely to be expressed at a level adequate enough for the CRISPR machinery to be able to function appropriately. Though again, they need to be repeated.

In fact, it is observed that when either of the two genes is knocked down, the other one decreases in its expression level as well. Since both sgRNAs are unlikely to have off-target effects, it could be possible that GATA4 and GATA6 may have a feedback mechanism within the bovine cumulus cells. The mechanistic knowledge of such inhibition remains elusive since no cis-regulatory elements of these two genes on each other have been reported to date.

It should be noted that, only technical triplicates were performed in this set of experiments, but no biological replicates were performed. There results therefore remain preliminary and needs to be corroborated by repeating in order to derive statistical significance.

Additionally, immunohistochemistry was carried out to address whether protein expression level is altered by pLenti-GATA6-CRISPR. From our data, it is demonstrated that treatment by this virus did not induce any observable difference in protein expression dynamics, as all cells stain positive for GATA6. These data should be interpreted while considering the half-life of GATA6. It could be possible that while mRNA level decreases, as shown by qPCR, the expression of GATA6 protein may still be of adequate level, due to lower turnover rate of already synthesised protein. Other experimental approaches, such as the ones that address protein 
expression level quantitatively, e.g. protein extraction and Western Blot, can be considered, as it will show a quantitative profile of any change in protein expression level. 


\subsection{Future directions}

Firstly, as stated before, the last qPCR experiment needs to be appropriately corroborated with appropriate repeats - GATA6 and GATA4 knock-out experiments need to be repeated to derive statistical significance. While these results seem promising, whether they can be produced consistently or not remains the more important question. Moreover, alternative strategies can be applied to further confirm the potential effects of the two lentiviruses. For example, surveyor nucleases, which cleaves target sequences when mismatches are detected. The cleaved DNA and then be visualised easily on a gel. As one of the main effects of CRISPR-induced lysis is to induce mismatches, as a result of nonhomologous endjoining, this is a simple method to confirm that the CRISPR-Cas9 machinery is recruited and acting at the desired genomic loci.

Secondly, it remains unclear how many viruses are present within the viral harvest, and the transfection efficiency cannot be easily quantified. It is important to achieve a high titre of viral production in order to infect embryonic cells. As suggested, to better evaluate the transduction efficiency, and therefore the number of functional viral particles, of the two CRISPR-activating lentiviruses, qPCR experiments on the treated cells, amplifying Cas9, or mCherry can be carried out to address if the lentivirus is incorporated into the host genome and expressed adequately.

Alternatively, it could be aimed to increase transduction efficiency by adding polybrene. Although we did not observe any effect upon its addition, this experiment is only carried out near the end of the research timeline. Additionally, only one attempt of lentiviral transduction with polybrene was made with a 3-week old and previously thawed lentiviral stock. As discussed above, it has come to our attention that the two CRISPR-activating lentiviral vectors are very prone to degradation. Further experiments should be carried out using freshly prepared viruses and transduction adjuvant (polybrene). 
Moreover, generating knock-out mutants during early embryo development is particularly hard due to the presence of a protein-rich capsule, the zona pellucida. Previous results from the Pfeffer lab suggests that the zona pellucida can be partially digested by proteinase reactions and produce viable embryos. Successful viral transduction of the embryo was also achieved in this manner. This was another aspect of research that was not addressed sufficiently. Due to time constraints, the knock-out efficiency of these two viruses on bovine embryos, by way of zona removal followed by viral transduction, $\mathrm{QPCR}$ and immunohistochemistry, was not addressed.

As a long-term goal, it should be kept in mind that genetic mosaicism is documented to occur during embryo development: the majority of genetically modified organisms had successful editing occurring in only some of the developing embryo (Belmonte et al., 2015; Yen et al., 2014). It is demonstrated recently that using multiple gRNA targeting the same gene can achieve a synergistic effect in inducing desired gene knock-outs (Zuo et al., 2017). It is, in fact, with these goals in mind that 3 different pairs of gRNAs were ordered at the start of the research project. Future experiments should aim to produce new lentiviral vectors that incorporate these sgRNAs.

Alternative, other methods of delivery of the CRISPR machinery can be considered. It was recently reported that multiwall carbon nanotubules have the ability to cross the zona pellucida and deliver DNA into an in vitro-fertilised bovine embryos (Munk et al., 2016). This method provides relative advantages by the complete lack of invasive procedures, whether be it microinjection or digestion of zona pellucida by proteinase. Normal development was observed in these embryos, suggesting the nanotubules have limited, if any, overall toxicity. Potentially, nanomaterials should be taken into consideration, as alternative means of delivery, to lentiviral gene delivery in the future. 


\section{Supplementary Data}

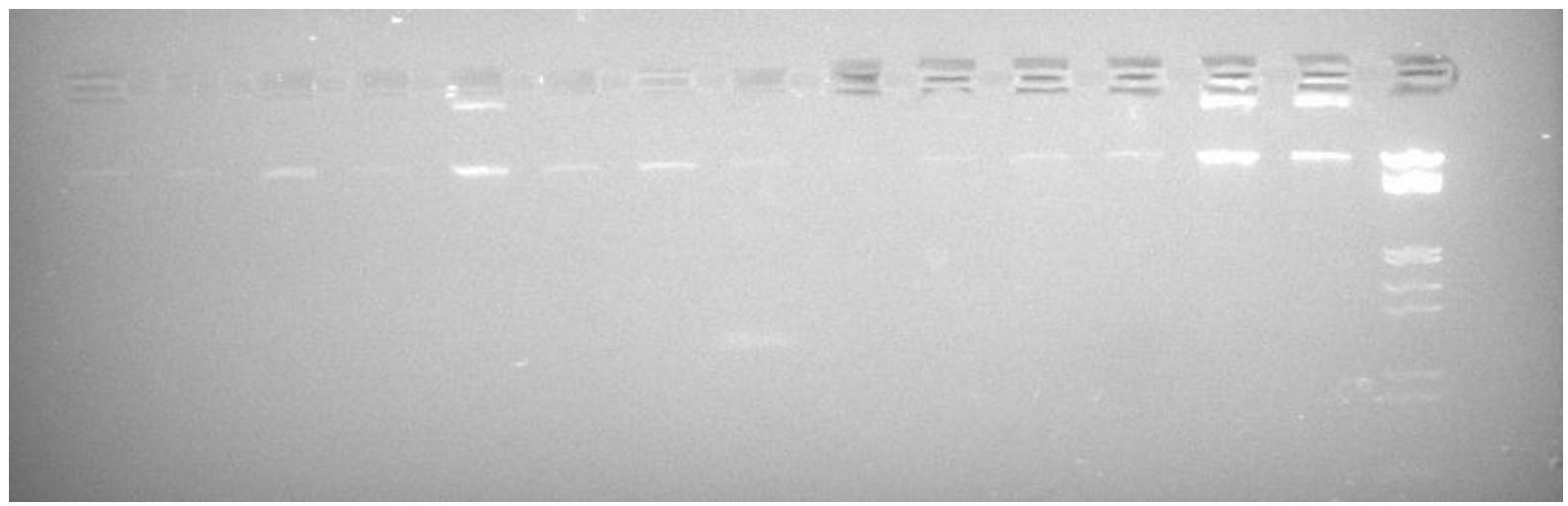

Figure 32 Gel electrophoresis of pLenti-GATA4-CRISPR isolated by ethanol precipitation. The low amount of plasmid DNA did not give any basis for logical deduction of plasmid sequences.

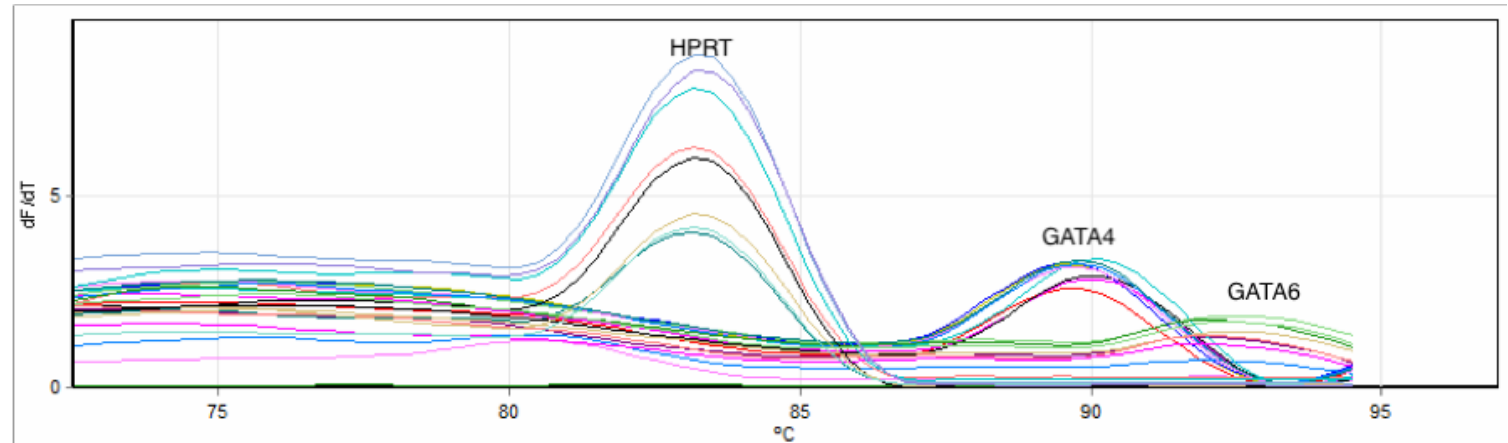

Figure 31 Melt curve graph of qPCR reaction addressing the efficacy of pLent-GATA4-CRISPR and pLenti-GATA6CRISPR. The lack of any observable signal below $80^{\circ} \mathrm{C}$ suggests that there are no non-specific PCR products. 


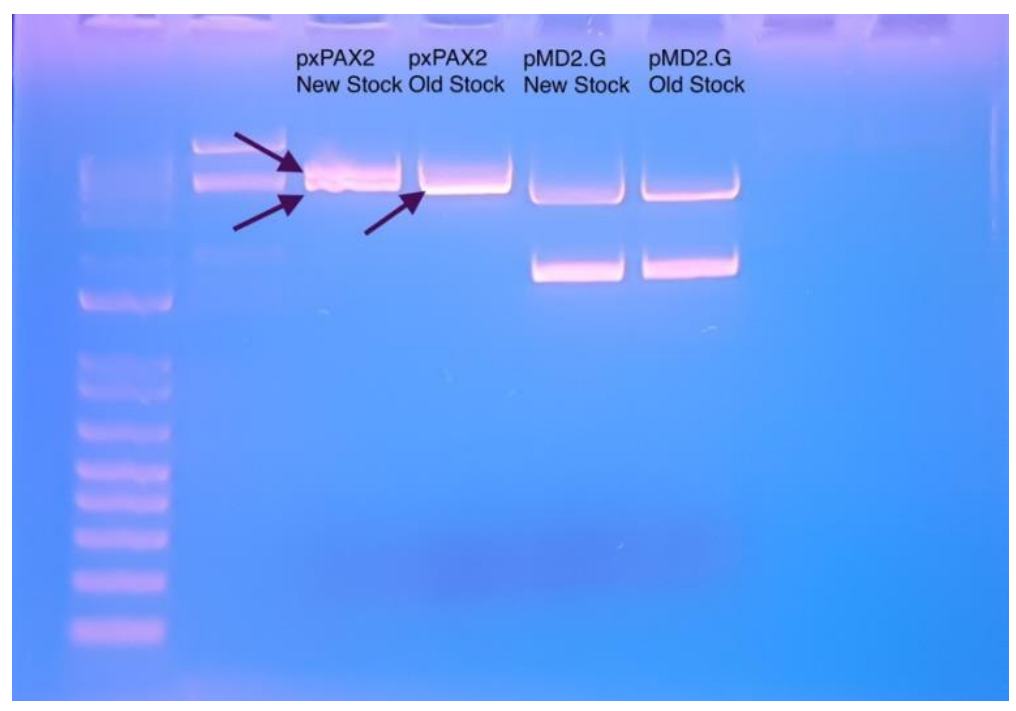

Figure 33 Gel electrophoresis of packaging plasmids digested by EcoRI. Note the difference between the presence of one band and two bands in the newer stock of PPAX2, which had been repeated thawed and frozen and that of the older stock which had been consistently left in $a-20^{\circ} \mathrm{C}$ freezer. 

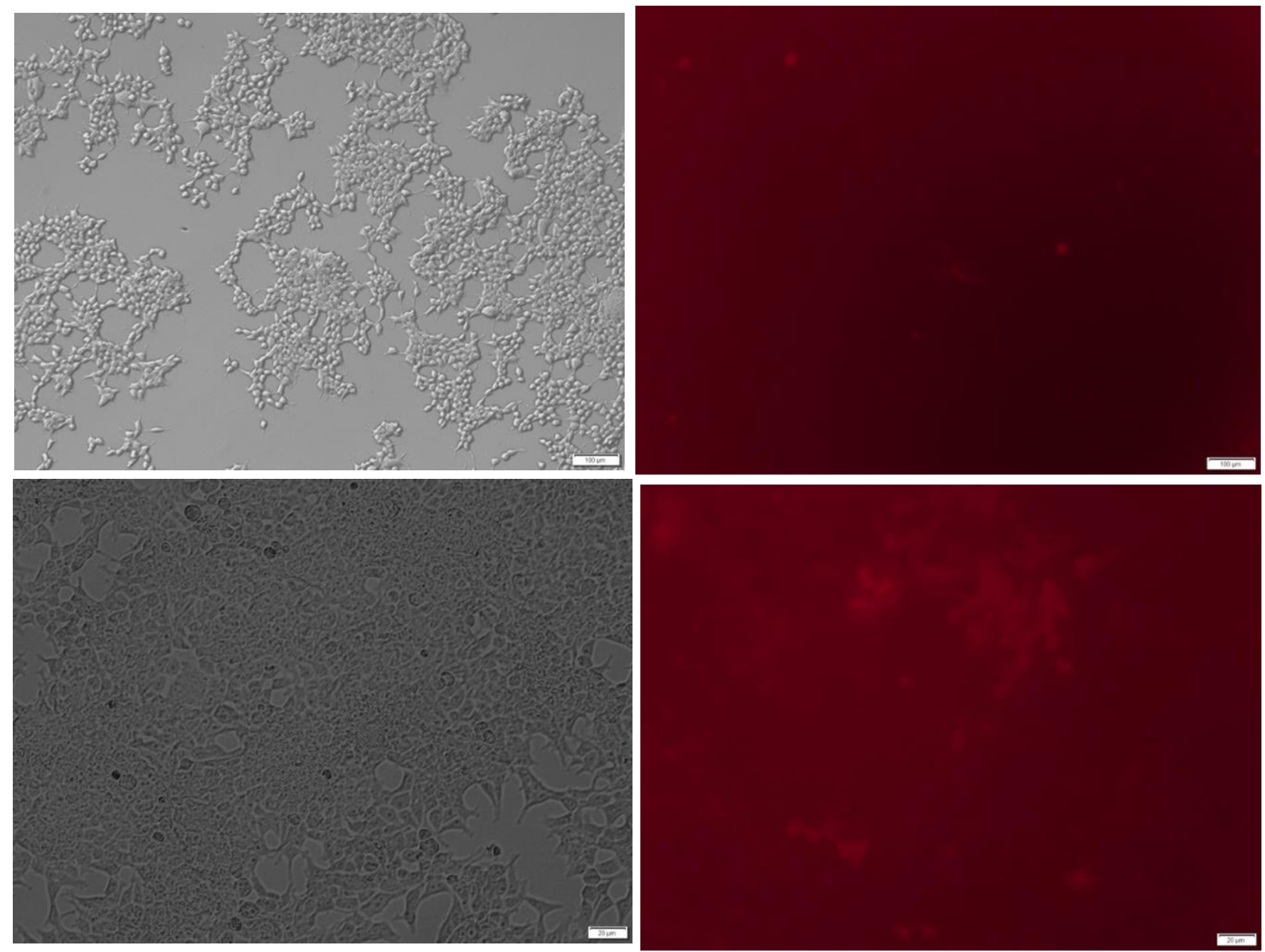

Figure 34 Development of $m$ Cherry fluorescent protein following lentiviral particle transduction over the course of 72 hours. (A) bright field and (B) TREX filter of HEK293 cells 48 hours post-transduction. (C) bright field and (D) TEREX filter of the same HEK293 cells 72 hours post-transductions. 


\section{Appendix}

Alkaline Lysis Solution I

Tris-CL (pH 8.0) $\quad 25 \mathrm{mM}$

EDTA (pH 8.0) $\quad 10 \mathrm{mM}$

This solution was prepared with molecular biology grade water, autoclaved and stored at $4^{\circ} \mathrm{C}$.

Alkaline Lysis Solution II

$\mathrm{NaOH} \quad 0.2 \mathrm{M}$

SDS $\quad 1 \%(\mathrm{w} / \mathrm{w})$

This solution was prepared with molecular biology grade water and stored at room temperature.

Alkaline Lysis Solution III

3M Potassium acetate

$60 \mathrm{~mL}$

Glacial acetic acid

$11.5 \mathrm{~mL}$

Molecular biology grade water

$28.5 \mathrm{~mL}$

This solution was stored at $4^{\circ} \mathrm{C}$.

LB Broth

$\begin{array}{ll}\text { Yeast extract } & 5 \mathrm{~g} \\ \text { Bactero-tryptone } & 10 \mathrm{~g} \\ \mathrm{NaCl} & 10 \mathrm{~g} \\ \mathrm{ddH}_{2} \mathrm{O} & \mathrm{Up} \text { to } 1 \mathrm{~L}\end{array}$

LB Agar

$15 \mathrm{~g}$ of bacterial agar was added into $1 \mathrm{~L}$ of LB broth and autoclaved. The solution was cooled to $55^{\circ} \mathrm{C}$ and appropriate antibiotics was added and poured onto petri dishes, which was left to dry overnight. 


\section{QIAGEN ${ }^{\circledR}$ Plasmid Mini, Midi and Maxi Kits}

The QIAGEN Plasmid Mini Kit (cat. nos. 12123 and 12125), the QIAGEN Plasmid Midi Kit (cat. nos. 12143 and 12145), the QIAGEN Plasmid Maxi Kit (cat. nos. 12162, 12163 and 12165) and the Plasmid Buffer Set (cat. no. 19046) can be stored at room temperature $\left(15-25^{\circ} \mathrm{C}\right)$ for up to 2 years if not otherwise stated on label.

Further information

- QIAGEN Plasmid Purification Handbook: www.qiagen.com/HB-1193

- Safety Data Sheets: www.qiagen.com/safety

- Technical assistance: support.qiagen.com

Notes before starting

- Add RNase A solution to Buffer P1, mix and store at $2-8^{\circ} \mathrm{C}$.

- Optional: Add LyseBlue ${ }^{\circledast}$ reagent to Buffer P1 at a ratio of 1:1000.

- Prechill Buffer P3 at $4^{\circ} \mathrm{C}$. Check Buffer P2 for SDS precipitation.

- Isopropanol and $70 \%$ ethanol are required.

- Symbols: - QIAGEN Plasmid Mini Kit; $\triangle$ QIAGEN Plasmid Midi Kit; and Q QIAGEN Plasmid Maxi Kit.

Table 1. Recommended LB culture volumes

\begin{tabular}{|lcc|}
\hline Kit & High-copy plasmid & Low-copy plasmid \\
\hline QIAGEN Plasmid Mini & $3 \mathrm{ml}$ & Not recommended \\
QIAGEN Plasmid Midi & $25 \mathrm{ml}$ & $100 \mathrm{ml}$ \\
QIAGEN Plasmid Maxi & $100 \mathrm{ml}$ & $500 \mathrm{ml}$ \\
\hline
\end{tabular}

1. Harvest overnight bacterial culture by centrifuging at $6000 \times \mathrm{g}$ for $15 \mathrm{~min}$ at $4^{\circ} \mathrm{C}$.

2. Resuspend the bacterial pellet in $\bullet 0.3 \mathrm{ml}, \Delta 4 \mathrm{ml}$ or $\mathbf{\square} 10 \mathrm{ml}$ Buffer $\mathrm{Pl}$. 
3. Add $0.3 \mathrm{ml}, \boldsymbol{\Delta} 4 \mathrm{ml}$ or $10 \mathrm{ml}$ Buffer P2, mix thoroughly by vigorously inverting 4-6 times and incubate at room temperature $\left(15-25^{\circ} \mathrm{C}\right)$ for $5 \mathrm{~min}$. If using LyseBlue reagent, the solution will turn blue.

4. Add $\bullet 0.3 \mathrm{ml}, \boldsymbol{\Delta} 4 \mathrm{ml}$ or $10 \mathrm{ml}$ prechilled Buffer P3, mix thoroughly by vigorously inverting 4-6 times. Incubate on ice for $5 \mathrm{~min}, \boldsymbol{\Delta} 15 \mathrm{~min}$ or $20 \mathrm{~min}$. If using LyseBlue reagent, mix the solution until it is colorless.

5. -: Centrifuge at $14,000-18,000 \times \mathrm{g}$ for $10 \mathrm{~min}$ at $4^{\circ} \mathrm{C}$. Re-centrifuge if the supernatant is not clear. $\boldsymbol{\Delta}$ and $\mathbf{\square}$ : Centrifuge at $\geq 20,000 \times \mathrm{g}$ for $30 \mathrm{~min}$ at $4^{\circ} \mathrm{C}$. Re-centrifuge the supernatant at $\geq 20,000 \times \mathrm{g}$ for $15 \mathrm{~min}$ at $4^{\circ} \mathrm{C}$.

6. Equilibrate a QIAGEN-tip • 20, $\Delta 100$ or 500 by applying $\bullet 1 \mathrm{ml}, \boldsymbol{\Delta} 4 \mathrm{ml}$ or - $10 \mathrm{ml}$ Buffer QBT, and allow column to empty by gravity flow.

7. Apply the supernatant from step 5 to the QIAGEN-tip and allow it to enter the resin by gravity flow.

8. Wash the QIAGEN-tip with $\bullet 2 \times 2 \mathrm{ml}, \Delta 2 \times 10 \mathrm{ml}$ or $\boldsymbol{\nabla} 2 \times 30 \mathrm{ml}$ Buffer QC. Allow Buffer $Q C$ to move through the QIAGEN-tip by gravity flow.

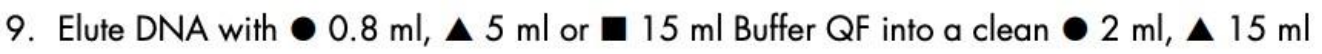
or $50 \mathrm{ml}$ vessel. For constructs larger than $45 \mathrm{~kb}$, prewarming the elution buffer to $65^{\circ} \mathrm{C}$ may help to increase the yield.

10.Precipitate DNA by adding $0.56 \mathrm{ml}, \boldsymbol{\Delta} 3.5 \mathrm{ml}$ or $10.5 \mathrm{ml}$ (0.7 volumes) roomtemperature isopropanol to the eluted DNA and mix. Centrifuge at $\geq 15,000 \times \mathrm{g}$ for $30 \mathrm{~min}$ at $4^{\circ} \mathrm{C}$. Carefully decant the supernatant.

11. Wash the DNA pellet with $1 \mathrm{ml}, \boldsymbol{\Delta} 2 \mathrm{ml}$ or $5 \mathrm{ml}$ room-temperature $70 \%$ ethanol and centrifuge at $215,000 \times \mathrm{g}$ for $10 \mathrm{~min}$. Carefully decant supernatant.

12. Air-dry pellet for 5-10 $\mathrm{min}$ and redissolve DNA in a suitable volume of appropriate buffer (e.g., TE buffer, $\mathrm{pH} 8.0$, or $10 \mathrm{mM}$ Tris. $\mathrm{Cl}, \mathrm{pH} 8.5$ ).

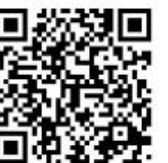

Scan QR code for handbook.

For up-to-date licensing information and product-specific disclaimers, see the respective QIAGEN kit handbook or user manual. Trademarks: QIAGEN ${ }^{\oplus}$, Sample to Insight", LyseBlue (QIAGEN Group). 1101291 03/2016 HB-0586-002 @ 2016 QIAGEN, all rights reserved.

Ordering www.qiagen.com/contact | Technical Support support.qiagen.com | Website www.qiagen.com 


\section{References}

Artus, J., Piliszek, A., \& Hadjantonakis, A. K. (2011). The primitive endoderm lineage of the mouse blastocyst: sequential transcription factor activation and regulation of differentiation by Sox17. Dev Biol, 350(2), 393-404. doi:10.1016/j.ydbio.2010.12.007

Au, V., Li-Leger, E., Raymant, G., Flibotte, S., Chen, G., Martin, K., . . Moerman, D. G. (2019). CRISPR/Cas9 Methodology for the Generation of Knockout Deletions in Caenorhabditis elegans. G3 (Bethesda, Md.), 9(1), 135-144. doi:10.1534/g3.118.200778

Avilion, A. A., Nicolis, S. K., Pevny, L. H., Perez, L., Vivian, N., \& Lovell-Badge, R. (2003). Multipotent cell lineages in early mouse development depend on SOX2 function. Genes Dev, 17(1), 126140.

Bai, H., Sakurai, T., Kim, M.-S., Muroi, Y., Ideta, A., Aoyagi, Y., . . Imakawa, K. (2009). Involvement of GATA transcription factors in the regulation of endogenous bovine interferon-tau gene transcription. Mol Reprod Dev, 76(12), 1143. doi:10.1002/mrd.21082

Bazer, F. W., Spencer, T. E., Johnson, G. A., Burghardt, R. C., \& Wu, G. (2009). Comparative aspects of implantation. Reproduction, 138(2), 195-209. doi:10.1530/rep-09-0158

Belmonte, J. C. I., Callaway, E. M., Churchland, P., Caddick, S. J., Feng, G., Homanics, G. E., . . Zhang, F. (2015). Brains, Genes, and Primates. Neuron, 86(3), 617-631.

Berg, D. A., \& Menino, A. R., Jr. (1992). Bovine embryos produce a urokinase-type plasminogen activator. Mol Reprod Dev, 31(1), 14-19. doi:10.1002/mrd.1080310104

Berg, D. K., Smith, C. S., Pearton, D. J., Wells, D. N., Broadhurst, R., Donnison, M., \& Pfeffer, P. L. (2011). Trophectoderm lineage determination in cattle. Dev Cell, 20(2), 244-255. doi:10.1016/j.devcel.2011.01.003

Berg, D. K., van Leeuwen, J., Beaumont, S., Berg, M., \& Pfeffer, P. L. (2010). Embryo loss in cattle between Days 7 and 16 of pregnancy. Theriogenology, 73(2), 250-260.

Bessonnard, S., De Mot, L., Gonze, D., Barriol, M., Dennis, C., Goldbeter, A., .. . Chazaud, C. (2014). Gata6, Nanog and Erk signaling control cell fate in the inner cell mass through a tristable regulatory network. Development, 141(19), 3637. doi:10.1242/dev.109678

Betteridge, K. J., \& Flechon, J. E. (1988). The Anatomy and Physiology of Pre-Attachment Bovine Embryos. Theriogenology, 29(1), 155-187. doi:Doi 10.1016/0093-691x(88)90038-6

Blomberg, L., Hashizume, K., \& Viebahn, C. (2008). Blastocyst elongation, trophoblastic differentiation, and embryonic pattern formation. Reproduction, 135(2), 181-195. doi:135/2/181 [pii] 10.1530/REP-07-0355

Boroviak, T., Loos, R., Lombard, P., Okahara, J., Behr, R., Sasaki, E., . . Bertone, P. (2015). LineageSpecific Profiling Delineates the Emergence and Progression of Naive Pluripotency in Mammalian Embryogenesis. Dev Cell, 35(3), 366-382. doi:10.1016/j.devcel.2015.10.011

Brinkhof, B., van Tol, H. T. A., Groot Koerkamp, M. J. A., Riemers, F. M., ljzer, S. G., Mashayekhi, K., ... Roelen, B. A. J. (2015). A mRNA landscape of bovine embryos after standard and MAPK-inhibited culture conditions: a comparative analysis. BMC Genomics, 16(1), 277. doi:10.1186/s12864-015-1448-x

Brunet, E., \& Jasin, M. (2018). Induction of Chromosomal Translocations with CRISPR-Cas9 and Other Nucleases: Understanding the Repair Mechanisms That Give Rise to Translocations. Adv Exp Med Biol, 1044, 15-25. doi:10.1007/978-981-13-0593-1_2

Chari, R., Mali, P., Moosburner, M., \& Church, G. M. (2015). Unraveling CRISPR-Cas9 genome engineering parameters via a library-on-library approach. Nature Methods, 12, 823. doi:10.1038/nmeth.3473

https://www.nature.com/articles/nmeth.3473\#supplementary-information

Chazaud, C., \& Yamanaka, Y. (2016). Lineage specification in the mouse preimplantation embryo. Development, 143(7), 1063. doi:10.1242/dev.128314 
Chazaud, C., Yamanaka, Y., Pawson, T., \& Rossant, J. (2006). Early Lineage Segregation between Epiblast and Primitive Endoderm in Mouse Blastocysts through the Grb2-MAPK Pathway. Dev Cell, 10(5), 615-624. doi:https://doi.org/10.1016/i.devcel.2006.02.020

Christodoulou, N., Kyprianou, C., Weberling, A., Wang, R., Cui, G., Peng, G., . . Z Zernicka-Goetz, M. (2018). Sequential formation and resolution of multiple rosettes drive embryo remodelling after implantation. Nat Cell Biol, 20(11), 1278-1289. doi:10.1038/s41556-018-0211-3

Clemente, M., de La Fuente, J., Fair, T., Al Naib, A., Gutierrez-Adan, A., Roche, J. F., . . Lonergan, P. (2009). Progesterone and conceptus elongation in cattle: a direct effect on the embryo or an indirect effect via the endometrium? Reproduction, 138(3), 507-517. doi:REP-09-0152 [pii]

10.1530/REP-09-0152

Crosier, A. E., Farin, P. W., Dykstra, M. J., Alexander, J. E., \& Farin, C. E. (2001). Ultrastructural Morphometry of Bovine Blastocysts Produced In Vivo or In Vitro1. Biology of Reproduction, 64(5), 1375-1385. doi:10.1095/biolreprod64.5.1375

Cui, Y., Xu, J., Cheng, M., Liao, X., \& Peng, S. (2018). Review of CRISPR/Cas9 sgRNA Design Tools. Interdisciplinary Sciences: Computational Life Sciences, 10(2), 455-465. doi:10.1007/s12539018-0298-z

Davis, H. E., Morgan, J. R., \& Yarmush, M. L. (2002). Polybrene increases retrovirus gene transfer efficiency by enhancing receptor-independent virus adsorption on target cell membranes. Biophys Chem, 97(2-3), 159-172. doi:10.1016/s0301-4622(02)00057-1

De Vries, A. (2006). Economic value of pregnancy in dairy cattle. Journal of dairy science, 89(10), 3876-3885.

Denicol, A. C., Block, J., Kelley, D. E., Pohler, K. G., Dobbs, K. B., Mortensen, C. J., ... Hansen, P. J. (2014). The WNT signaling antagonist Dickkopf-1 directs lineage commitment and promotes survival of the preimplantation embryo. Faseb j, 28(9), 3975-3986. doi:10.1096/fj.14-253112

Diskin, M. G., Murphy, J. J., \& Sreenan, J. M. (2006). Embryo survival in dairy cows managed under pastoral conditions. Anim Reprod Sci, 96(3-4), 297-311.

Doudna, J. A., \& Charpentier, E. (2014). The new frontier of genome engineering with CRISPR-Cas9. Science, 346(6213), 1258096. doi:10.1126/science.1258096

Driver, A. M., Peñagaricano, F., Huang, W., Ahmad, K. R., Hackbart, K. S., Wiltbank, M. C., \& Khatib, H. (2012). RNA-Seq analysis uncovers transcriptomic variations between morphologically similar in vivo- and in vitro-derived bovine blastocysts. BMC genomics, 13, 118-118. doi:10.1186/1471-2164-13-118

Duranthon, V. J. M. d. I. R. (2016). L'embryon préimplantatoire: acquis et nouveautés. 1(1).

Feuer, S., \& Rinaudo, P. (2012). Preimplantation stress and development. Birth Defects Res C Embryo Today, 96(4), 299-314. doi:10.1002/bdrc.21022

Fogarty, N. M., McCarthy, A., Snijders, K. E., Powell, B. E., Kubikova, N., Blakeley, P., . . Kim, D. (2017). Genome editing reveals a role for OCT4 in human embryogenesis. Nature, 550(7674), 67.

Frankenberg, S., Shaw, G., Freyer, C., Pask, A. J., \& Renfree, M. B. (2013). Early cell lineage specification in a marsupial: a case for diverse mechanisms among mammals. Development, 140(5), 965-975. doi:10.1242/dev.091629

Frum, T., Halbisen, M. A., Wang, C., Amiri, H., Robson, P., \& Ralston, A. (2013). Oct4 cellautonomously promotes primitive endoderm development in the mouse blastocyst. Dev Cell, 25(6), 610-622. doi:10.1016/j.devcel.2013.05.004

Guo, G., Huss, M., Tong, G. Q., Wang, C., Li Sun, L., Clarke, N. D., \& Robson, P. (2010). Resolution of Cell Fate Decisions Revealed by Single-Cell Gene Expression Analysis from Zygote to Blastocyst. Developmental Cell, 18(4), 675-685. doi:https://doi.org/10.1016/j.devcel.2010.02.012 
Hamazaki, T., Kehoe, S. M., Nakano, T., \& Terada, N. (2006). The Grb2/Mek pathway represses Nanog in murine embryonic stem cells. Mol Cell Biol, 26(20), 7539-7549. doi:10.1128/mcb.00508-06

Home, P., Kumar, R. P., Ganguly, A., Saha, B., Milano-Foster, J., Bhattacharya, B., . . Paul, S. (2017). Genetic redundancy of GATA factors in the extraembryonic trophoblast lineage ensures the progression of preimplantation and postimplantation mammalian development. Development, 144(5), 876-888. doi:10.1242/dev.145318

Hunter, R. H., \& Wilmut, I. (1984). Sperm transport in the cow: peri-ovulatory redistribution of viable cells within the oviduct. Reprod Nutr Dev, 24(5a), 597-608.

Jinek, M., Jiang, F., Taylor, D. W., Sternberg, S. H., Kaya, E., Ma, E., ... Doudna, J. A. (2014). Structures of Cas9 Endonucleases Reveal RNA-Mediated Conformational Activation. Science, 343(6176), 1247997. doi:10.1126/science.1247997

Kabadi, A. M., Ousterout, D. G., Hilton, I. B., \& Gersbach, C. A. (2014). Multiplex CRISPR/Cas9-based genome engineering from a single lentiviral vector. Nucleic Acids Res, 42(19), e147. doi:10.1093/nar/gku749

Kang, M., Piliszek, A., Artus, J., \& Hadjantonakis, A.-K. (2013). FGF4 is required for lineage restriction and salt-and-pepper distribution of primitive endoderm factors but not their initial expression in the mouse. Development, 140(2), 267. doi:10.1242/dev.084996

Krajden, M., Minor, J. M., Rifkin, O., \& Comanor, L. (1999). Effect of multiple freeze-thaw cycles on hepatitis $B$ virus DNA and hepatitis C virus RNA quantification as measured with branchedDNA technology. J Clin Microbiol, 37(6), 1683-1686.

Kubisch, H. M., Larson, M. A., \& Roberts, R. M. (1998). Relationship between age of blastocyst formation and interferon-tau secretion by in vitro-derived bovine embryos. Mol Reprod Dev, 49(3), 254-260. doi:10.1002/(sici)1098-2795(199803)49:3<254::Aid-mrd5>3.0.Co;2-n

Kuijk, E. W., van Tol, L. T. A., Van de Velde, H., Wubbolts, R., Welling, M., Geijsen, N., \& Roelen, B. A. J. (2012). The roles of FGF and MAP kinase signaling in the segregation of the epiblast and hypoblast cell lineages in bovine and human embryos. Development, 139(5), 871-882. doi:10.1242/dev.071688

Labun, K., Montague, T. G., Gagnon, J. A., Thyme, S. B., \& Valen, E. (2016). CHOPCHOP v2: a web tool for the next generation of CRISPR genome engineering. Nucleic Acids Research, 44(W1), W272-W276. doi:10.1093/nar/gkw398

Le Bin, G. C., Munoz-Descalzo, S., Kurowski, A., Leitch, H., Lou, X., Mansfield, W., . . Nichols, J. (2014). Oct4 is required for lineage priming in the developing inner cell mass of the mouse blastocyst. Development, 141(5), 1001-1010. doi:10.1242/dev.096875

Lino, C. A., Harper, J. C., Carney, J. P., \& Timlin, J. A. (2018). Delivering CRISPR: a review of the challenges and approaches. Drug Deliv, 25(1), 1234-1257. doi:10.1080/10717544.2018.1474964

Lodato, M. A., Ng, C. W., Wamstad, J. A., Cheng, A. W., Thai, K. K., Fraenkel, E., . . Boyer, L. A. (2013). SOX2 co-occupies distal enhancer elements with distinct POU factors in ESCs and NPCs to specify cell state. PLoS Genet, 9(2), e1003288. doi:10.1371/journal.pgen.1003288

Machado, G. M., Ferreira, A. R., Pivato, I., Fidelis, A., Spricigo, J. F., Paulini, F., . . Dode, M. A. (2013). Post-hatching development of in vitro bovine embryos from day 7 to 14 in vivo versus in vitro. Mol Reprod Dev, 80(11), 936-947. doi:10.1002/mrd.22230

Maddox-Hyttel, P., Alexopoulos, N. I., Vajta, G., Lewis, I., Rogers, P., Cann, L., . . Trounson, A. (2003). Immunohistochemical and ultrastructural characterization of the initial post-hatching development of bovine embryos. Reproduction, 125(4), 607-623. 
Maddox-Hyttel, P., Alexopoulos, N. I., Vajta, G., Lewis, I., Rogers, P., Cann, L., . . Trounson, A. (2003). Immunohistochemical and ultrastructural characterization of the initial post-hatching development of bovine embryos. REPRODUCTION-CAMBRIDGE-, 125(4), 607-623.

Massip, A., \& Mulnard, J. (1980). Time-lapse cinematographic analysis of hatching of normal and frozen-thawed cow blastocysts. J Reprod Fertil, 58(2), 475-478.

Molotkov, A., Mazot, P., Brewer, J. R., Cinalli, R. M., \& Soriano, P. (2017). Distinct Requirements for FGFR1 and FGFR2 in Primitive Endoderm Development and Exit from Pluripotency. Dev Cell, 41(5), 511-526.e514. doi:https://doi.org/10.1016/i.devcel.2017.05.004

Morris, S. A., Graham, S. J. L., Jedrusik, A., \& Zernicka-Goetz, M. (2013). The differential response to Fgf signalling in cells internalized at different times influences lineage segregation in preimplantation mouse embryos. Open Biology, 3(11).

Morris, S. A., Teo, R. T. Y., Li, H. L., Robson, P., Glover, D. M., \& Zernicka-Goetz, M. (2010). Origin and formation of the first two distinct cell types of the inner cell mass in the mouse embryo. Proceedings of the National Academy of Sciences of the United States of America, 107(14), 6364-6369.

Munk, M., Ladeira, L. O., Carvalho, B. C., Camargo, L. S. A., Raposo, N. R. B., Serapião, R. V., . . Brandão, H. M. (2016). Efficient delivery of DNA into bovine preimplantation embryos by multiwall carbon nanotubes. Scientific Reports, 6, 33588. doi:10.1038/srep33588

https://www.nature.com/articles/srep33588\#supplementary-information

Negron-Perez, V. M., Zhang, Y., \& Hansen, P. J. (2017). Single-cell gene expression of the bovine blastocyst. Reproduction, 154(5), 627-644. doi:10.1530/rep-17-0345

Nichols, J., Zevnik, B., Anastassiadis, K., Niwa, H., Klewe-Nebenius, D., Chambers, I., . . Smith, A. (1998). Formation of pluripotent stem cells in the mammalian embryo depends on the POU transcription factor Oct4. Cell, 95(3), 379-391.

Niemann, H., Carnwath, J. W., Herrmann, D., Wieczorek, G., Lemme, E., Lucas-Hahn, A., \& Olek, S. (2010). DNA methylation patterns reflect epigenetic reprogramming in bovine embryos. Cell Reprogram, 12(1), 33-42. doi:10.1089/cell.2009.0063

Nishioka, N., Inoue, K., Adachi, K., Kiyonari, H., Ota, M., Ralston, A., ... Sasaki, H. (2009). The Hippo signaling pathway components Lats and Yap pattern Tead4 activity to distinguish mouse trophectoderm from inner cell mass. Dev Cell, 16(3), 398-410.

O'Leary, N. A., Wright, M. W., Brister, J. R., Ciufo, S., Haddad, D., McVeigh, R., . . Pruitt, K. D. (2016). Reference sequence (RefSeq) database at NCBI: current status, taxonomic expansion, and functional annotation. Nucleic Acids Res, 44(D1), D733-745. doi:10.1093/nar/gkv1189

Ozawa, M., Sakatani, M., Yao, J., Shanker, S., Yu, F., Yamashita, R., ... Hansen, P. J. (2012). Global gene expression of the inner cell mass and trophectoderm of the bovine blastocyst. BMC Developmental Biology, 12(1), 33. doi:10.1186/1471-213X-12-33

Pfeffer, P. L. (2018). Building Principles for Constructing a Mammalian Blastocyst Embryo. Biology (Basel), 7(3). doi:10.3390/biology7030041

Plusa, B., Piliszek, A., Frankenberg, S., Artus, J., \& Hadjantonakis, A. K. (2008). Distinct sequential cell behaviours direct primitive endoderm formation in the mouse blastocyst. Development, 135(18), 3081-3091. doi:10.1242/dev.021519

Ralston, A., Cox, B. J., Nishioka, N., Sasaki, H., Chea, E., Rugg-Gunn, P., . . Rossant, J. (2010). Gata3 regulates trophoblast development downstream of Tead4 and in parallel to Cdx2. Development, 137(3), 395. doi:10.1242/dev.038828

Red-Horse, K., Zhou, Y., Genbacev, O., Prakobphol, A., Foulk, R., McMaster, M., \& Fisher, S. J. (2004). Trophoblast differentiation during embryo implantation and formation of the maternal-fetal interface. The Journal of Clinical Investigation, 114(6), 744-754. doi:10.1172/JCI22991

Robinson, R. S., Hammond, A. J., Wathes, D. C., Hunter, M. G., \& Mann, G. E. (2008). Corpus luteumendometrium-embryo interactions in the dairy cow: underlying mechanisms and clinical relevance. Reprod Domest Anim, 43 Suppl 2, 104-112. doi:RDA1149 [pii] 
10.1111/j.1439-0531.2008.01149.x

Sakurai, N., Takahashi, K., Emura, N., Hashizume, T., \& Sawai, K. (2017). Effects of downregulating TEAD4 transcripts by RNA interference on early development of bovine embryos. The Journal of reproduction and development, 63(2), 135-142. doi:10.1262/jrd.2016-130

Salmon, N. A., Handyside, A. H., \& Joyce, I. M. (2005). Expression of Sox8, Sf1, Gata4, Wt1, Dax1, and Fog2 in the mouse ovarian follicle: implications for the regulation of Amh expression. Mol Reprod Dev, 70(3), 271-277. doi:10.1002/mrd.20208

Sampson, T. R., Saroj, S. D., Llewellyn, A. C., Tzeng, Y. L., \& Weiss, D. S. (2013). A CRISPR/Cas system mediates bacterial innate immune evasion and virulence. Nature, 497(7448), 254-257. doi:10.1038/nature12048

Sanjana, N. E., Shalem, O., \& Zhang, F. (2014). Improved vectors and genome-wide libraries for CRISPR screening. Nat Methods, 11(8), 783-784. doi:10.1038/nmeth.3047

Schneider, C. A., Rasband, W. S., \& Eliceiri, K. W. (2012). NIH Image to ImageJ: 25 years of image analysis. Nature Methods, 9(7), 671-675. doi:10.1038/nmeth.2089

Schrode, N., Saiz, N., Di Talia, S., \& Hadjantonakis, A.-K. (2014). GATA6 levels modulate primitive endoderm cell fate choice and timing in the mouse blastocyst. Dev Cell, 29(4), 454-467. doi:10.1016/j.devcel.2014.04.011

Sheng, G. J. (2015). Epiblast morphogenesis before gastrulation. Developmental Biology, 401(1), $17-$ 24. doi:10.1016/j.ydbio.2014.10.003

Shorten, P. R., Ledgard, A. M., Donnison, M., Pfeffer, P. L., McDonald, R. M., \& Berg, D. K. (2018). A mathematical model of the interaction between bovine blastocyst developmental stage and progesterone-stimulated uterine factors on differential embryonic development observed on Day 15 of gestation. J Dairy Sci, 101(1), 736-751. doi:10.3168/jds.2017-12845

Simmet, K., Zakhartchenko, V., Philippou-Massier, J., Blum, H., Klymiuk, N., \& Wolf, E. (2018). OCT4/POU5F1 is required for NANOG expression in bovine blastocysts. Proceedings of the National Academy of Sciences, 115(11), 2770. doi:10.1073/pnas.1718833115

Strumpf, D., Mao, C. A., Yamanaka, Y., Ralston, A., Chawengsaksophak, K., Beck, F., \& Rossant, J. (2005). Cdx2 is required for correct cell fate specification and differentiation of trophectoderm in the mouse blastocyst. Development, 132(9), 2093-2102.

Szczelkun, M. D., Tikhomirova, M. S., Sinkunas, T., Gasiunas, G., Karvelis, T., Pschera, P., . . Seidel, R. (2014). Direct observation of R-loop formation by single RNA-guided Cas9 and Cascade effector complexes. Proc Natl Acad Sci U S A, 111(27), 9798-9803. doi:10.1073/pnas.1402597111

Tessanne, K., Golding, M. C., Long, C. R., Peoples, M. D., Hannon, G., \& Westhusin, M. E. (2012). Production of transgenic calves expressing an shRNA targeting myostatin. Mol Reprod Dev, 79(3), 176-185. doi:10.1002/mrd.22007

Thomasen, J. R., Willam, A., Egger-Danner, C., \& Sørensen, A. C. (2016). Reproductive technologies combine well with genomic selection in dairy breeding programs. Journal of Dairy Science, 99(2), 1331-1340. doi:10.3168/jds.2015-9437

Tiscornia, G., Singer, O., \& Verma, I. M. (2006). Production and purification of lentiviral vectors. Nat Protoc, 1(1), 241-245. doi:10.1038/nprot.2006.37

Ugai, H., Watanabe, S., Suzuki, E., Tsutsui-Nakata, H., Yokoyama, K. K., \& Murata, T. (2002). Stability of a recombinant adenoviral vector: optimization of conditions for storage, transport and delivery. Jpn J Cancer Res, 93(5), 598-603. doi:10.1111/j.1349-7006.2002.tb01296.x

Upton, J. S. (2019). Using Lentivirus and CRISPR to Modify Cattle Embryonic Genes. (Master of Cell and Molecular Bioscience), Victoria University of Wellington. 
Valdez Magana, G., Rodriguez, A., Zhang, H., Webb, R., \& Alberio, R. (2014). Paracrine effects of embryo-derived FGF4 and BMP4 during pig trophoblast elongation. Dev Biol, 387(1), 15-27. doi:10.1016/j.ydbio.2014.01.008

van Leeuwen, J., Berg, D. K., \& Pfeffer, P. L. (2015). Morphological and Gene Expression Changes in Cattle Embryos from Hatched Blastocyst to Early Gastrulation Stages after Transfer of In Vitro Produced Embryos. PLoS One, 10(6), e0129787. doi:10.1371/journal.pone.0129787

Wang, H., La Russa, M., \& Qi, L. S. (2016). CRISPR/Cas9 in Genome Editing and Beyond. Annu Rev Biochem, 85, 227-264. doi:10.1146/annurev-biochem-060815-014607

Wu, G., Han, D., Gong, Y., Sebastiano, V., Gentile, L., Singhal, N., . . Scholer, H. R. (2013). Establishment of totipotency does not depend on Oct4A. Nat Cell Biol, 15(9), 1089-1097. doi:10.1038/ncb2816

Xu, H., Xiao, T., Chen, C.-H., Li, W., Meyer, C. A., Wu, Q., . . Liu, X. S. (2015). Sequence determinants of improved CRISPR sgRNA design. Genome research, 25(8), 1147-1157. doi:10.1101/gr.191452.115

Yagi, R., Kohn, M. J., Karavanova, I., Kaneko, K. J., Vullhorst, D., DePamphilis, M. L., \& Buonanno, A. (2007). Transcription factor TEAD4 specifies the trophectoderm lineage at the beginning of mammalian development. Development, 134(21), 3827-3836.

Yamanaka, Y., Ralston, A., Stephenson, R. O., \& Rossant, J. (2006). Cell and molecular regulation of the mouse blastocyst. Dev Dyn, 235(9), 2301-2314. doi:10.1002/dvdy.20844

Yang, Q. E., Fields, S. D., Zhang, K., Ozawa, M., Johnson, S. E., \& Ealy, A. D. (2011). Fibroblast Growth Factor 2 Promotes Primitive Endoderm Development in Bovine Blastocyst Outgrowths. Biol Reprod, 85(5), 946-953.

Yen, S. T., Zhang, M., Deng, J. M., Usman, S. J., Smith, C. N., Parker-Thornburg, J., . . Behringer, R. R. (2014). Somatic mosaicism and allele complexity induced by CRISPR/Cas9 RNA injections in mouse zygotes. Dev Biol, 393(1), 3-9.

Zhu, M., Leung, C. Y., Shahbazi, M. N., \& Zernicka-Goetz, M. (2017). Actomyosin polarisation through PLC-PKC triggers symmetry breaking of the mouse embryo. Nature Communications, $8(1)$, 921. doi:10.1038/s41467-017-00977-8

Zuo, E., Cai, Y. J., Li, K., Wei, Y., Wang, B. A., Sun, Y., . . Yang, H. (2017). One-step generation of complete gene knockout mice and monkeys by CRISPR/Cas9-mediated gene editing with multiple sgRNAs. Cell Res, 27(7), 933-945. doi:10.1038/cr.2017.81 